Portland State University

PDXScholar

1983

\title{
Tillamook Indian basketry : continuity and change as seen in the Adams Collection
}

\author{
Ailsa Elizabeth Crawford \\ Portland State University
}

Follow this and additional works at: https://pdxscholar.library.pdx.edu/open_access_etds

Part of the Archaeological Anthropology Commons, Fiber, Textile, and Weaving Arts Commons, and the Indigenous Studies Commons

Let us know how access to this document benefits you.

\section{Recommended Citation}

Crawford, Ailsa Elizabeth, "Tillamook Indian basketry : continuity and change as seen in the Adams Collection" (1983). Dissertations and Theses. Paper 3262.

https://doi.org/10.15760/etd.3253

This Thesis is brought to you for free and open access. It has been accepted for inclusion in Dissertations and Theses by an authorized administrator of PDXScholar. Please contact us if we can make this document more accessible: pdxscholar@pdx.edu. 
AN ABSTRACT OF THE THESIS OF Ailsa Elizabeth Crawford for the Master of Arts in Anthropology presented July 22, 1983.

Title: Tillamook Indian Basketry: Continuity and Change as seen in The Adams Collection.

APPROVED BY MEMBERS OF THE THESIS COMMITTEE:

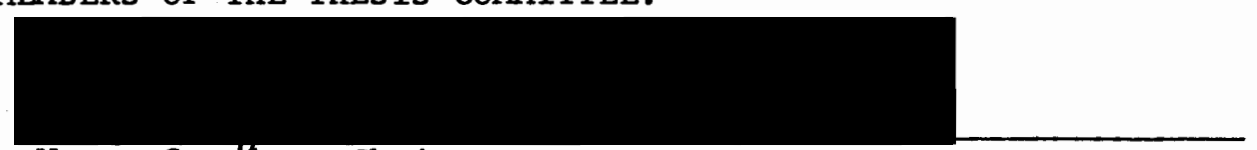

Wayne Suttles, Chairman

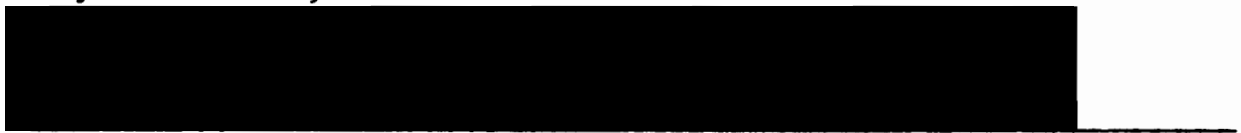

Danie1 J. Scheans

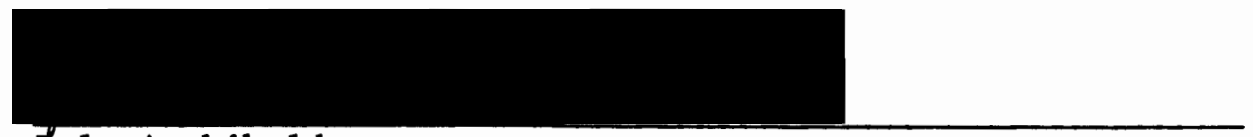

Dale Archibald

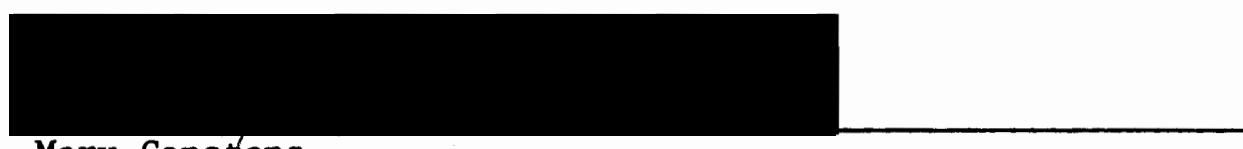

Mary Constans

In the Adams Collection at the Tillamook County Pioneer Museum, Tillamook, Oregon, there are 29 baskets that were probably made between 1880 and 1940. They are mostly of raffia, are somewhat faded from their original, bright, commercial colors, and are generally quite small. Despite the fact that these baskets are well-documented and were made by Tillamook women, they are the sort that have been overlooked by anthropologists and by collectors because of their non-"traditional" appearance. In order to determine what relationship these baskets have to Tillamook basketry made earlier, I analyzed them and 39 Tillamook baskets from four 
other museum collections for features of structural and decorative techniques, shape, size, and stitch qualities, and noted the materials used.

From this basketry analysis, I have found that those features which show the greatest amount of variation are size, shape, and materials used. By using Graburn's analysis of the changes in the arts and crafts of colonially-dominated peoples, those of the Fourth World, I have been able to demonstrate that the variations which appear in the Adams Collection baskets are those which can be expected to be found in the arts of people undergoing cultural disruptions and are not unique to the Adams baskets.

Both the Adams baskets and many of the baskets in the rest of my sample appear to have developed from a Nehalem Tillamook tradition. These baskets possess many features in common with some of the basketry from the neighboring Chinookan Clatsop and the linguistically related Salishan Chehalis and may well bear far greater resemblance to the basketry from these groups than to the basketry from the southern part of the Tillamook area, which through population disruption and decimation and an overlay of ambiguous Siletz attribution, can only be guessed at.

I have concluded that there probably was not a Tillamook basketry style co-terminous with the Tillamook language but that within the Tillamook-speaking area, baskets were made that were local variations developed from a very widespread tradition found in southwestern Washington and northwestern Oregon and that the Adams Collection of baskets is simply the most recent development of the Nehalem Tillamook tradition. 
TILLAMOOK INDIAN BASKETRY: CONTINUITY AND CHANGE AS SEEN IN THE ADAMS COLLECTION

by

AILSA ELIZABETH CRAWFORD

A thesis submitted in partial fulfillment of the requirements for the degree of

MASTER OF ARTS

in

ANTHROPOLOGY

$$
\begin{gathered}
\text { Portland State University } \\
\text { (C) } 1983
\end{gathered}
$$


TO THE OFFICE OF GRADUATE STUDIES AND RESEARCH:

The members of the Committee approve the thesis of Ailsa Elizabeth Crawford presented July 22, 1983.

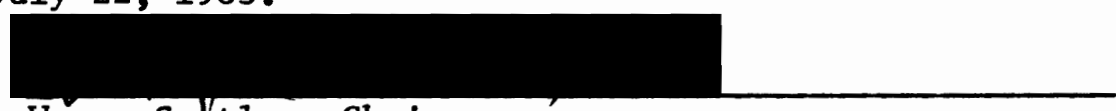

Wayne Suttles, Chairman

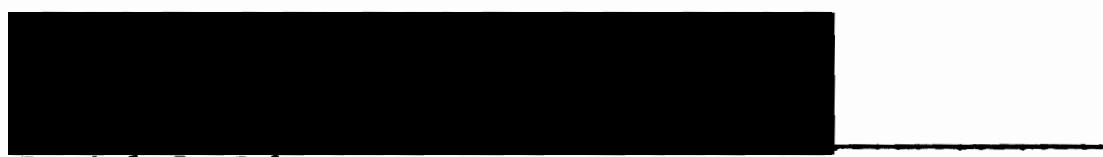

Daniel J. Scheans

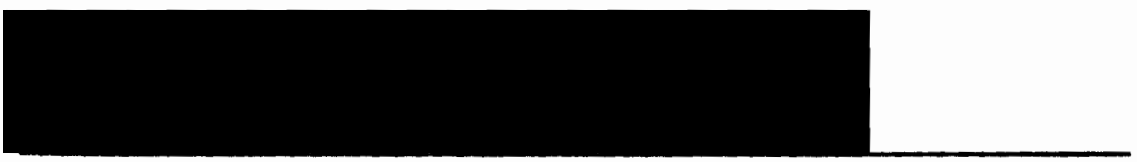

Dale Archibald

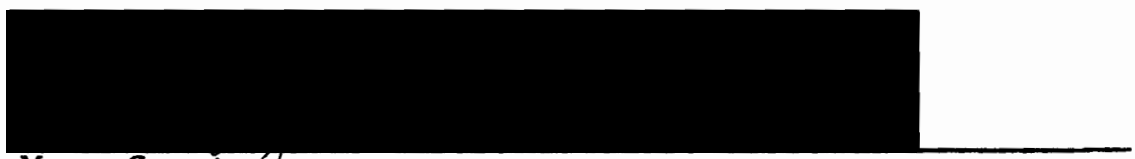

Mary Constans

APPKOVED:

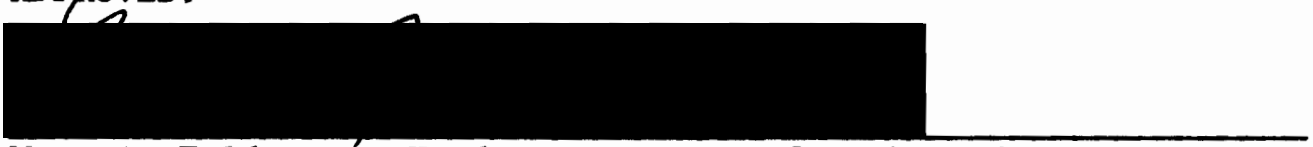

Marc R. Feldesman, Head, Department of Anthropology

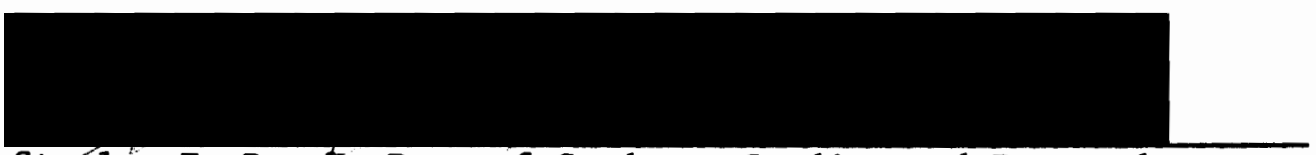

Stanley E. Rauch, Dean of Graduate Studies and Research 


\section{ACKNOWLEDGMENTS}

I would like to express my gratitude to Dr. Wayne Suttles for his invaluable guidance throughout the course of this research and most especially for the moral support that his enthusiam for the topic gave me.

The comments and criticisms from Dr. Daniel J. Scheans and Dale Archibald were helpful, and their interest in this study was encouraging. Wayne Jensen, Director of the Tillamook County Pioneer Museum has been most generous with his time and with the facilities of the museum.

To my mother, Janet Witter, I extend a special thanks for her belief that this was possible, for her financial support, and for her illustrations of Tillamook basketry techniques and motifs.

I am grateful to Carolyn Marr for bringing the Wilkes Collection to my attention, to Daniel D. Sullivan for his help with the lettering for the maps, and to Sheila Crawford, Mary Richardson, and Yvonne Hajda for their moral support.

The deadlines for this study would never have been met without the skill and understanding of Margaret LaFaive, who typed the manuscript. And finally, I am indebted to the Jacobs Research Fund for supporting the initial research I did with Rena Boyer in 1977 and to Rena, herself, for her knowledge and memories of the Garibaldi Tillamook Indians. 
ACKNOWLEDGMENTS ...................... 1 . . . . LIST OF TABLES .................... vi LIST OF FIGURES . . . . . . . . . . . . . . v vii CHAPTER

I INTRODUCTION .......................... 1 The Adams Collection ............... 2 Statement of Purpose ............... 3

II THE TILlAMOOK INDIANS ................ 6 Territory ................... 6 Language ................. 7 The Regional Setting of the Tillamook ......... 7 The Relations of the Tillamook With Their Neighbors . . . 8 A Synoptic History of the Tillamook ........... 10 The Effect of the Reservations on the Tillamook ...... 12 The Adams Family . . . . . . . . . . . 13

III THE TILlAMOOK AS A FOCUS OF RESEARCH . . . . . . . . 17 Sources of Bias ................. . 17 Tillamook Basketry in the Literature . . . . . . . 21

IV THE BASKETRY . . . . . . . . . . . . . 23 The Distribution of Basketry Techniques in North America . . 23 Archeological Evidence for Twining . . . . . . . . 24 Data Source ... . . . . . . . . . . 25 Data Collecting ... . . . . . . . . . . 28 
Data Analysis . . . . . . . . . . . . . . 30

Tillamook Basketry Technology . . . . . . . . . . . 32

Structural Techniques

Decorative Techniques

Shape .................. . . 4 47

Materials ................ . . 51

Design Motifs

Symbolism

The Adams Collection . . . . . . . . . . . . . . 64

The Other Tillamook Group . . . . . . . . . . . . 79

V CONTINUITY AND CHANGE IN TILLAMOOK BASKETRY . . . . . . . . . 88

Sources of Continuity in Tillamook Basketry . . . . . . . 89

Sources of Change in Tillamook Basketry . . . . . . . . . 92

Directions of Change . . . . . . . . . . . . . . 97

Tillamook Basketry Style . . . . . . . . . . . . 101

Summary and Conclusions . . . . . . . . . . . . . 110

REFERENCES CITED . . . . . . . . . . . . . . . . . . . 113

APPENDIX A - TILLAMOOK BASKETRY TERMS . • • . . . . . . • . . . . 121

APPENDIX B - THE BASKETRY . . . . . . . . . . . . . . . . 113 


\section{LIST OF TABLES}

TABLE

PAGE

I Tillamook Basketry Attribute Variables . . . . . . . . . 43

II Tillamook Basket Shapes . . . . . . . . . . . . . 49 


\section{LIST OF FIGURES}

FIGURE

PAGE

1. Map, Indian Language Groups of the Coasts of Washington and Oregon . . . . . . . . . . . . . . . . . 5

2. Map, the Garibaldi Area . . . . . . . . . . . . 6

3. The Genealogy of Basket-makers of the Adams Family . . . . . 16

4. Basketry Analysis Form . . . . . . . . . . . . . . 29

5. Basketry Analysis Cards . . . . . . . . . . . . . . 31

6. Basketry Techniques . . . . . . . . . . . . . . 42

7. Basketry Motifs . . . . . . . . . . . . . . 59

8. Basketry Motifs .. . . . . . . . . . . . . 63

9. TCPM 1290 . . . . . . . . . . . . . . . . 70

10. TCPM 1291 . . . . . . . . . . . . . . . . . 71

11. $\operatorname{TCPM} 1301$. . . . . . . . . . . . . . . 72

12. TCPM 1304 . . . . . . . . . . . . . . . . 73

13. TCPM (left to right) $1309,1306,1321,1308$. . . . . . . . 74

14. TCPM 1310 . . . . . . . . . . . . . . . . . 75

15. TCPM 1314 (side) . . . . . . . . . . . . . . 76

16. TCPM 1314 (base) . . . . . . . . . . . . . . . 77

17. TCPM 1319 . . . . . . . . . . . . . . . . . 78

18. บ0 1-894 . . . . . . . . . . . . . . . . . . . . 83

19. U0 1-897 . . . . . . . . . . . . . . . . . . . . 84 
vii

FIGURE

PAGE

20. UO 1-15653 . . . . . . . . . . . . . . . . . 85

21. UP 1-15657 • . . . . . . . . . . . . . . . . . 86

22. OHS $18783 / 68-366$. . . . . . . . . . . . . . . . . . . 87 
CHAPTER I

INTRODUCTION

My original approach to this study of Tillamook basketry was shaped by the classic literature on the basketry of North American Indians, as exemplified by Otis T. Mason (1904) and by the description of basketry in the ethnographies of particular groups in the Northwest Coast.

My initial purpose was to examine Tillamook baskets in order to describe the traditional Tillamook style and to compare it with the basketry styles of the surrounding area of the Northwest.

As my research progressed, I gradually came to realize that my sample of baskets did not necessarily represent traditional basketry and that even the question of what was traditional would have to be explored.

Fortunately, it was at this point that I found Nelson H. H. Graburn's illuminating introduction to Ethnic and Tourist Arts (1976), an anthology concerning the transition of ethnic arts from their function in traditional societies to their function in societies dominated by colonial powers. The framework that Graburn has proposed for the analysis of the acculturation of ethnic arts has enabled me to focus on a group of baskets which exhibit many nontraditional features but which, for all of these non-traditional features, are no 
less the product of Tillamook basket-makers and are derived from Tillamook antecedents.

\section{THE ADAMS COLLECTION}

The baskets which are the focus of this study are in the Adams Collection in the Tillamook County Pioneer Museum in Tillamook, Oregon. Many of the 29 baskets in this collection were made by women of the Adams family of Garibaldi, a town 10 miles north of Tillamook, Oregon, and situated on Tillamook Bay. It seems likely that none of these baskets were made before 1880 , while the most recent ones may have been made in the early 1930s. The collection was donated to the museum in 1935 by members of the Adams family.

Nearly all of the baskets are made in variations of twining techniques and occur in a range of sizes and shapes. Most of them are decorated and many are made of non-native material, such as raffia.

Until recently, with the publication of papers such as those in the Graburn anthology and Brasser (1975) on Algonkian basketry change, there has been no developed context for the study of nontraditional, or acculturated, arts. Baskets like those in the Adams Collection have received little serious attention. Classic studies of basketry have usually focused on the traditional attributes of baskets; baskets which exhibited non-traditional qualities may have been seen as anomalous or aberrant or untypical and were easily set aside.

The baskets in the Adams Collection might have suffered the same fate were it not that they are in a collection in a museum, are 
well-documented for provenience and general date of manufacture and that there are 29 of them; too many to dismiss as casually as one might a single basket.

Graburn has demonstrated that it is possible to examine such a collection as the Adams's baskets as "arts of the Fourth World." In this context, the focus of analysis is not only the product but also the process of the development of the product from a native tradition of style and craft to its most recent form.

\section{STATEMENT OF PURPOSE}

The purpose of this study is to place the Adams Collection of Tillamook baskets within a Tillamook style through the study of other known Tillamook basketry, the study of basketry of neighboring and related groups, and from a survey of the available literature about the Tillamook, as well as from my notes about the Adams family, which I made during conversations with Rena Boyer, an Adams family member. 
CHAPTER II

\section{THE TILLAMOOK INDIANS}

The word "Tillamook" is derived from the Chinook term for the people of Nehalem (Boas 1898:23). As it is now used, "Tillamook" includes the people and the dialect variations of the Nehalems, Tillamooks, Nestuccas, Salmon Rivers, and Siletz (Hodge 1907: 418, 572, 750, and 757), and I have used it in this inclusive manner.

The Nehalem term for their language was hutyayu (Ede1 1939:2). Hodge cites a number of terms that may refer to other local dialects and population centers, but precise geographic designations are absent.

I know of no native term that is equivalent to the current usage of "Tillamook", whether for the people or for the language.

\section{TERRITORY}

The Tillamook occupied the western slope of the Coast Range, along the ocean coast of Oregon (See Figures 1 and 2). The northernmost boundary was at Tillamook Head, just south of Seaside, and the southernmost boundary was at Otter Rock, south of the Siletz River mouth. This area included the Nehalem, Nestucca, Salmon, and Siletz rivers, and Tillamook Bay and the rivers that flow into it (Berreman 1937:39), each with its own population. The Tillamook may have claimed hunting areas up into the Coast Range, as Berreman describes for the 


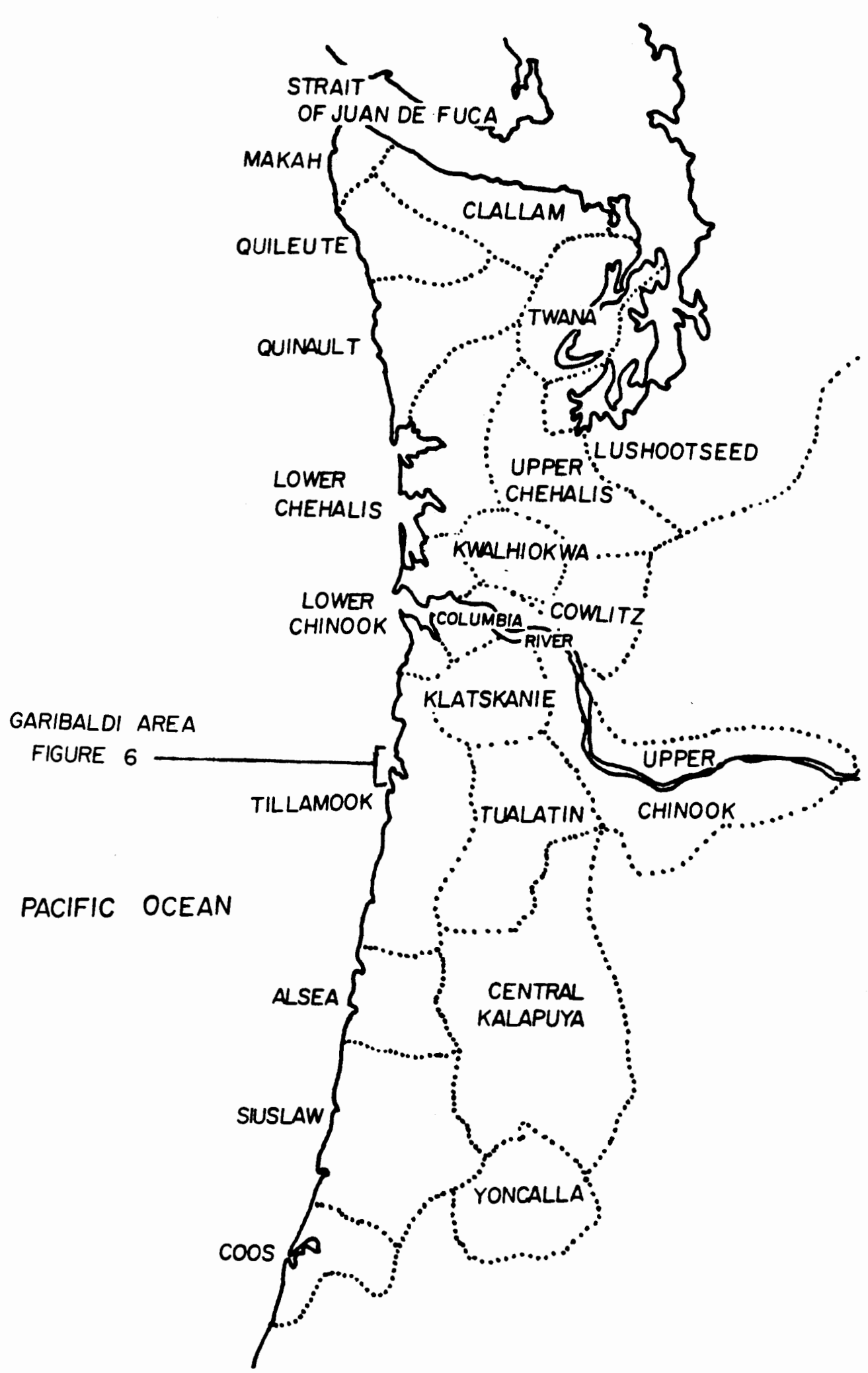

Figure 1. Indian Language Groups of the Coasts of Washington and Oregon. Map adapted from the preliminary version of Suttles 1978. 


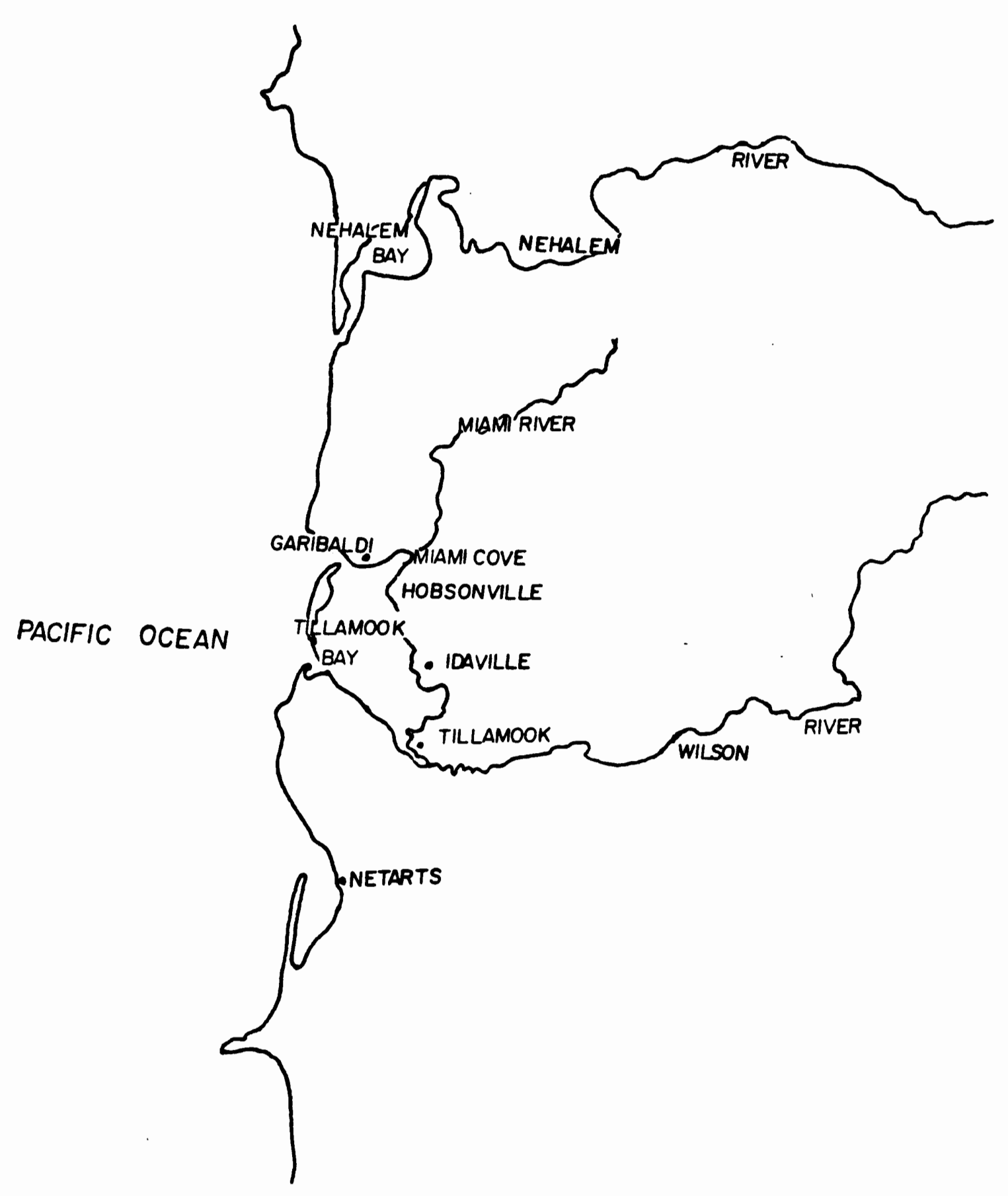

Figure 2. The Garibaldi Area. 
Alsea (1937:37). The villages recorded by Lewis and Clark were all situated near the river mouths (Coues 1893:796).

\section{LANGUAGE}

The Tillamook language was the most southerly of the Salishan languages, the greater number of which were spoken in Washington and British Columbia. Tillamook-speakers were separated from their linguistic relatives by Chinookan-speakers along the Columbia River.

Tillamook was spoken in several dialects. While Edel (1939:2) says that a northern and a southern dialect existed, the Thompsons (1966:313) describe an intergrading series of dialects for the area. Louis Fuller (Harrington 1942:0342), a Salmon River Tillamook, said that his speech was a little different from Tillamook spoken further north and that the Nehalem dialect was different yet but that he could understand it.

THE REGIONAL SETTING OF THE TILLAMOOK

On the basis of ethnographic data and environmental similarity, scholars who have distinguished sub-areas within the Northwest Coast culture area have generally included the Tillamook with the Salishan speakers of western Washington, the Chinookan and Athapaskan speakers of the Lower Columbia and, minimally, the northern portion of the Oregon coast.

Lewis (1906:202), Kroeber (1939:30), and Driver and Massey (1957:173) include the Tillamook within a sub-area of the Northwest Coast, while Murdock and 0'Leary (1975:3:67) have proposed an Oregon Seaboard culture 
area coordinate with the Northwest Coast culture area extending southward from Shoalwater Bay into northwestern California. Murdock and 0 'Leary and Kroeber distinguish the ocean orientation found further north from the orientation toward bays and rivers found among the people from Puget Sound southward, including the Tillamook.

The place of the Tillamook in the general Northwest Coast culture area appears to be secure, despite the lack of detailed, descriptive material about them.

\section{THE RELATIONS OF THE TILLAMOOK WITH THEIR NEIGHBORS}

The neighbors of the Tillamook were all speakers of non-Salishan languages. To the north, along the coast, were the Chinookan Clatsop and Inland, on the Nehalem River drainage, were the Athapaskan Klatskanie. To the east, on the far side of the Coast Range, from north to south, were the Kalapuyan speakers of Tualatin-Yamhill, Mary's River, and Yoncalla. South, along the coast, were the Alsean, Siuslawan, and Coosan speakers.

The Tillamook maintained social relations with these groups, and this is reflected in the evidence that we have of trade and of marriage. Early explorers noted the movement of goods throughout the area, and the genealogies of Tillamook families give evidence of the movement of people. The Klatskanie, about whom very little is known, are the one group of people for which I have found no direct evidence of trade or marriage with the Tillamook. I assume that they were participants in the trading that was general in the Northwest, particularly since they were situated in an area that was probably traversed by people moving goods between the coast and the Willamette Valley. 
$\underline{\text { Trade }}$

Lewis and Clark encountered Clatsop and Chinook people trading with the Tillamook for whale oil, and later saw Cathlamet people trading with the Clatsop for some of the same oil (Thwaites 1905(3):329). Bear-grass (Xerophyllum tenax) and wapato (Sagittaria latifolia) tubers were also items of trade, since they were not native to the coast environment.

Marriage

Silas Smith (1901:256), the son of Celiast (also known as Helen), a Clatsop woman, and Solomon Smith, a White man in the Wyeth party, wrote of Tillamook men bringing Chehalis or Chinook women in for marriage and of Tillamook women leaving for marriage elsewhere.

Lewis and Clark noted houses of both the Clatsop and Tillamook in the vicinity of Seaside, where they established their salt-cairn (Thwaites $1905(3): 313)$. Nearly 90 years later, Boas (1894) found that Clatsop people were speaking the Nehalem dialect of Tillamook near Seaside; the result of what Boas discovered was a long history of intermarriage between the two groups.

The genealogies of the Indians who have worked with anthropologists, linguists, and other researchers illustrate the intermarriage among groups within and without the Tillamook area. Louis Fuller was an informant at Siletz for both Barnett (1937) and Harrington (1942). Fuller's father's father was a Tillamook from Salmon River and his father's mother was a Clatsop. His mother's father was from Yaquina and her 
mother was from Siletz. Clara Pearson, a Tillamook neighbor of the Adamses, was at one time married to an Alsea (Harrington 1942:0797). A Tualatin village chief was said to be part Tillamook, which was quite possible since the Tualatin Kalapuya were known to have travelled to the coast to trade with the Tillamook to fish and to get wives (Gatschet 1877, in Zenk 1976:46).

Rena Boyer's mother's mother's father was Tillamook and her mother's mother's mother was Clatsop.

\section{A SYNOPTIC HISTORY OF THE TILLAMOOK}

Among the earliest of the recorded meetings of Europeans with people believed to be Tillamook was that of a crew of the American ship Columbia, commanded by Robert Gray; they dropped anchor in what may have been Tillamook Bay where, once on shore, an altercation ensued. One of the crew was killed by the Indians; and in retaliation, the ringleader of the Indians was shot. The place was recorded in the ship's $\log$ as Murderer's Harbour, but little about the native people was reported (Haswe11, in Howay 1969:34).

In the winter of $1805-1806$, members of the Lewis and Clark Expedition lived on Clatsop Plains, north of the Tillamook. They recorded their observations about the Indians there, including the Tillamook; and during a trip south, perhaps as far as Nehalem Bay, they elicited information from which they estimated that there were about 1,000 Tillamook living in 50 houses in the area (Thwaites 1905(3):117). 
Later estimates of the Tillamook population were much lower than those of Lewis and Clark; in 1845 Wilkes reported that there were 400 Tillamook and in 1849 Lane recorded only 200 (Hodge 1907(2):750-751). While these figures may reflect differences in where and how a census or estimate was arrived at, there is little doubt that an actual decline in the population size did occur and may have been caused, in part, by the epidemics of the 1830s. Although the epidemics were centered in the Willamette Valley, from where they spread to the coast along the Columbia River, and appear not to have moved southward on the coast at that time (Boyd 1975:139), the Tillamook were in the infected areas for the purposes of trade and marriage.

Beckham (1977) has described the events that altered the lives of the Indians of western Oregon as domination by the White settlers and the government occurred. The Tillamook were affected by many of these events.

The fur trade brought the first big influx of Whites into the northwest corner of Oregon. In 1811, the Pacific Fur Company was established by Astor at Fort George, now Astoria; and in 1825, the Hudson's Bay Company built Fort Vancouver on the Columbia River, now the site of Vancouver, Washington.

In 1850 the Oregon Donation Land Act was passed. It gave land to Oregon settlers, but it was Indian land for which the government had not acquired the title. In order for the government to obtain title to the land, Anson Dart travelled along the coast of Oregon making treaties with the Indians, but these treaties were never ratified by Congress. 
White settlement not only took land away from the Indians, but finally took many of the Indians away from their lands. In order to remove the Indians from the lands favored by Whites for settlement, the Siletz Reservation, in 1855, and the Grand Ronde Reservation, in 1857, were established, bringing together Indians from all along the Oregon coast and into northern California, as well as Indians from the more eastern Takelma and Shasta groups (Kent 1973:5).

These reservations were gradually diminished in area and in population. Thirty years after the establishment of them, the Dawes Severalty Act of 1887 authorized the allotment of some of the land to individual Indians and the sale to Whites of land deemed "surplus". In 1956, Public Law 588 terminated the Siletz and Grand Ronde Reservations.

THE EFFECT OF THE RESERVATIONS ON THE TILLAMOOK

The reservations began as large areas of land but were financially impoverished. This was a direct result of the failure of Congress to ratify the treaties; no authority existed for the allocation of funds to support the Indians at the start, although this was later remedied (Beckham 1977).

The poverty on the reservations encouraged Indians to leave, often for employment in hop fields and lumber camps of Whites. In 1877, the agent at Grand Ronde reported that there were probably several hundred Indians who belonged at Grand Ronde scattered about the country but that he had neither funds nor authority to round them up (Commissioner of Indian Affairs AR 1887:185). On the other 
hand, Indians who had not settled on reservations made use of the facilities that were finally established on them. Some Indians from Salmon River made weekly trips by wagon to Grand Ronde to avail themselves of the smithy, woodworking shop, flour mill, and medical aid (Commissioner of Indian Affairs AR 1885:162). These nonreservation Indians continued to live off the land by fishing and hunting in their usual places until White settlement encroached, and they were gradually shunted to the perimeters of newly established towns on the coast. In order to eke out a living, they, too, sought employment in lumber camps and mills, as fishermen, and as general laborers.

It was not until 1945 that the United States Court of Claims ruled that the Tillamook, among other groups, had any legal claims to the land that they had ceded. In 1962, after years of legal entanglements which reduced the monies available for settlement, the descendants of the Tillamook and Nehalem who were alive at the time of the treaties arranged by Anson Dart in 1851, were each to receive $\$ 620$ (Beckham $1977: 187)$.

\section{THE ADAMS FAMILY}

I began my study of Tillamook basketry in 1977, when I met Rena Goff Boyer, who was then living in Portland, Oregon. Through her I learned something of the lives of the Garibaldi-Tillamook and of their basketry.

Rena's great-grandfather, Illga Adams (Also Dila, Delga, and Indian Adams), was a Tillamook married to a Clatsop-Chinook woman, 
Maggie Adams. They and their daughters, Emma, Jane, and Lizzie, lived in the Idaville area south of Garibaldi, presumably within the area where the Nehalem dialect of Tillamook was spoken.

About 1911, after the deaths of Maggie and Illga, the family moved to the edge of an area known as Hobsonville, on the south side of Miami Cove and across from Garibaldi. Near the Adams's house were houses of other Indians, including Ellen Center and Clara Pearson, who had both served as informants for the Jacobses in the 1930s. In 1931 Edel also worked with Clara Pearson and members of the Adams family, and in 1942 Harrington did some work with Clark Pearson. This area become known derisively among Whites as "Squawtown".

Until 1927, when she was 17, Rena lived here with the three daughters of Illga and Maggie, her mother Nora, who was Jane's daughter, a sister and a brother, and other relatives who stayed from time to time. From Rena's recollections, it appears that Emma, Jane, and Lizzie maintained as much as they were able of their traditional culture. They spoke Tillamook, as well as Chinook Jargon, gathered shellfish and plant foods, and made baskets for their own uses, for trade, and for sale. It was from them that Nora, and eventually Rena, learned the craft. Lizzie was particularly well known for her baskets, despite her failing vision and ultimate blindness.

Rena left Garibaldi in 1927 to go to school in Monmouth, Oregon. By the end of the 1930s, Lizzie and Nora had died; and in 1942, Emma and Jane died (See Figure 3). From what Rena told me, it appears that Maggie and Illga Adams were typical of many of the Nehalem-Tillamook in not leaving their homes 
and going to the reservations, even though they did have relatives at Grand Ronde and at Siletz. However, some relations of the Adams family who may have had ties further north, went to Washington where, Rena said, relatives of hers were enrolled in the Quinault tribe. In 1906, of the 30 Tillamook who had been alive in 1851 or were heirs to the individuals who were alive then, only 10 lived in the Garibaldi area; 15 were at Siletz and two were living at Grand Ronde. While there were other Indians living in Garibaldi they appear to have had other than Tillamook affiliation or Tillamook ancestry unrecognized by the authorities (McChesney 1906:17-18).

References to the Adams family can be found in Boge (1972 and 1975), Sauter and Johnson (1974), and McChesney (1906). Photographs of members of the family can be found in Boge and in Sauter and Johnson, as well as in the collections of the Tillamook County Pioneer Museum and the Oregon Historical Society. 


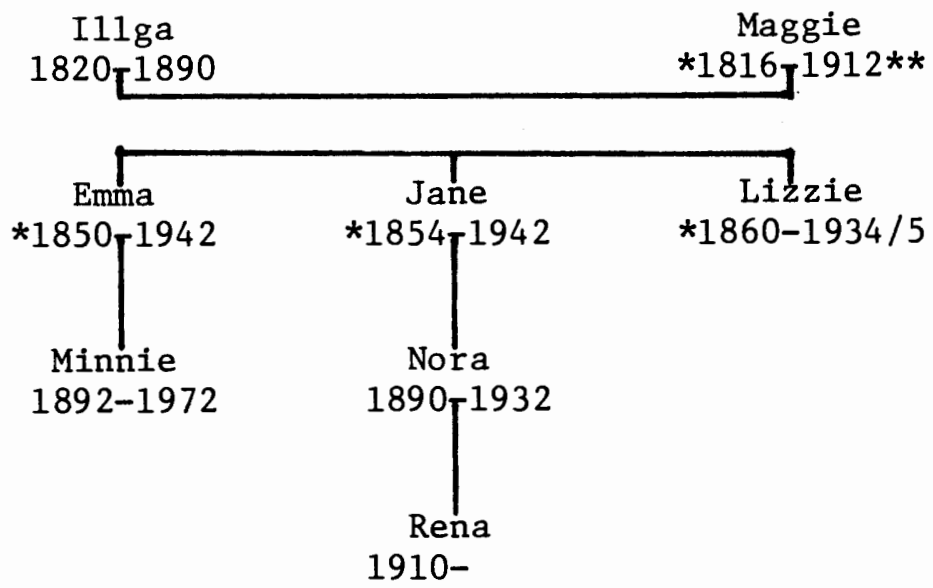

*These dates of birth are from McChesney (1906:17)

$* *$ Boge $(1979: 101)$

Figure 3. The genealogy of the basket-makers in the Adams Family. 
CHAPTER III

THE TILLAMOOK AS A FOCUS OF RESEARCH

There is very little mention of the Tillamook in the literature about the Northwest Coast peoples, and there is even less mention of Tillamook basketry. The cause of this may be found in largely unstated biases which have affected the choices made by researchers in their selection of groups to study. These biases appear to have drawn the interest of researchers to the areas north of the Columbia River and away from the Tillamook. The effect of such biases on research is probably not limited to the Tillamook or to the Northwest Coast.

\section{SOURCES OF BIAS}

I believe that these biases have grown out of: 1) the history of exploration, 2) collecting in the area, 3) from assumptions that scholars have made about the native peoples of the Northwest Coast, and 4) from the circumstances of the Tillamook themselves.

\section{Explorations}

The earliest explorations of the Northwest Coast and contact with the people occurred on Vancouver Island and northward. The material culture encountered here and eventually collected was highly visible, distinct from "primitive arts" in the rest of North America, and it was exotic. The masks, spoons, weapons, baskets, and other goods collected here may well, in the minds of the explorers and 
collectors, have become the standard for the material culture of the Northwest Coast, eclipsing styles with less visibility.

\section{Collecting}

Among collectors, there appear to have been some notions of tradition and purity which motivated them to collect some objects and to neglect others. These notions are particularly evident in the references to basketry. Holmes $(1888: 196)$ saw the use of untraditional materials in basketry as "contaminating". Mason (1904:540) believed that the collectors' "mission" was to encourage "aboriginal" shapes in basketry and "aboriginal" decoration on them. He wrote at a time when basketry was still being produced fairly widely and hoped, through collectors, to encourage Indians to maintain traditional basketry styles rather than to produce forms reflecting degeneration.

George Dorsey (Sprague 1971:215) stated his views quite clearly

in a 1901 letter to a buyer for the Field Museum:

As a rule I never buy anything in which flannel or any other American goods appears to dominate; in fact, I stear /sic/ as clear as possible of all objects which show the white man's influence.

More recently, in comments on northern California basket-makers,

Gunther (1968:104-5) remarked that:

- . the women who have continued to weave have allowed themselves to deviate from this tradition in the use of color and execution of dubious designs for the sake of pleasing a white customer.

She added that this circumstance provided a "dismal picture" for the traditional basketry. 
But what is traditional basketry? From these comments, it appears that it is the basketry in which these scholars do not detect White influences. What about elements in a basketry style that have as their source the basketry of another Indian group? Mason (1904:504) saw the practice of basket-makers imitating other styles as one which ". . confounds the student of folklore absolutely. . . ." But marriage patterns placed women outside their own groups and must have resulted in the gradual merging of styles. This process, over time, produced the highly regarded "traditional" basketry. The same process, using materials and influences of Whites produced the inferfor basketry of which these scholars speak. And it produced a basketry that was more difficult to pigeon-hole.

Assumptions About the Native People

In much of the literature about the peoples of the Northwest Coast, there is often the assumption, explicit or not, that the area north of the Strait of Juan de Fuca was the center of the development of the Northwest Coast art style and that these people, notably the Wakashans, were emulated, with varying degrees of success, by the presumed more recent Salishan arrivals to the coast from the interior (Drucker 1965:153). Suttles $(1975,1977)$ explores both of these assumptions in detall.

I believe that these assumptions have lead researchers to select for study those groups which were thought to have the "real thing" culturally and away from the groups that were thought to have copied or paraphrased it. 
The Tillamook may be just one example of a group which has been ignored because they lived south of the Wakashans and were linguistically affiliated with the Coast Salish.

The Tillamook

The researchers who studied the peoples of the Northwest Coast, like the collectors who desired only traditional material goods, sought groups whose traditions and living styles had not yet been disrupted by White settlement. In speaking of the Indians that he saw in Victoria, Boas $(1888: 628)$ said that the city was not the place to study the Indian, but that: "We must visit him in his village, where he lives undisturbed by the contact with Europeans, according to his ancient customs."

Boas may have had this Iuxury; but by the 1890 s in northwestern Oregon, such opportunities were not to be found. The disruption of the Tillamook through disease, the removal to reservations in some cases, and White encroachment on their land, put them on the periphery of White society and settlements that sprang up along the coast, and at the bottom of the economy. Their traditional culture was no longer coherent, and they seem not to have been regarded as worthy of investigation, despite the knowledge of former customs which remained in the memories of these people.

Although Boas (1898 and 1923) elicited stories and vocabulary from some Tillamook at Siletz in 1890 and Frachtenberg (1917) recorded some Tillamook vocabulary at Siletz Reservation, it was not until the 1930s that attention was once again focused on the Tillamook by the Jacobses 
and Edel and in the 1940s by Harrington. More recently, Tillamook archeological sites at Netarts have been investigated by Newman (1959).

\section{TILLAMOOK BASKETRY IN THE LITERATURE}

The sources that I consulted vary in the amount of detailed information that they contain about Tillamook basketry.

Mason (1904:421) refers to the Tillamook indirectly in his initial discussion of Salishan basket-making, but he does provide illustrations of two Tillamook baskets collected by Boas in 1890 and describes one of them in some technical detail (1904:436 and plates 165, center, and 167 , upper).

Barnett (1937:171) recorded elements of Tillamook basketry, such as materials, techniques, and products; but his informants' information was limited. They were men and it was women who traditionally made baskets. Many of the elements that these informants were asked about were left unanswered. I assume that this reflects their limited knowledge more than it does the absence of an element in the Tillamook basketry complex.

M. Douglas (1947), in her M. A. thesis on Oregon Indian basketry, describes Tillamook baskets in the greatest detail to be found. She examined baskets in the Museum of Natural History at the University of Oregon and described four of them, including the techniques and materials used.

Further mention of Tillamook basketry can be found in the work of the amateur archeologists Sauter and Johnson (1974). This volume contains photographs of some of the baskets from the Adams Collection; 
but the Tillamook attribution for others, also from the Tillamook County Pioneer Museum, is in error. The basket in Figure 41 may be Klamath while the one in Figure 42 is clearly Nootka or Makah, on the basis of the whaling scene on it; neither is Tillamook.

In publications in which any Oregon coast baskets are represented, it is often only Siletz Reservation basketry which is shown (i.e., Miles and Bovis 1969:15). The distinctiveness of these baskets appears to have eclipsed all other basketry from the Oregon coast, even to the extent that Rozaire (1977:33) refers to "Siletz" as a "catch-all" term for all basketry of the Oregon Indians, clearly not the case (See M. Douglas 1947, Spier and Sapir 1930, or Mason 1904 for examples of other basketry from Oregon). 
CHAPTER IV

THE BASKETRY

THE DISTRIBUTION OF BASKETRY TECHNIQUES IN NORTH AMERICA

The Tillamook basketry techniques appear to have been a part of a widespread tradition of basket-making. The principal structural basketry techniques in aboriginal North America have been categorized in a variety of ways, depending upon the lumping and splitting proclivities of the categorizers. Mason (1904:133) suggested a two-part division of coiled and of woven basketry, including every sort that is not coiled with the woven ones. Weltfish (1930:455) lists coiling, plaiting, twining, and wickerwork, the last which she then adds to twining, as the principal techniques. Driver and Massey (1957:332) concur with Weltfish and map aboriginal basketry techniques in North America accordingly (1957:333, map 121).

Twining and coiling co-existed across most of western North America, to the south and east of the Northwest Coast, as well as in isolated pockets further east among the 0jibwa and Pawnee (Driver and Massey 1957:333).

In the greater part of the Northwest Coast, including the Tillamook area, twining was the dominant basketry technique and coiling was absent, with the exception of some groups in the Salishan area where coiling was highly developed, although not to the exclusion of twining (Haeberlin et al. 1928:136). 
ARCHEOLOGICAL EVIDENCE FOR TWINING

The antecedents of Tillamook twining are very old. The archeological evidence of twining in the Northwest demonstrates that it was well-developed and used for a variety of products over millenia ago.

The oldest fragments have been found at Fort Rock Cave in Oregon. These pieces have been dated at 11,000-8,000 BP. Done in plain twining, the decorative technique has been described for these pieces as false embroidery (Bedwel1 and Cressman 1970:18).

A great range of products has been uncovered in water-saturated, "wet", sites in the Northwest Coast. At Ozette on the northern Washington coast, over 1,000 items, including entire and fragmentary twined baskets, hats, pouches, and mats, were found in one of several houses buried in a mud slide 300 to 500 years ago (Croes 1977:19). North of 0zette, on the Strait of Juan de Fuca at the mouth of the Hoko River, basketry material similar to that found at 0zette has been dated 2,000 years earlier, to 2,500 BP (Croes and Blinman 1980:222) and in British Columbia at Musqueam, on the Fraser River delta, twined fragments have been found that are about 3,000 years old (Borden 1976:235, 242).

In 1980, John Woodward uncovered fragments of open-twining on a shoreline in Tillamook County. These fragments, perhaps of a mat associated with a weir, were done in plain, s-slant twining and were made from material identified as western larch (Larix occidentalis) or Douglas fir (Pseudotsuga menziesii). They have been dated to $\mathrm{AD}$ 1410-1635, and represent the earliest twining discovered on the Oregon coast (personal communication, 1982). 


\section{DATA SOURCE}

In addition to the 29 baskets in the Adams Collection, I also found 39 baskets with Tillamook provenience in museums in Washington and Oregon. I had originally hoped to examine $150-200$ baskets for this study and was surprised to find so few identified as Tillamook. I have based my analysis only on these identified baskets, since I did not begin my study with a full understanding of the range and variety of Tillamook basketry and did not want to second guess what was or was not Tillamook. This approach has limited the size of my sample but has eliminated my predisposition to use only my earliest criteria, and thus it has widened the range of variation that I considered.

My original optimism for a larger sample was influenced by the first collections that I saw, which turned out to be the largest that I would see, a fact unknown to me until I was well into the research.

\section{$\underline{\text { Museums }}$}

Of the nine museums that I visited in search of Tillamook basketry, only five contained Tillamook baskets. The other four, which had seemed likely sources, either had no Tillamook baskets or none identified as Tillamook.

In the following list of museums, and brief description of what I found in them, I have included an abbreviation for each one, after its name. These abbreviations are those that accompany the basket catalog numbers in the text.

Tillamook County Pioneer Museum (TCPM) Tillamook, Oregon. The Adams Collection, which is the focus of this study, contains 29 baskets, 
some of which were made by members of the Adams family of Garibaldi between 1880 and 1935.

There are other baskets in this museum which may be Tillamook but have no provenience attributed to them. This study may help to identify them.

Museum of Natural History (UO) University of Oregon, Eugene, Oregon. I studied 27 Tillamook baskets here. Nineteen were from the Patterson Collection which was developed by Mrs. Isaac Lee Patterson beginning about 1895. Mrs. Patterson was extremely proud of the Tillamook baskets in her collection, as can be seen from her comment about them:

I consider my Tillamuks the rarest baskets I have. I have had them 20 years and the woman I bought them from said that she had had them 30 years. Not only is the stitch interesting (the bird-cage) but some of these baskets were woven to attempt something that would be pleasing to the white people. I have more Tillamuks than anyone I know of.

Accompanying her collection is Mrs. Patterson's documentation of where she collected baskets, the dates of collection, the prices that she paid for them, and some names of people from whom she bought them or who made them. There are also photographs of her collection of baskets from other areas in the West and of some of her Tillamook baskets. Although the documentation for this collection has not, as of now, been matched with particular pieces in the collection, it would be an attractive project for future research and study.

The remaining eight Tillamook baskets are from the Lewis A. McArthur, Mrs. Annie Knox, and Mrs. Vincent Cook Collections. I did not find dates of collection for these pieces. The McArthur Collection was made by 
Mrs. Harriet McArthur, who I believe is the same person cited by Mason (1904:462) and listed by him as a collector of "rarities" (1904:540,543). Horner Museum (HM) Oregon State University, Corvallis, Oregon. Seven of the eight baskets here are in the Tartar Collection. These baskets were collected by Emma Davis Kennedy, whose daughter, Rose, married Dr. Nathan L. Tartar. In the files of the museum is a photograph taken at Siletz between 1911-1916 of Mrs. Kennedy with E1la Ben, a Yuki basket-maker (Kasner 1976).

Oregon Historical Society Museum (OHS) Portland, Oregon. The three Tillamook baskets here are in the Mrs. William (Zilpha) Galloway Collection which was given to the Oregon Historical Society by the Oregon Museum of Science and Industry in 1958. I did not find any documentation for these baskets except the identification of them as Tillamook.

Thomas Burke Memorial Washington State Museum (TBW) University of Washington, Seattle, Washington. The single Tillamook basket here was collected by Myron Eells in 1892 from Mrs. Hawks, a Quinault woman, at Quinault, Washington, and was identified by her, or by Eells, as Tillamook. Clatsop County Historical Society--Flavel House (CCF) Astoria, Oregon. Only a few of the baskets in this collection have any provenience attributed to them, mostly Clatsop and Chinook, and none are labelled Tillamook. Some of the unlabelled ones appear to be very similar to known Tillamook baskets.

Lincoln County Historical Society (LCH) Newport, Oregon. There is a large collection of Siletz Reservation baskets here, but none are identified as Tillamook. The Copeland Collection, acquired by Clarinda Copeland, an owner of a general store at Siletz, makes up a large portion of the Siletz Reservation baskets. 
Cowlitz County Historical Society (CCW) Kelso, Washington. Although I did not find Tillamook baskets here, there are some well-documented ones from the Siletz Reservation.

Maryhill Museum Goldendale, Washington. I found no Tillamook baskets here.

DATA COLLECTING

In order to study the baskets outside museum settings, I kept a written record of them and I photographed them.

\section{Basketry Analysis Form}

I developed a Twined Basketry Analysis Form (Figure 4) on which to record information about the baskets and to have a checklist for noting attributes. As models for this form, I drew on Adovasio (1977) and Smith (1949), both of whom had developed such forms in greater detail than I eventually used. On the form, I considered the basket shape, measurements, techniques of twining used on the sides and base, the stitch slant, rim finish, base start and shape, presence or absence of three-strand twining (which I erroneously recorded as three-strand braiding), and the materials used. I later added space for the gauge of the twining. I recorded all measurements in inches.

\section{Photographic Record}

I photographed the baskets with Kodak Ektachrome 400 slide film using natural light where possible and available light otherwise. The photographs in this study are prints from my slides. 
TWINED BASKETRY ANALYSIS FORM

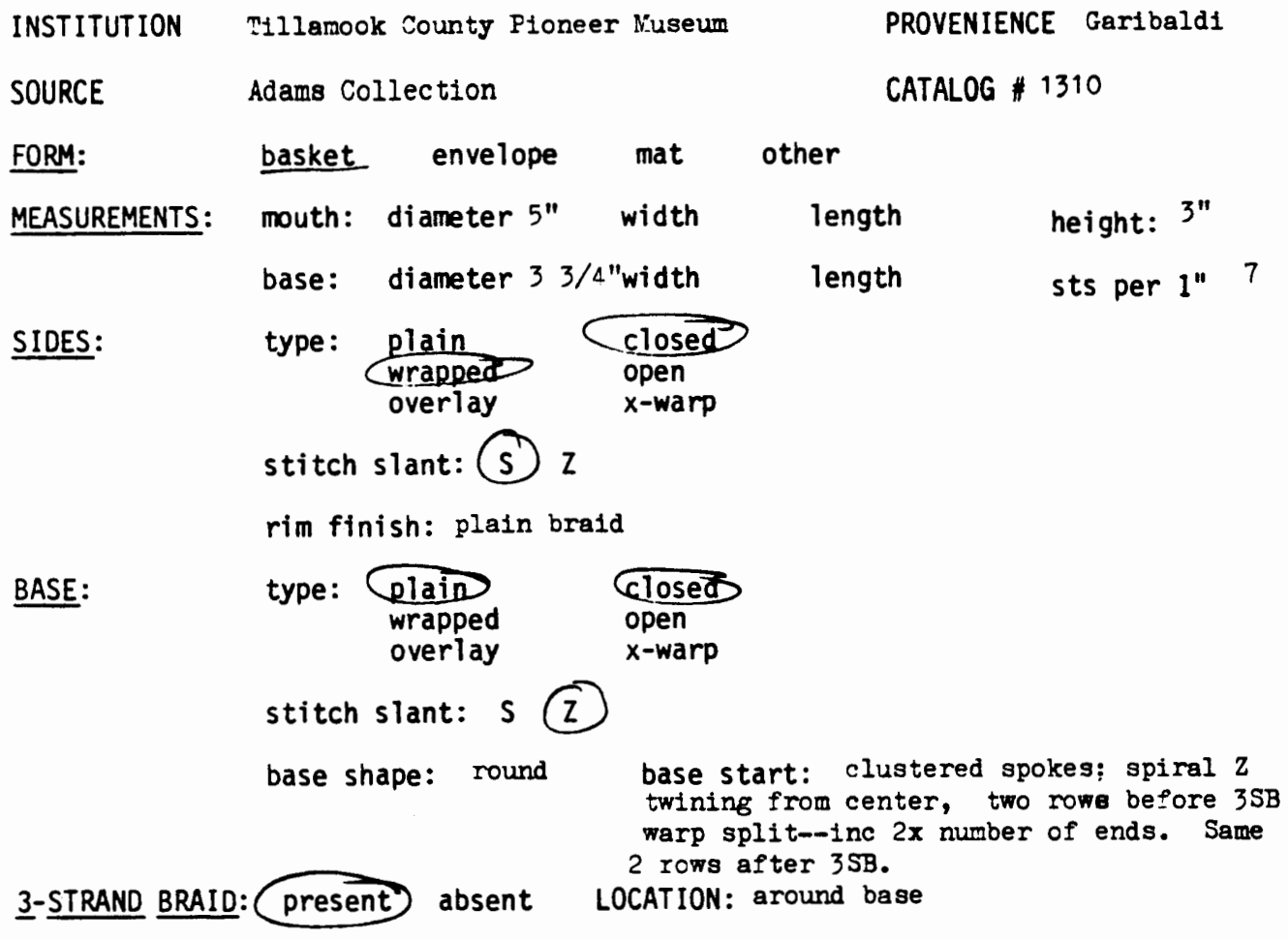

1 slide

\section{PROVENIENCE Garibaldi} SB

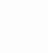

MATERIALS: Genus species

weft Xerophyllum tenax raffia: red, plain, black, green

warp Carex?

GENERAL DESCRIPTION

Tight, nice little basket . Nicely made. Vertical zig-zag design in red on white 
DATA ANALYSIS

\section{Attributes}

The basket attributes that I considered in this study include the body, base, and rim construction, the base start, three-strand twining, handles, stitch slant, stitch gauge, height and shape of the baskets. I also considered the attributes of ornamentation including the presence or absence of decoration, the arrangement of the design field, the style of decoration--structural change, or color change, or both; and the decorative techniques used.

Attribute Variables

I used Jones (1976) for the variables of the attributes that I considered. Although I found it necessary to add and to delete some variables, using an established list was helpful and ensured that I would consider aspects of the basketry already recognized in the literature.

For each attribute, I have listed the variables and have noted the absolute occurrence of them in the Adams Collection and in the Other Tillamook group in Table I (page 43).

In order to develop this table of attribute variables, I gave each variable a number. On three-by-five cards, I established attribute areas and recorded the appropriate variable number within each area. This made sorting through the data easier than using the form on which I had initially collected it. Hand sorting was feasible because of the small size of this sample. (Figure 5). 


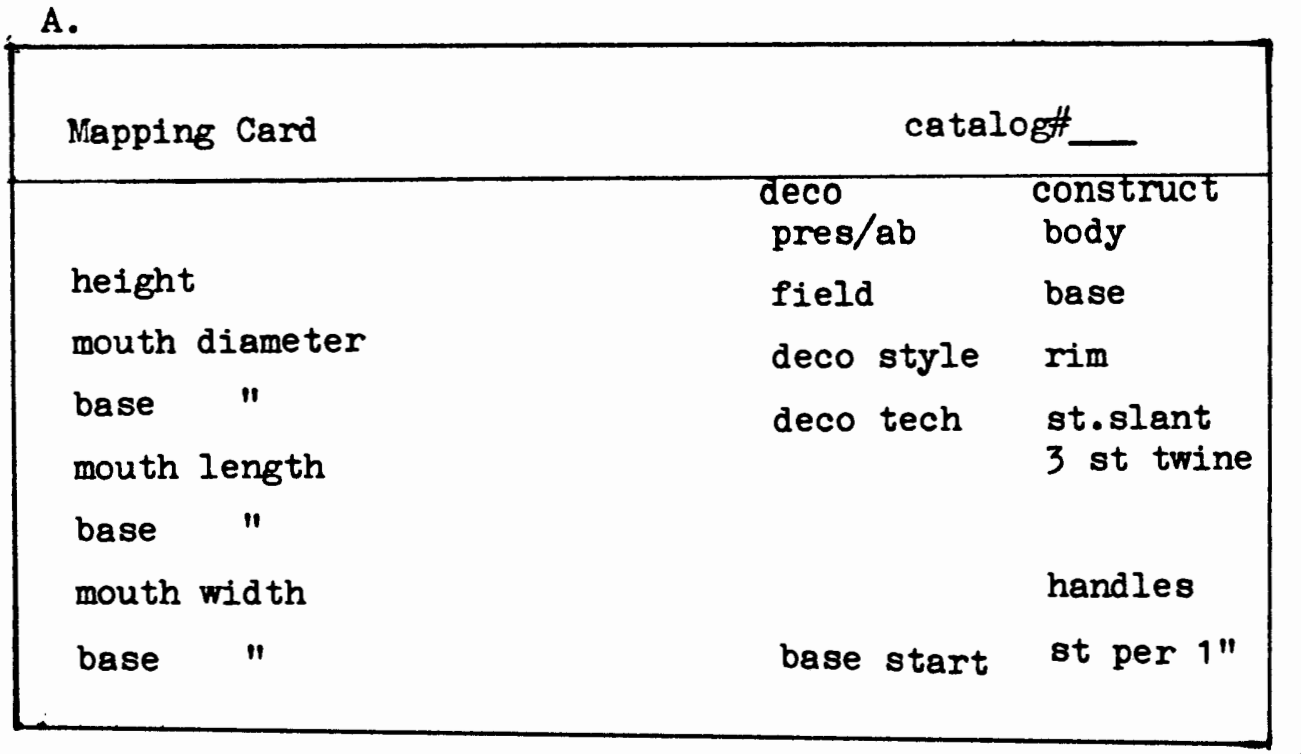

B.

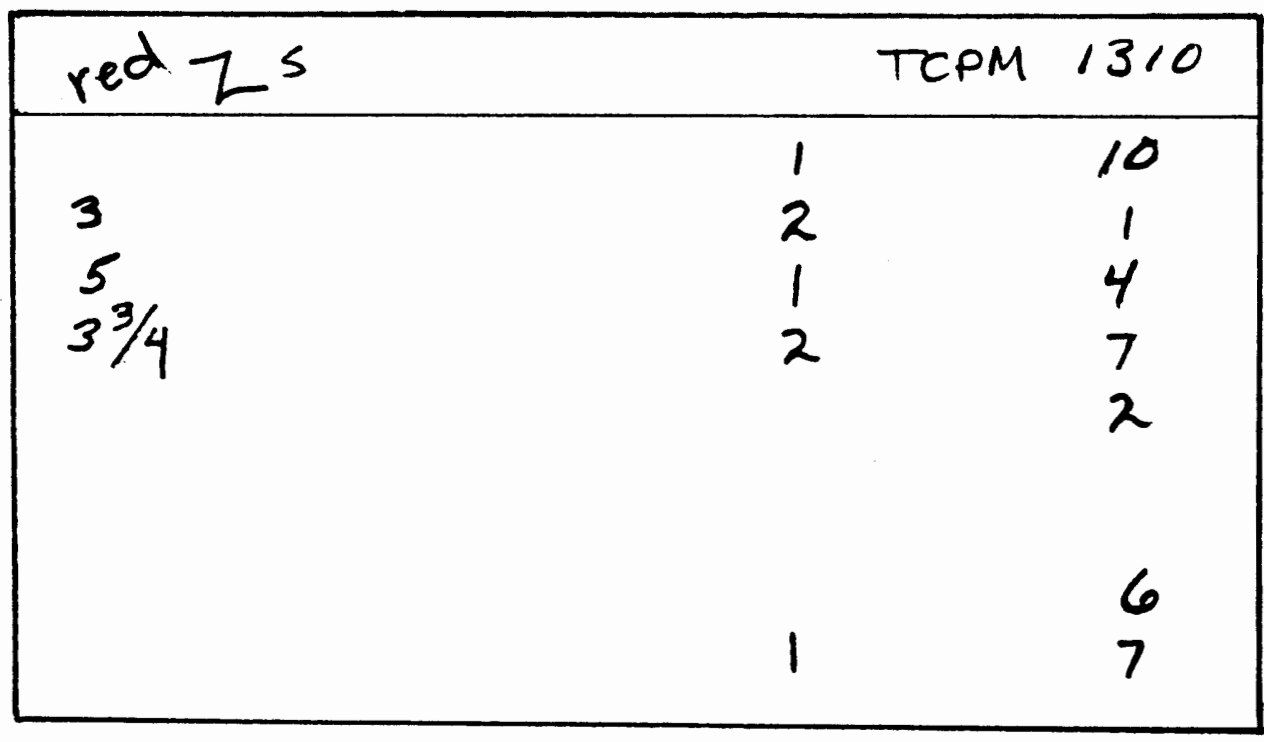

Figure 5. Basketry Analysis Cards: A. Mapping card with attribute areas. B. Attribute variables recorded by number. 


\section{TILLAMOOK BASKETRY TECHNOLOGY}

Boas, Ede1, the Jacobses, and Harrington all recorded Tillamook terms for various parts of a basket and the processes for constructing them (Appendix A).

The terms that I have used for describing the techniques that I found in Tillamook basketry are those that $I$ found in the textile and basketry literature and do not necessarily reflect Tillamook categories. I have made every effort to preserve the definitions and use of terminology as it appears in the literature. In some cases, I have found that the terminology is ambiguous or ill-defined and have attempted to give a clear definition of my use of a term

More detailed descriptions of basketry techniques and definitions of terms can be found in Mason (1904), Jones (1976), Croes (1977), and Emery (1966), currently the Curator Emeritus of Technical Studies at the Textile Museum in Washington D.C.

Basketry Anatomy

In order to follow my descriptions of the basketry, it is necessary to know the parts of a basket and the terms that I have used for them.

Base start: The way in which warp strands are arranged and the first twining stitches made.

Base: The portion of the basket parallel to the opening on which the basket does, or theoretically could, rest. Wall pouches, meant to be hung, might not actually be able to rest on the base. 
Body/sides/wa11s: The portion of a basket between the base and the rim, for which I have used these terms interchangeably.

Margin: The area of the basket just below the rim (Mason, 1904;436) and on which a band of ornamentation often occurs.

Mouth: The opening of the basket parallel with the base.

Rim: The edge of the basket surrounding the mouth, or on wallpouches, the edge of the front of each pouch.

\section{Structural Techniques}

The following brief descriptions are of the structural techniques for the body, base, and rim that I found in my sample. The structural techniques in basketry can be weft or warp dependent or equally weft and warp dependent.

\section{Weft Variations}

The weft is responsible for more variation than is the warp. It is the weft that is manipulated to create these variations in technique.

Plain twining. A pair of flexible weft elements encompasses each warp element; they are given a half turn between the warps, reversing their positions on the front and back, and are carried along horizontally, repeating the twist or turn, between successive warps.

Open, plain twining. This is the same as plain twining but with spaces between the rows, revealing the warp.

Wrapped twining. Two weft elements are used; one is usually rigid and passive and the other is flexible and active. In Tillamook baskets, the rigid, passive element is held horizontally behind the warps, while 
the flexible element is wrapped around both the passive weft and the warp for each stitch. The stitches on the face of the basket lie at an angle, and on the interior they are vertical.

Ful1-turn twining (Figure 6a). Full-turn twining does not appear as a designation for a variation of plain twining in the literature for Northwest Coast basketry. Birrell (1959:67) describes it as Maori, or Taniko, twining. Emery (1966:203) calls it full-turn twining; and I have chosen to use this term because it is technically, rather than geographically, descriptive.

Full-turn twining is produced by giving the weft element pairs two twists between warp elements, rather than only one. If one were to use a brown weft and a white one in plain twining, the stitches on both sides of the basket would be alternately brown and white. In full-turn twining, except for the stitch between the warps, the actual warp-encompassing stitches would be entirely brown or entirely white on the surface. The openwork of the baskets done in this technique, and it only occurs on openwork, may be made more stable by the extra twist between the warps. Three-strand twining. This technique uses three flexible weft elements and results in a rope-like effect that is distinguishable from plain or wrapped twining. On the outside of the basket, each weft crosses two warps, while on the inside each weft crosses only one warp. Three-strand twining is often done in the stitch slant opposite that of the rest of the basket and is usually found in a single row at the base perimeter or just below the rim finish. In some cases, what appears to be a row of three-strand twining may actually be part of a braided rim finish. The distinction has not always been clear to me. 
Wicker. Wicker is different from twining because it has only one weft element which passes over and under the warp elements alternately.

Diagonal twining. Weft elements enclose pairs of warp elements and these warp pairs are alternated every other row. I did not identify diagonal twining for any baskets, but M. Douglas does identify it for a Tillamook basket (1947:44; UO 1-15658/L2-337).

Warp Variations

In Tillamook basketry, the warp elements can be concealed as in any close twining or revealed to be parallel or crossed.

Parallel warp. In nearly all of the basketry, the warps lie parallel to each other, visible or not.

Crossed-warp. The crossed-warps are created by moving every other warp across the adjacent one and twining each element on either side of the cross. The cross itself is not twined.

\section{Warp/Weft Variations}

Checkerwork, twill, and plaiting are techniques which involve equal manipulation of the warp and weft elements.

Checkerwork. This is also referred to as "plain weave" (Emery 1966:76) since it is structurally the most elementary of all the weaves. Each weft element passes alternately over and under each successive warp element.

Twill. Twill is similar to checkerwork, but in one variation of the many possible, each weft element passes over two warp elements, progressing by one warp in successive rows. 
Plaiting. Some authors have equated plaiting with checkerwork and twill (Douglas, F. 1935:67; Douglas, M. 1947:7; Croes 1977:70; and Weber 1982:27). Some of those in the textile field equate plaiting with braiding (Birre11 1959:279 and d'Harcourt 1974:10). Mason (1904:193) states that "braid work is a term preferable to plaiting" and does not mention plaiting in his list of basketry terms.

The problem of the definition of plaiting appears to be a confusion of process with product. In the plaiting process, the warp and weft are indistinguishable from each other, not because they look alike, but because all of the elements belong to a single set and each element performs both the weft and warp functions. This interlacing of a single set of elements (Emery 1966:60) can best be seen in matting, for which Croes (1977:129) and Drucker (1963:99) correctly note that there is no definite warp. Each element of the single set is folded back into the mat at the margin to resume its warp/weft function as it courses through the mat. Although the appearance of a mat might be that of oblique checkerwork, it is not created in that way.

In the descriptions of the baskets, I shall use the term "checkerwork" for the weaving process which uses two elements and reserve "plaiting" for braiding techniques.

\section{Base Starts}

I found two principal arrangements of the initial warp on the base of Tillamook baskets and two less usual ones. In some cases no "start" as such was apparent; the base was composed entirely of checkerwork or twill. The cluster starts and the parallel warp starts are the most usual; only a few instances of the other starts occurred. 
Warp-cluster. Nearly all of the baskets that have a round base are begun on warps that are tightly gathered in the center and then radiate spoke-fashion outward.

Warp-cross. This variation of the warp-cluster start results in the same radiating warps. Two small groups of parallel warp elements are laid on top of each other at a 90 degree angle and twined together.

Parallel warp. Baskets that have a rectangular base are usually begun on warps laid parallel to each other. The weft is twined across them, sometimes in a long spiral, but more often simply back and forth the length and width of the rectangle.

Seam or double layer. The object that results from this start may be more appropriately described as a bag rather than a basket since it has no base, in a sense. Two sets of parallel warps are laid on top of each other and twined together for one or several rows before being separated to form the sides.

\section{Rim Finishes}

Braids and wrapping are the most common rim finishes in my sample. The rims of two baskets are covered with cloth which may conceal one of the other techniques.

Braid. Croes (1977) describes several rim finishes in detail, some of which result in a braided appearance. Neither M. Douglas (1947) nor Jones (1976) distinguish among the several sorts of braids possible. I have followed them in calling any rim finish that looks like braid, a braid, although I recognize that some variation does exist. Open, double braid. An exception to all of the braids which look very much alike, are those found on the rims of clam baskets. They 
are made by braiding clusters of warp ends and then working them into a single, or more often double, horizontal braid. The openness of this finish occurs between the last row of twining on the basket and the first row of horizontal braid, in the places where the vertical warp elements are first braided together. The openings may have been used for lacing the mouth of the basket closed (Figure 6c).

Wrapping. The warp ends are wrapped around a rigid horizontal element held behind them and are bound to it with another element for this rim finish.

\section{Decorative Techniques}

The decorative techniques in Tillamook basketry include simple color change, weft-overlay twining, warp-overlay, and beading. These can occur alone or in combination. They are all incorporated into the structure of the basket during the process of manufacture; I did not find any instances of decoration applied to the finished basket, such as painting.

Color change. The simplest decoration resulting from color change are single or multiple rows of different colors using the same color in both weft elements (Figure 10). An elaboration of this is dependent on each weft being a different color. This results in the alternation of color stitch-by-stitch along a row (Figure 10). By the careful placement of the stitches, a variety of patterns is possible.

In plain twining, both of the colored wefts are active. In wrapped twining, more than two colors can be used more easily; the unneeded wefts can become the passive element or can be carried along with the continuously passive element until needed in the design. 
Weft-overlay twining. Weft-overlay is similar to plain twining, but one or more of the structural weft elements are covered with a decorative element the width of the structural one, but perhaps not so strong that it can be used alone. By careful manipulation of the wefts, the decorative element is visible only on the outside surface of the basket. Warp-overlay. Warp-overlay is a technically more simple process than weft-overlay, since no manipulation of the overlay strands is necessary. The decorative element is laid on top of the warp strand, along its length, and is held in place by subsequent rows of open twining over it so that the decorative element remains visible (Figure 18). Beading. Mason (1904:193) defines beading as a technique of decoration on coiled basketry, but he also describes an ornamentation on twined Tillamook basketry as beading ( $p$. 436). Jones (1976:58) seems to define beading as a technique that applies only to coiling, but she is not explicit: "Beading--a strand worked over and under successive stitches. The design is not visible on the inside of the basket." However, she does include beading as a variable that can occur with false-embroidery, a twining technique. I have chosen to use the term to describe the limited, decorative device of working a weft strand over and under warp strands in twined basketry. In this situation, it is visible on the inside and on the outside of a basket.

In my use of the term, beading differs from checkerwork by the use of a broader, flatter weft material in beading than is used for the warp it is worked over and under (Figure 6a).

Beading is the one decorative technique that theoretically could be inserted into the basket after it is made. In the examples of beading 
that I have seen in my sample, the beading wefts, often in two rows sideby-side, are worked in quite tightly between the rows of twining which border them. There is no indication that they were not incorporated into a basket during its manufacture.

False-embroidery. Although false-embroidery is identified for a Tillamook basket at the University of Oregon (UO 1-15578) and in photographs in Mason (1904:436 and plate 165), the technique, in the first instance, is actually weft-overlay twining and probably is also in the Tillamook and Clallam baskets pictured in Mason. All of the stitches on each basket slant in the same direction, which would not be the case if false-embroidery had been used. I did not find any occurrence of false-embroidery in my sample of Tillamook baskets.

Stitch slant (Figure 6b). I have based my descriptions and definitions of stitch slant on the direction in which the stitches slant when the basket is held vertically, rim or mouth up. This does have a logical basis; it is my understanding that a basket was twined horizontally across the warps from the base to the rim. By holding a basket vertically it is possible to describe the stitches in the sequence in which they were made. How they were created, by left or right-handed basketmakers or twined clockwise or counter-clockwise, is not an issue in this study. I have no evidence for any of those factors and am concerned solely with the appearance of the baskets and the stitches in them.

Twined stitches can slant upward to the right or downward to the right. The slant of a stitch on the face of a basket is the result of the direction in which the weft strands have been twisted. Writers have used an array of ways in which to describe the slant of a stitch. These 
include "down to the right" and "down to the left: (Douglas, M. 1947:11), the use of arrows oriented in the direction meant "L " or " (Copeland 1956:38), "leftward pitch" and rightward pitch" (Thompson et al., 1980:17) and "lean up-to-the-right" and "lean up-to-the-1eft" (Croes 1977:77). I have chosen to use the terminology that is usually applied to the twist in yarn or cordage in order to describe the slant of twined stitches. This creates some ambiguity, which I will clarify here.

The chief problem in using twist terminology is that the twist of the weft and the resulting slant of the stitch are opposite. When the weft elements are twisted toward the weaver, a $\mathrm{Z}$-twist in the weft is created but an S-slant in the stitch on the face of the basket results. And the reverse if is true for $\mathrm{z}$-slant stitches.

The $S$ and Z-slant which I refer to in this study are solely descriptors for stitch slant and not for weft twist. Z-slant stitches go up to the right and S-slant stitches go down to the right (Figure $6 \mathrm{~b}$ ). Stitch slant has been regarded as diagnostic for provenience by Thompson et al $(1980: 16)$, and Croes (1977:77) claims that stitch slant is culturally encouraged. However, Jones (1976:75) believes that stitch slant reflects only individual work habits and would have no diagnostic value for provenience.

In the Adams Collection nearly $90 \%$ of the baskets, both the sides and bases, were done in S-slant twining. Since most of these baskets were made by members of the Adams family, this seems to support Croes's statement that slant was culturally encouraged. In the Other Tillamook group, approximately $61 \%$ of the baskets used S-slant and $36 \%$ used Z-slant 
A.

beading

ful1-turn twining

B.

S-slant stitches

Z-slant stitches

C.

double-braid rim
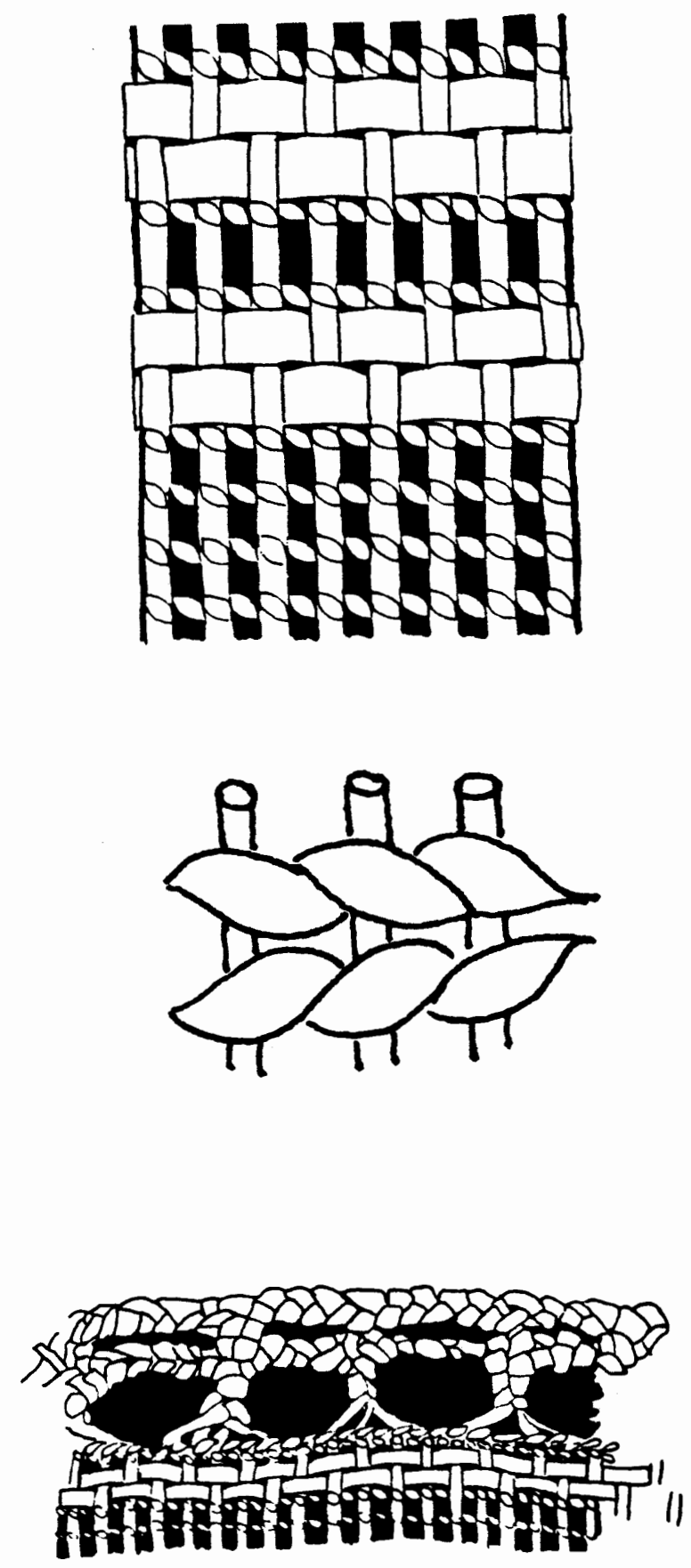

Figure 6. Basketry techniques 
on the basket sides. In the instances where both $\mathrm{S}$ and $\mathrm{Z}$-slant occur on the sides or on the base, it is often for decorative effect.

Although my sample is small, it does appear that Tillamook basketry tends to have $S$ more of ten than Z-slant twining.

Stitch gauge. I determined the stitch gauge in the basketry by counting the number of stitches along a row for an inch. The more stitches there are, the finer the gauge is. The material used in a basket, the techniques employed, and the skill of the maker are all factors which affect stitch gauge.

The Tillamook baskets in my sample ranged from three to 12 stitches to the inch. I have divided this range into coarse, fine, and very fine, terms which describe only the gauge and not the basket-makers skill or 1ack of it.

\section{TABLE I}

TILLAMOOK BASKETRY ATTRIBUTE VARIABLES

\section{Body Construction Variables}

1. closed, plain twining

2. open, plain twining

3. fu1l-turn twining

4. twill

5. wrapped twining

6. open, plain twining--S and $\mathrm{Z}$ slant

7. plain twining plus checkerwork

8. crossed-warp twining

9. crossed-warp plus checkerwork

10. closed, plain twining plus wrapped twining
$\underline{\mathrm{AC}} \quad \underline{\mathrm{OT}}$

$\begin{array}{ll}1 & 8\end{array}$

1

1

8

1

$8 \quad 11$

2

0

$3 \quad 0$

14

10

6 
Body Construction Variables (continued)

11. closed, plain twining plus three-strand twining between base and rim

12. wrapped twining plus open, plain twining

13. closed, plain twining plus wrapped twining plus open, plain twining

Base Construction Variables

1. closed plain twining

2. open, plain twining

3. full-turn twining

4. twill

5. checkerwork

6. wrapped twining

7. closed plain twining--S and $\mathrm{Z}$ slant

8. checkerwork plus twining

9. "seam"

10. twining plus twill

11. wicker

12. closed, plain twining plus wrapped twining

Rim Construction Variables

1. wrapped

2. open with double-braid

3. open with single braid

1

4. braid

5. loops of cord 
1. warp-cluster 14

2. warp-cross 4

3. two layers of warp ("seamed" base) 0

4. checkerwork 0

5. twill 2

6. checkerwork plus twining 0

7. parallel warp 9

Three-strand Variables

1. absent

2. perimeter of base only

3. perimeter of rim only

4. perimeter of base and rim

5. perimeter of rim and body

$\begin{array}{ll}0 & 1\end{array}$

6. perimeter of rim and base, and body

0

1

Handle Variables

1. soft, braided

2. wrapped, figure-eight

3. wooden

$\begin{array}{ll}0 & 1\end{array}$

4. absent

$8 \quad 30$

5. loop for hanging

6. hide-wrapped

7. twisted fiber

8. attached to body loops

Decoration Variables

1. decorated

2. undecorated 
Design Field Variables

1. horizontal bands

2. Vs

$\begin{array}{ll}0 & 1\end{array}$

3. not applicable (warp and weft-overlay)

Decoration Technique Variables

1. different colored strand

2. weft-overlay

3. warp-overlay

01

4. weft and warp-overlay

03

5. beading

6. beading plus different colored strand

11

7. different colored strand plus overlay

01

8. different colored strand plus overlay plus beading

$0 \quad 1$

9. cross-warp band

10. cross-warp band plus different color strand

Stitch Slant Variable

1. S body and base

2. Z body and base

3. S body, Z base

4. S body

5. Z body, wicker base

6. $\mathrm{Z}$ body, $\mathrm{S}$ and $\mathrm{Z}$ base 
Stitch Slant Variable (Continued)

$\begin{array}{ccc}\frac{\mathrm{AC}}{1} & & \mathrm{OT} \\ 1 & 4 \\ 0 & 1 \\ 3 & 0\end{array}$

9. $\mathrm{S}$ and $\mathrm{Z}$ body, $\emptyset$ base

Stitch Gauge Variable

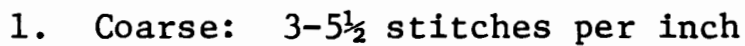

2. Fine: 6-8 stitches per inch

11 20

3. Very Fine: 9-12 stitches per inch

4. no information or not applicable

1

2

Height Variable

1. 1-5 inches high

23

8

2. 5-10 inches high

6

3. 10-15 inches high

0

11

4. 15-20 inches high

0

5. no information

0

1

SHAPE

Shape is an attribute of basketry that has been used for diagnostic purposes (Copeland 1956) and for assessing stylistic change (Jones 1976: 77). I have not used the shapes that I found in my sample as necessarily diagnostic for Tillamook basketry, although some may be, because my sample is sma11; and for the number of baskets in it, there is great variation in shape.

Categories of this sort can contain an element of subjectivity; not everyone would combine or separate the baskets as I have done. Nevertheless, these categories do demonstrate the range of shapes in my sample. 
While no one shape is predominate, three of them do represent nearly two-thirds of my sample: rounded-base cylinders, flat trapezoids, and inverted truncated cones. Among the rest of the baskets, nine categories are each represented by only one piece.

I have constructed these categories only for the purpose of describing the range of shapes in my sample and not for illustrating any traditional Tillamook categories.

Croes (1977:34-35) has been helpful to me for describing the shapes in geometric terms, where appropriate. For other baskets not so easily described, I have used terms as clear and descriptive as possible.

In the table below, I have divided the baskets into two groups, those with round bases and those with rectangular or oval ones and have listed them from greater to lesser frequency. The first column contains the name of the shape, the second contains representations of the shapes-base (B), section ( $S$ ), and mouth (M)--and the last two list the number of baskets within a shape category in the Adams Collection (AC) and the Other Tillamook group (OT). 
TABLE II

TILLAMOOK BASKET SHAPES

$\underline{B} \quad \underline{S} \quad \underline{M} \quad \underline{A C} \quad \underline{\text { TT }}$

Baskets with Round Bases

rounded-base cylinders

$\square \bigcirc 105$

inverted, truncated cone

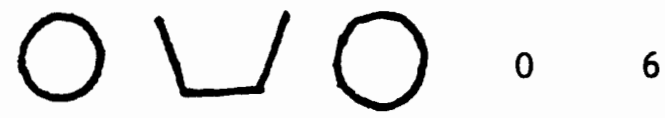

flat-base cylinder
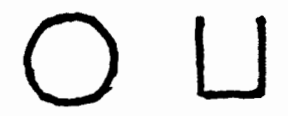<smiles>c1ccccc1</smiles>

3

0

truncated sphere
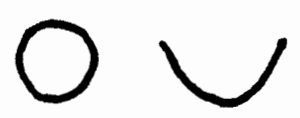<smiles>c1ccccc1</smiles>

"shouldered", rounded-base cylinder
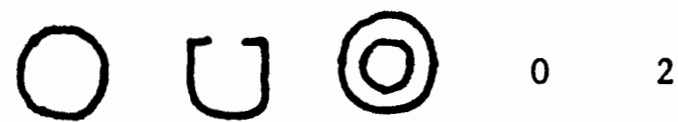

truncated cone

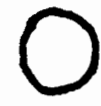

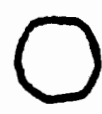

01

jar

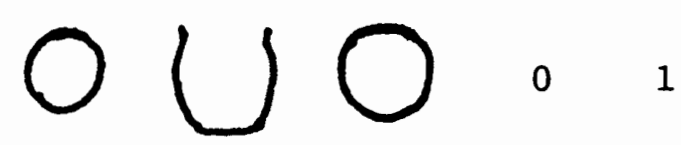

truncated ovoid
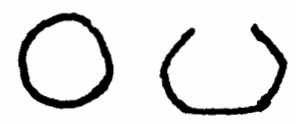

(1)

01

composite, cylinder-topped, inverted, truncated cone
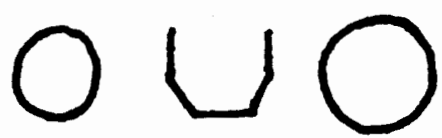

0

1

Baskets with Rectangular or Oval Bases

flat trapezoids

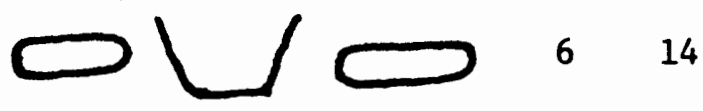

flat rectangles

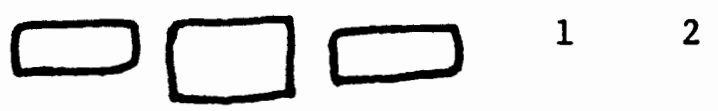

"seamed" rectangles

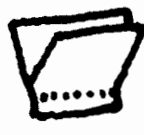

inverted, truncated pyramid

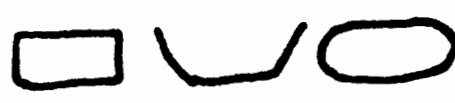

11 
Baskets with Rectangular or Oval Bases (Continued)

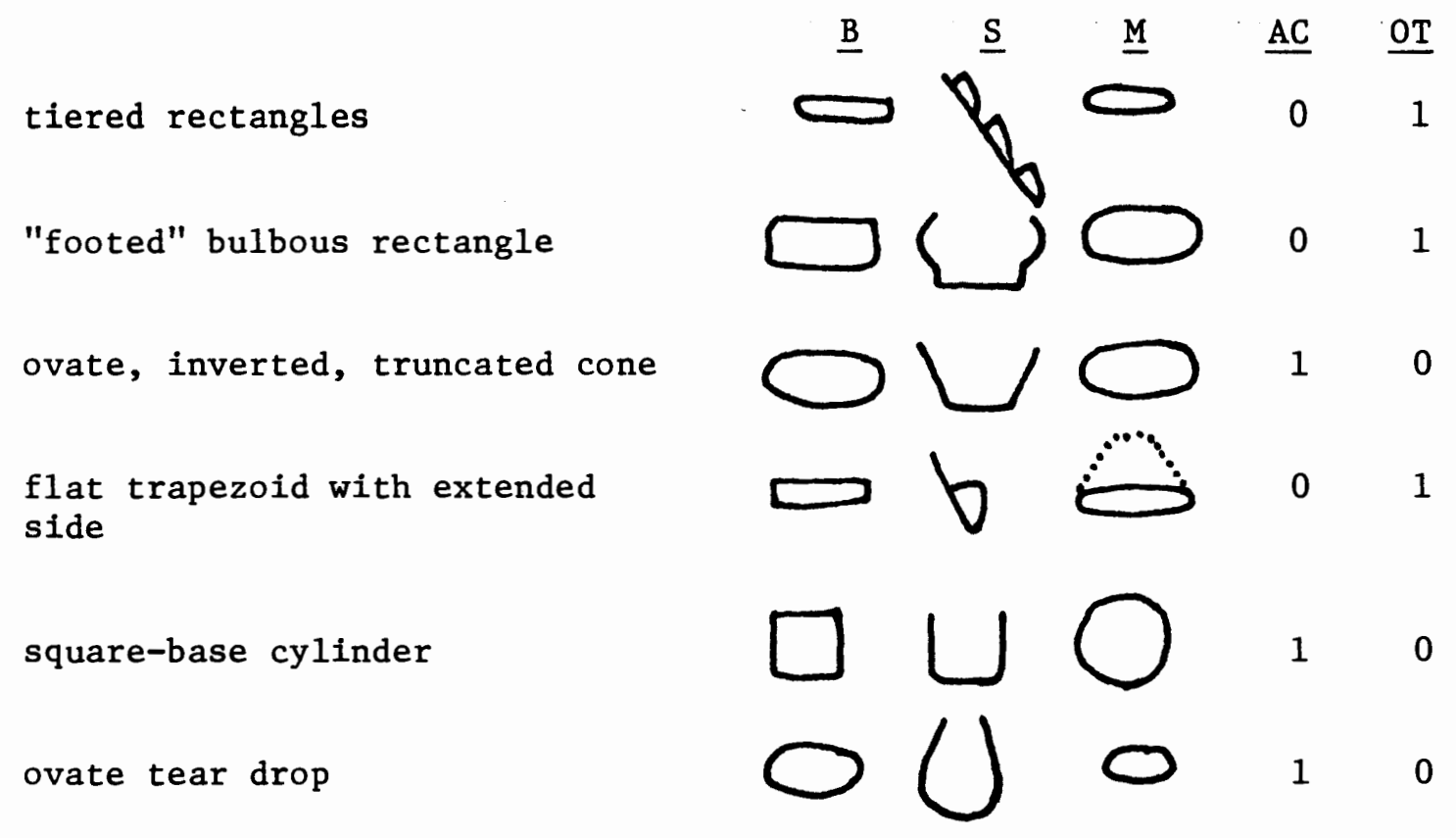

Rena Boyer used some terms for kinds of baskets that are not reflected in the table of shapes. Rena described one kind of basket as a "clam basket" because a use of them was in gathering shell-fish. They were carried on the back of the bearer by means of a tumpline which was worn across the chest, as illustrated in Gogol $(1979: 9)$, or across the forehead. Several of the clam baskets in my sample have tumplines associated with them. Mason (1904, plate 166) has a photograph of a Tillamook clam basket collected by Boas in 1890. Most of the clam baskets are in the flat trapezoid category. Another term Rena used was "shopping-bag", made up of both flat trapezoids and of flat rectangles. Constructed on a rectangular base, these baskets are usually a bit wider across the top edge than at the base and have a pair of handles. The flat trapezold with an extended side and the tiered rectangles Rena described as wall-pouches. She said that they were used to put things in, such as keys or mail or other odds and ends, and hung on the wall in a convenient place. 
I have used the term "envelope". for the smaller and flatter trapezoids and flat rectangles.

The last kind of basketry not reflected in the shapes listed previously is that which covered bottles and jars. The covered bottles are composed of cylinders, a rectangle, and the ovate tear-drop.

\section{MATERIALS}

I have not concentrated on distinguishing among the native basketry materials used in the body of basketry that I have examined. However, I have noted the decorative materials and those that are non-native, since they are both far more distinctive and identifiable than are the many varieties of conifer roots, deciduous shoots, or reeds and sedges, once they have been dried, split, dyed, and aged. Gunther (1945) describes many uses of plants among the peoples of Western Washington. Some of these may well occur in the Tillamook materials.

Structural Materials

Traditional structural materials. The traditicnal materials used in Tillamook basketry were derived from plants, whether they were for structural elements, decorative ones, or dyes.

Barnett $(1937: 171)$ recorded the use of hazel (Corylus spp.) and conifer roots, bear-grass (Xerophyllum) and maidenhair-fern (Adiantum). It is likely that hazel shoots, not roots, is what were used, although Barnett's entry reads ambiguously and with no further explanation.

I recorded the use of cedar, or "swamp grass", or a "threecornered grass", and of what I later identified as common rush (Juncus effusus) (Turner 1979:169), or wiregrass (Colville in Mason 1904:207), 
from Rena Boyer, the Tillamook descendant of the Adams family with whom I investigated Tillamook basketry.

I found what is probably cedar bark used for decorative purposes in a few baskets in the Horner Museum. I did not find it documented for other Tillamook baskets.

The "swamp reed" that Rena described to me may have been Phragmites spp. On the visit that she and I made to Garibaldi, we were unable to find it. The highways, widened and in some cases newly laid since she lived there, and the pasturage for cows have all taken their toll on the old basketry material sites.

The "three-cornered grass" is more readily identifiable by the description of its distinctive stem with three edges, or corners, running the length of it. This is probably a Carex, or sedge, many species of which are triangular in cross-section (Turner 1979:122-127), but not all of which are suitable for basketry, as I discovered. I once collected some in the Nehalem area, only to learn from Rena that the proper sort became soft and bendable when it dried, whereas my samples became more sharp-edged and brittle.

Both the Phragmites spp. and Carex spp. are recorded as basketry materials in British Columbia (Turner 1979:122, 127, and 146) and Carex barbarae is reported for the Pomo in northern California (Newman 1974:7).

Turner notes that Juncus effuses was of only minor importance in the basketry of the Comox (1979:169) while Colville mentions the use of Juncus spp. by several groups for teaching basketry to children (Mason 1904:206-207). I failed to find any identification of it in the museum records for the specimens that I saw, nor did I recognize it in any of the basketry. 
Cat-tail (Typha latifolia) leaves and tule (Scirpus lacustris)

stems are both evident in the basketry, more often as warp than as weft elements. Cat-tail and tule are distinguishable from all other materials but, with only the naked eye, not always from each other.

Non-traditional structural materials. The principal non-traditional structural material in the basketry is raffia, which was used extensively by the Adamses as weft material. In several baskets I encountered lengths of wire worked into the rims, which may have been added by a subsequent owner, rather than by the maker.

\section{Decorative Materials}

Traditional decorative materials. The two most frequently used traditional decorative materials in Tillamook basketry are bear-grass (Xerophyllum tenax) and maidenhair-fern (Adiantum pedatum) stem.

Bear-grass, also called white grass, mountain straw, and in the older 1iterature, squaw grass, is a plant with a shiny, flat, straplike leaf. It grows at higher elevations than the ocean coast provides and was apparently an item of trade between the people of the coast and more interior groups (Thwaites 1905:338). In 1931 Lizzie Adams, via May Edel, sent a letter to a relative at Salmon River, asking if she had any mountain straw, since Lizzie had used all of hers in her weaving (Edel 1931). Rena told me that in order to split the bear-grass into narrower segments and to weave with it, women wore protective leather "finger stalls", because the edges of the leaves were so sharp. Beargrass was used in its natural white state and it was dyed. 
Maidenhair-fern stems are dark and are fairly shiny. Of ten the color is nearly black, but it also appears as a reddish-brown. This variation occurs on the stem itself; the upper side is usually blacker than the underside.

The dull black of the scouring rush (Equisetum spp.) root contrasts with the shiny maidenhair-fern stem. Rena said that the scouring rush root was used, and I identified it in some baskets, but there is no mention of it in the literature for Tillamook basketry. Turner (1979:64) mentions its use by some British Columbia and western Washington groups, and Coville (in Mason 1904:205) describes the use of it by basket-makers in western and southwestern Washington.

Rena said that "sea grasses" were used as decorative elements. The sort that she indicated on the beach were long, narrow, matte-white strands. I have not seen this material in basketry, although Kasner (1976:42) mentions the use of "sea grasses" by the Siletz Reservation basket-makers but with no further identification of this material. Non-traditional decorative material. The only non-traditional decorative elements that I found were raffia and yarn. Rena said that the raffia was ordered, already dyed, from the Portland Seed Company in the 1920s. Raffia is used in many of the baskets in the Adams Collection, as well as in several in the other collections; but I found only one instance of yarn used (U01-15656). In another basket (UO 1-15657) the weft of a decorative band is gone, but some fibers remain which may be what was left of red yard after moths got to it.

Another material that may have been decorative, or protective, or both, is commercial cloth folded over and stitched to the rim of a basket. 
One example (TCPM 1328) has what once may have been a white, now grey, satin ribbon on it. Another (HM 15590-128) has a strip of green cloth stitched to it with green yarn. It may be that these pieces were added by the purchaser or some subsequent owner.

Dyes

Plant materials were of ten dyed for the decorative effect. The following description of the dyes used by the Tillamook is limited, considering the dyes possible and used in western Washington and along the Columbia River, as recorded by F. Douglas (1934:50-52) and Gunther (1945). It is 1ikely that the Tillamook made use of as great a range of the available material for dye-stuffs as did the neighboring groups.

Traditional dyes. Hemlock (Tsuga heterophylla) bark was used to obtain colors ranging from red to browns and black by people in British Columbia (Turner 1979:115) and is recorded for the Tillamook by Barnett (1937:171). Another source of red was the red alder (Alnus rubra) recorded by Barnett for groups south of the Tillamook and probably used by the Tillamook.

Yellow was derived at Siletz Reservation from Oregon grape (Berberis nervosa) and wolf moss (Evernia vulpina) (Kasner 1976:42), although Barnett (1937:194) obtained no evidence for the use of wolf moss. His informant was an elderly man who may have been unfamiliar with some aspects of what was traditionally a woman's craft. Mud-dye, the one exception I found to plant-derived dyes, was used to darken materials to a brown, a deep brown, or a grey-black (Barnett 1937:171). Kasner (1976:43) states that these colors were 
obtained by burying the basketry materials under clay muds for long periods of time.

Non-traditional dyes. In the Adams Collection, colors other than reds, yellows, black, and browns can be seen on the bear-grass and the raffia. Rena told me that some commercial dyes were obtained from the J. K. Gill Company in Portland. These probably are not limited to, but include, the blues and purples, since these colors were not readily available from the traditional plant sources.

\section{Design Motifs}

Decoration on Tillamook basketry takes the form of narrow bands of repeated motifs. Frequently, several bands of figures occur; and in some cases, a single band may be nearly as wide as the basket is high, covering the greater portion of the basket surface. A motif may also be repeated as an overall pattern, without borders confining it to a band. I have used the term bound to describe bands that have distinct borders or edges and the term free to describe horizontal repeated motifs without borders.

The design motifs are usually the result of simple weft color change, rather than structural change, with the contrasting stitches carefully placed in order to create the figures.

Five of the design motifs were illustrated and native terms for them were recorded by Edel (1931, Box 4) when she interviewed members of the Adams family in Garibaldi. Although they are not labelled as basketry designs, they do reflect some of the motifs seen in Tillamook basketry in the Adams Collection and in the Other Tillamook pieces. If 
they are basketry designs, and I assume that they are, they also may demonstrate that the basket-makers recognized them as distinct elements. With the exception of Rena's term "dog", the terms that I have used for these basketry motifs are my own and are not intended to reflect the native ones. The motifs from the Adamses are: 1) "dogs", 2) steps, 3) solid triangles, 4) zig-zags, and 5) fret-work. In addition to these motifs, I also found: 6) "animals", 7) elongated Zs, 8) open triangles, 9) diagonals, 10) chevrons, 11) squares, 12) cross-hatching, 13) lozenges, 14) columns, and 15) over-all dots.

The motifs. Many of the motifs have some diagonal elements which depend on the stitch slant, as well as color, for their form. Any lines in a motif which angle down to the right need to be based on S-slant stitches so that they will be continuous. Lines which angle down to the right but are set in Z-slant stitches counter the stitch slant and appear as a row of dots. In most of the Tillamook baskets, the diagonal motif elements coincide with the S-slant stitches; but there are some instances in which they do not, notably in cross-hatching, where diagonals must cross each other.

1. "dogs" (Figure 7a) - When I asked Rena what this figure was, she said "We call them dogs." In the Adams Collection, the "dogs" occur only in the margin and are always black. They face to the right, coinciding with the S-slant stitches.

Small "animals" similar to, but somewhat varied from, the "dogs" appear on several of the Other Tillamook baskets. Since I do not know if the differences are significant, or what the significance might be, I have lumped them generally as "animals", reserving "dogs" for the Adams's baskets. 
2. steps (Figure 7f) - This motif appears to be more complex than its structure actually is. The basic arrangement of the stitches creates multiple, alternating dark and light lines which rise vertically, bend horizontally to the right at a 90 degree angle, and turn upward again. Repeats of these vertical and horizontal lines create nested steps. The more complex version uses three colors. The third color is confined to bands around the basket and is integrated into only one of the other two colors. In the Adams Collection, this motif occurs in a three-color version of red, white, and black on three baskets. In the Other Tillamook group it occurs in two colors as a band; as an over-all pattern; and in three colors as an all-over pattern of red, green, and white. The central envelope of a wall pouch (Figure 21) has a variation of this motif.

3. solid-triangles (Figure 7e) - Solid-triangles occur in bands and usually rest on a base line. They are frequently used to border one or both sides of another patterned band but also occur in the margin. Bands of triangles can be arranged to face point-to-point leaving diamond-shaped negative space between them or can be mirrored base-to-base creating dark diamonds (Figure 20).

4. zig-zags (Figure 13b)- This motif occurs singly and in nested pairs both free and bound. One line of the zig-zags is usually fairly vertical while the more angled one follows the slant of the stitches. Figurel $3 \mathrm{~b}$, a covered bottle from the Adams Collection, has two nested and free zig-zags around it, while in Figure 17 the single zig-zags occur in two bound bands.

5. fret-work (Figure 8c) - When fully developed, with several repeats, this motif is formed of columns of interlocking rectangles, of which 
A.

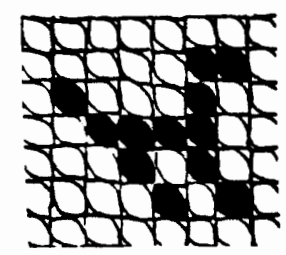

$B$.

C.
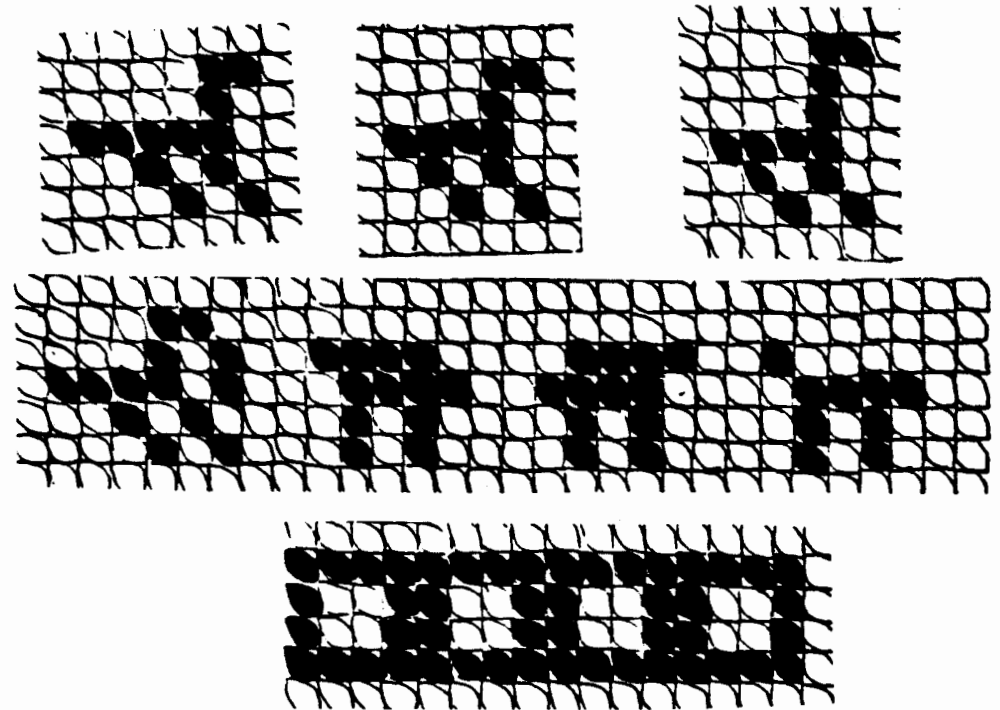

D.

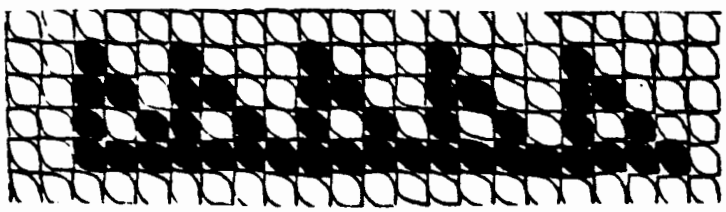

E.

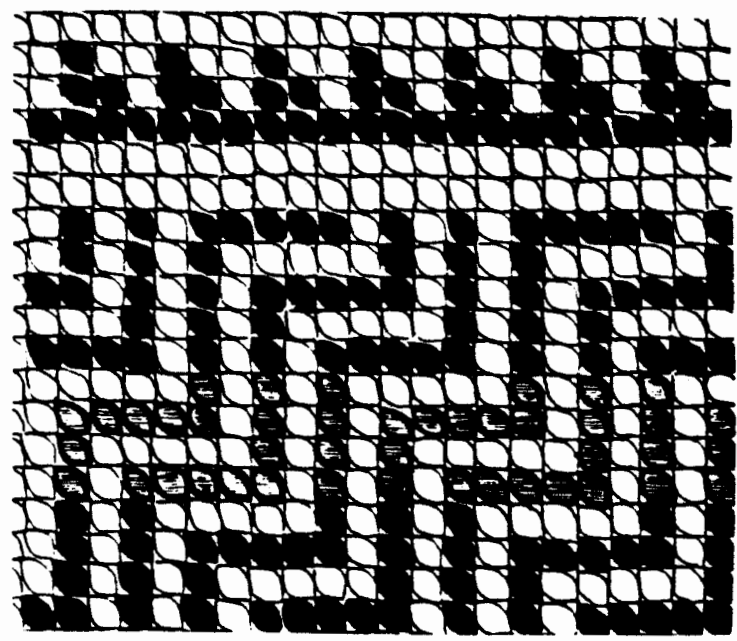

Figure 7. Basketry Motifs. A. A typical "dog" from the Adams's baskets. B. Variations of "animals". C. Squares. D. Open-triangles. E. Solid-triangles. F. Steps. 
I found only one example (UO 1-15656). More often only a single repeat of the motif was done, appearing as alternating open-crosses and open, capital-letter Is.

6. "animals" (Figure 7b) - Several versions of these "animals occur on the baskets in the Other Tillamook group. Some of them are identical to the Adams's "dogs" but were not necessarily known by that term to their makers. Most of these "animals" vary in the presence or absence of a tail and in the length of the neck. One version has a long, bent neck, possibly representing a bird (Figure 2i). This same basket has a band of what I assume to be animals, which vary a little from each other and look as though the maker forgot where she was in working out the design.

7. elongated Zs (Figure 14) - This motif looks a bit like a vertical zig-zag. It occurs in bands bordered by open-triangles in both examples. This is one of the largest single motifs $I$ saw. Each $Z$ is three or four stitches wide and angles upward to the left for four rows or so from the base line, before angling upward to the right and then again to the left (Figure 14). The Zs are each bordered by a line of the same color which follows the angles of the Zs.

8. open-triangles (Figure 7d) - Open-triangles occur in the same locations as the solid-triangles: on the margin and bordering bands of other motifs. The open-triangle is created by simply substituting the ground color for the color of the rest of the triangle in the central stitch. When the open-triangles rest on a base line, they appear to have a hole in them (Figure 14). When they do not rest on a base line, they look like upside down Vs. 
9. diagonals (Figure $8 \mathrm{~b}$ ) - This motif occurs free or bound in single lines or clusters of lines repeated across the surface. On TCPM 1315, the diagonals take up most of the surface of the basket below the margin and are free. On UO 1-15660, they occur bound in clusters of three lines in one band and in another they are mirrored, countering the stitch slant and appearing as non-continuous lines.

10. chevrons (Figure 8d) - When the diagonals are mirrored, they appear as chevrons.

11. squares (Figure 7c) - This motif occurs on a wall pouch (UO 1-12723) in four bands, two on each envelope. Alternating dark and light squares, each two stitches high and two wide, are repeated within dark horizontal rows.

12. cross-hatching (Figure $8 a$ ) - The basic components of this motif are pairs of diagonal lines which cross each other as they angle upward in opposite directions. These are repeated within two narrow bands outlined in black on UO $1-12676$.

13. lozenges - This motif is a filled parallelogram with the ends angled upward to the right. Their size and placement are quite distinctive. They occur only on HM 881-3-56 and are very large, nearly an inch high and two inches wide, and are widely spaced in three unbound rows around the basket.

14. columns (Figure 8b) - This motif is of alternating dark and light short stripes in bands. Each stripe is a single warp wide. The columns often appear in conjunction with over-all dots, but they do occur alone on one basket (OHS 73-127.51). 
15. over-all dots (Figure 8B) - Alternating dark and light stitches, shifted by one stitch every other row make up this motif. When bands of over-all dots are alternated with bands of columns, the columns appear to dissolve into dots and reform into columns up the basket sides.

\section{Symbolism}

The 15 design motifs that I recorded from Tillamook basketry are not meant to document the complete design repertoire of the Tillamook basketmakers, nor are the categories of designs which I constructed meant to reflect native ones. And it is possible that more than one set of categories was used among Tillamook basket-makers. There is no basis for supposing that even Rena's category of "dogs" was used throughout the Tillamook area in the same form or with the same name.

Whether or not any of these designs carried symbolic meaning is a question that cannot be answered positively. I have not found native terms for all of these designs and the five that I have will have to await translation to see if they are more than simply names for the motifs.

Kroeber (1905:161-162) draws a distinction between symbolic meaning and design names. In his study of California basketry, he found that designs had names but "were free from attempts at picture writing or the expression of religious ideas."

Others who have discussed the question of symbolic meaning in designs have concluded that were there an association of the two, it was probably known only to the basket-maker herself (Farrand 1900:399; Mason 1904:315; Douglas, F. 1934:44).

In addition to the possibility of symbolism in designs, F. Douglas (1934; 非1:43) also discusses the use of color and symbolic meaning for 
A.

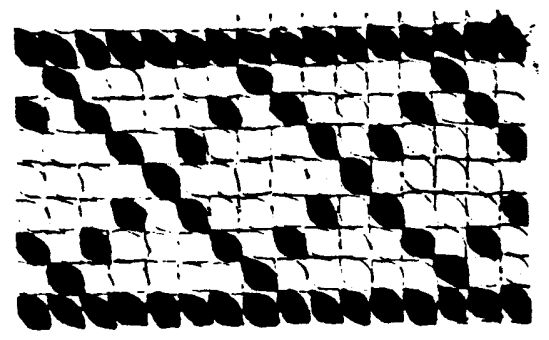

C.

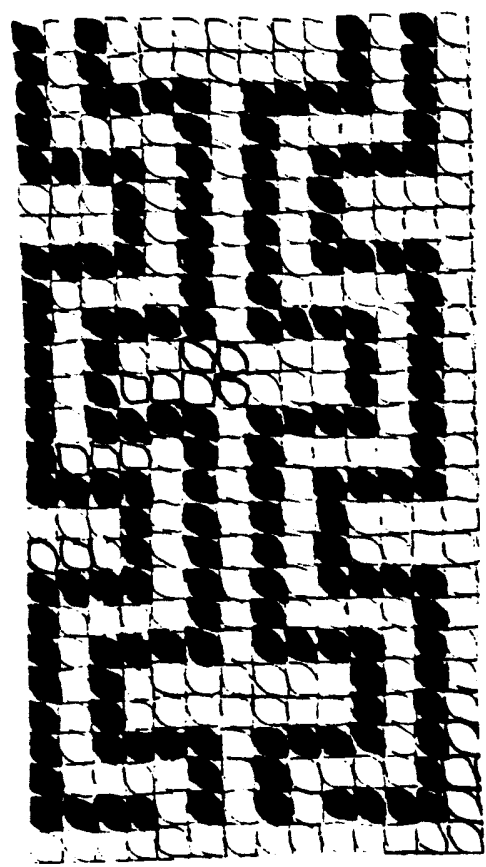

B.

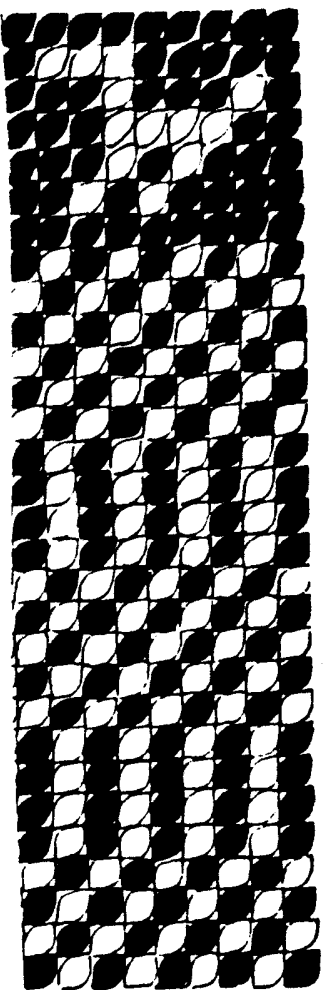

D.

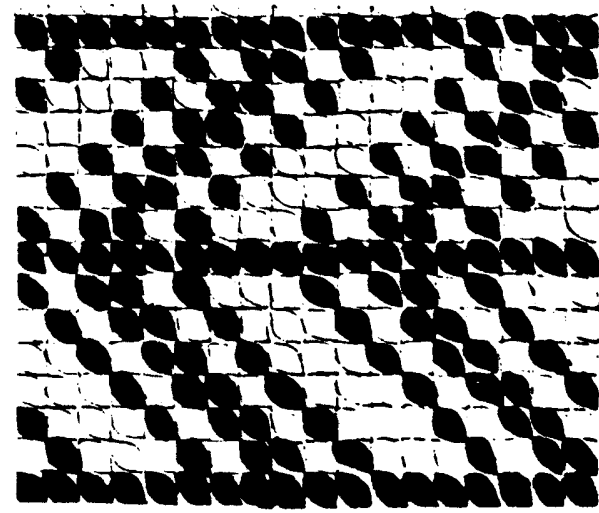

Figure 8. Basketry Motifs. A. Cross-hatching. B. Z-slant twining of (from top to bottom) an. animal, over-all dots, and columns. C. Fret-work. D. Chevrons : composed of "mirrored" bands of clustered diagonal lines. 
some North American Indian groups. I found no such purpose recorded for the colors used by the Tillamook.

Since Tillamook basketry is no longer being produced, it seems unlikely that, were there any symbolism associated with it, we shall ever know what it was.

THE ADAMS COLLECTION

The Adams Collection is composed of baskets made by women of the Adams family and of baskets owned by them. In the summer of 1977, Rena Boyer and I visited the Tillamook County Pioneer Museum and examined this collection. During that visit, Rena told me much of what she knew about Tillamook basketry and who, from her family, had made various baskets, as she remembered them. It is worth noting that in addition to the baskets, the Adams Collection also contains several sewed cat-tail bags, the beginning of a cat-tail mat, and several mat-making tools, such as creasers and needles.

The following description of the pieces in the collection is a general one, focusing on some aspects of it. A detailed description of the individual baskets can be found in Appendix B. Eleven of the baskets appear in photographs at the end of this section.

The majority of the baskets in this collection are fairly deep, rounded-base cylinders with some variation in the sides of greater or lesser outward flaring, but there are also rectangular envelopes, large, handled "shopping bags", as Rena called them, covered bottles, a wall pouch, and clam baskets. 
Bear-grass and raffia are the principal weft materials used in their natural white to tan to brown color and also dyed shades of red, blue, yellow, and black for decorative use. Cat-tail, tule, and sedges are used for the warp, and in some cases, for the weft as well.

All but three of the baskets are done entirely in twining, with closed, wrapped twining; plain twining; and open, plain twining predominating. The other three baskets are of checkerwork with some twining incorporated into them.

The twining is all done in S-slant stitches except for the base of one basket which is entirely in Z-slant, and three envelopes which have both $S$ and Z-slant, open twining arranged for decorative effect.

The baskets with round bases are usually begun on a warp cluster and the base is completed in closed, plain twining. The baskets with rectangular bases are begun on parallel warps and are also finished in closed, plain twining.

Nearly all of the twined baskets have a single row of three-strand twining on the base perimeter, and it is always done in Z-slant.

The rims of these baskets are usually finished in a braid, as I have loosely used the term, although one basket has a piece of satin ribbon covering the rim.

The usual handle is a soft, thin braided one, but four baskets have a wrapped, figure-eight handle ornamented with chevrons of a contrasting color. This handle style is peculiar to the baskets in this collection; I have not noted it elsewhere.

All but one of the baskets have some decoration on them. Decoration is arranged in horizontal bands and created with simple changes of 
color, although there are a few instances of variation in structure. The bands occur both as areas of solid color and as repeated motifs. The baskets in this collection are generally quite small; none are over nine inches high and only six of them are over five inches. Seven baskets are under two and a half inches high.

The stitch gauge is in the range that I have defined as Coarse, for most of the baskets, but two are in the Very Fine range. This coarse stitch gauge, in conjunction with the small size of the baskets, has affected the integrity of the motifs on several baskets.

A noticeable feature of these baskets are those which can be grouped together on the basis of a common arrangement of color and twining technique, decorative motifs, or size. The similarities among some of these baskets are clearly more than coincidental and do suggest that at least one, and perhaps even several individual styles, can be detected within this collection. Rena attributed 12 of the 29 baskets to her great aunt Lizzie. If these 12 were done by Lizzie, it would appear that more were too, since some of the unattributed ones are very similar to the attributed ones in shape, size, stitch gauge, and the resulting general appearance of the baskets.

Among the baskets which can be grouped together on the basis of shared features are two "shopping bags" (TCPM 1291, Figure 10 ; TCPM 1300) and two covered bottles (TCPM 1301, Figure 11; TCPM 1320). Rena attributed TCPM 1291 to Lizzie. All four of these baskets are done in alternating bands of closed, wrapped twining and open, plain twining with natural and colored raffia and white bear-grass weft on sedge or tule warp. The stitch gauge of the bottles is slightly finer than the 
gauge of the "shopping bags" and may be caused by having something firm to work against in the case of the covered bottles. The "shopping bags" both have twisted raffia handles which have been worked into the structure of the basket in the last band of wrapped twining.

The similarity of these pieces makes it difficult to imagine that more than one person made them; Lizzie may have made all of them.

The step motif is a striking one and occurs on four of the baskets (TCPM 1304, Figure 12; TCPM 1314, Figure 15; TCPM 1325, and TCPM 10336). In TCPM 1314, it is most fully developed in a red and black raffia and white bear-grass band on a natural, tan raffia ground. This band of red and black "steps" alternating with white ones is bordered on either edge with black solid-triangles. In TCPM 10336, it is equally well done in a much finer stitch gauge and appears in two separate bands without the triangles. Instead, around the margin is a repeat of "dogs". Rena said that her mother, Nora, had made this envelope-shaped basket and had given it to Kate Farley, the wife of Captain Robert Farley, of the Coast Guard in Garibaldi.

TCPM 1325 is a small, covered, white, glass jar on which the steps are done in the same fashion as TCPM 1314 but without the triangles; the decorative band covers most of the surface.

TCPM 1304 (Figure 12) is a small basket with the same motif worked into it; but here it is difficult to see, due to the size of the basket, the stitch gauge and the colors used. In place of the white beargrass used on TCPM 1314, for instance, this basket has the natural, tan raffia of the background used in the motif itself. As a result, the design is difficult to distinguish from the background. The triangles 
on either edge of the band are separated from it by one or two rows of the tan raffia so that they do not help to hold the design together. The large stitch gauge, four stitches to the inch, on this nearly four inch diameter basket, decreases the number of stitches and resulting design elements that can be repeated in an area and contributes to the disintegration of the motif.

TCPM 1315 is a small basket, much like TCPM 1304 in size, shape, and gauge. It has open-triangles repeated in the margin, but they do not rest on a base line and tend to "float", visually. The band of the diagonals which cover the lower half of the basket also do not have any horizontal edges and they, too, "float". TCPM 1304 and TCPM 1315 are similar enough to each other to probably have been made by the same person.

Another basket which is similar to both of those above in shape and gauge and materials is TCPM 1319. This one is a little larger and has bands of black zig-zags around it. Widely spaced "dogs" stand on the upper-most band near the margin and are repeated around the basket. Three baskets (TCPM 1308 and 1309, Figure 13; and TCPM 1324) are begun on warp layers, twined across near the ends to form a "seam" rather than a flat base. These are all done in open twining and are all about the same size. This "seam" is very reminiscent of the bases on some of the cat-tail bags from the Lower Columbia and may have been derived from them. I have not seen it used in small, raffia twined baskets elsewhere. Rena said that Lizzie made TCPM 1309. It and TCPM 1308, which has the addition of a band of wrapped twining with open-triangles across it, are similar enough to have been made by the same person. 
The traditional, functional clam-baskets are quite large. Those that I saw are up to 20 inches high. There are two baskets here that Rena said were models of the larger clam baskets. TCPM 1302 is made of cat-tail, rather than split root, usually spruce, and is only four inches high. TCPM 2182 is larger and is made of split root but is spherical rather than trapezoidal. Rena suggested that if anyone in her family had made this basket it was probably Lizzie, but she left open the possibility that it had come from elsewhere. From looking at all of the baskets in the collection, that is not an unreasonable possibility. Among the smallest baskets, of which there are seven, are two which are miniatures of the larger rounded-base cylinders. They have all of the features of the more full-sized baskets, including horizontal bands of ornamentation in wrapped twining and three-strand twining on the base. Rena attributed TCPM 1327 to Lizzie and said that she, Rena, and Lizzie had made TCPM 1329.

Two of these small baskets are done in checkerwork. TCPM 1326 is of cat-tail and TCPM 1328 is a mix of checkerwork and twining. Rena attributed both of these to Lizzie.

The attribution to Lizzie of these very small baskets, as well as some of the much larger ones suggests that they may have been made for much different purposes. Rena learned to make baskets from Lizzie, and perhaps these small baskets were all the product of members of Rena's generation learning the skill at Lizzie's instruction.

The mix of techniques throughout the collection, as well as in the individual baskets, and the variations in size, shape, and color, all 


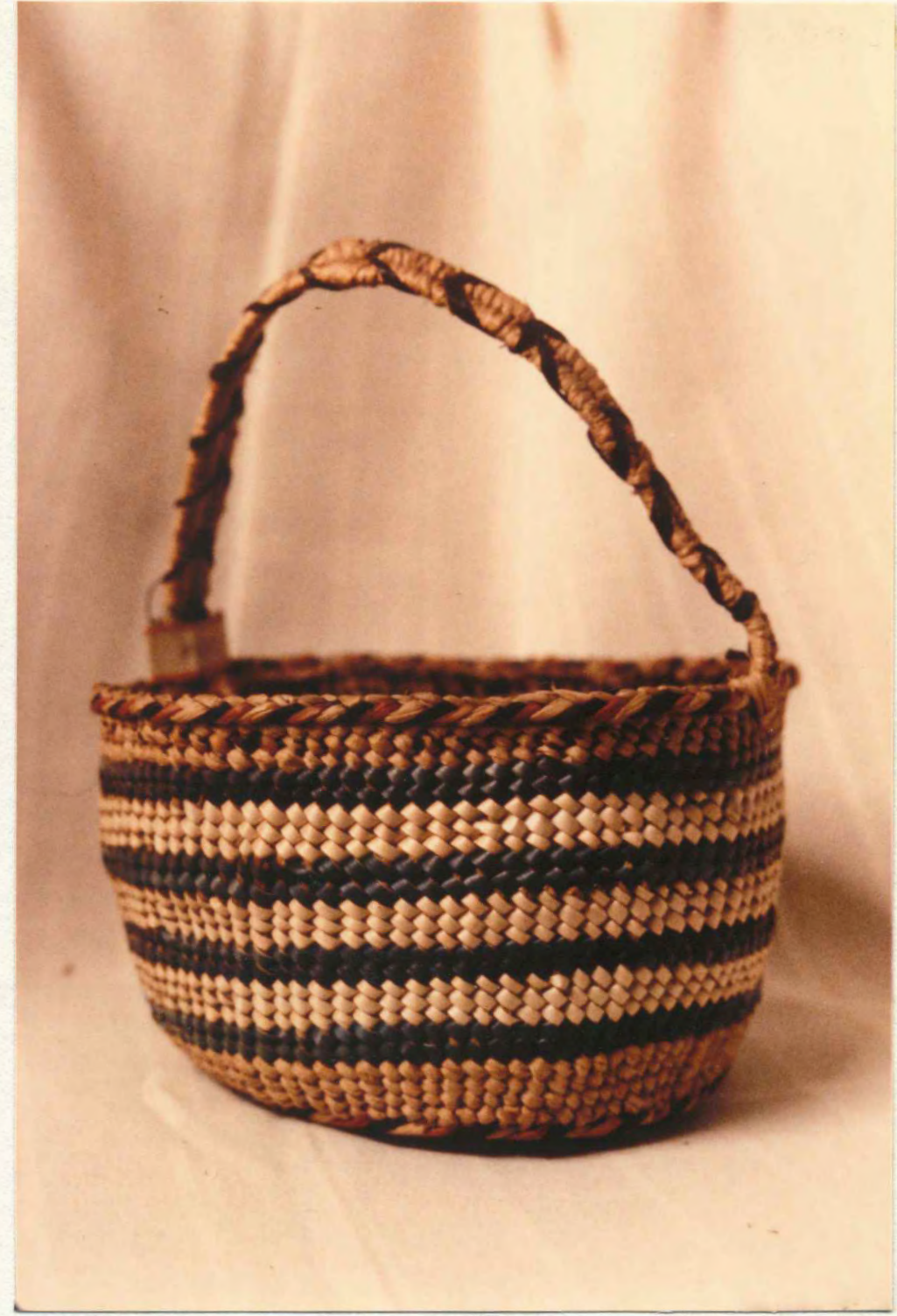

Figure 9. TCPM 1290 


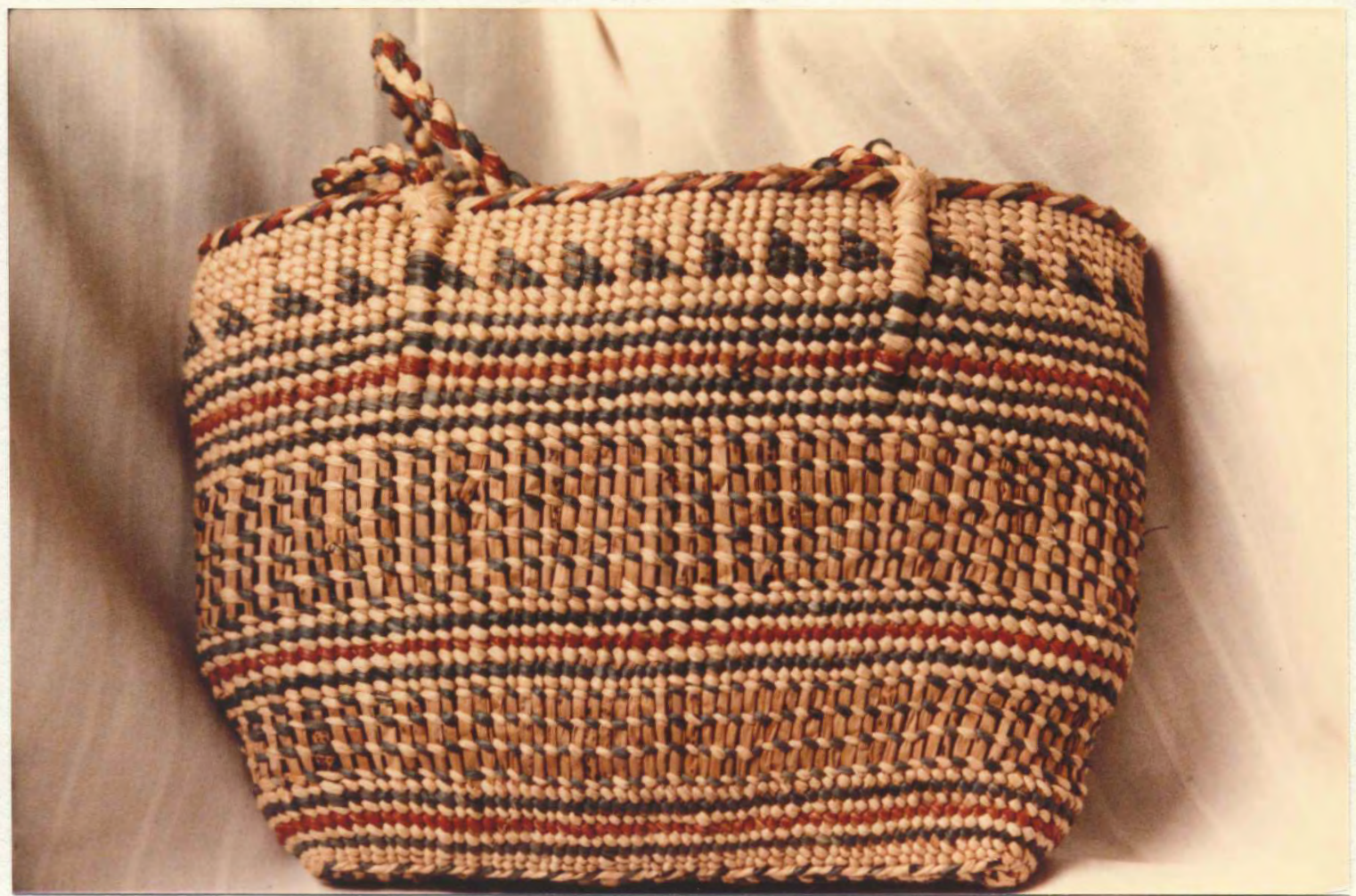

Figure 10. TCPM 1291 


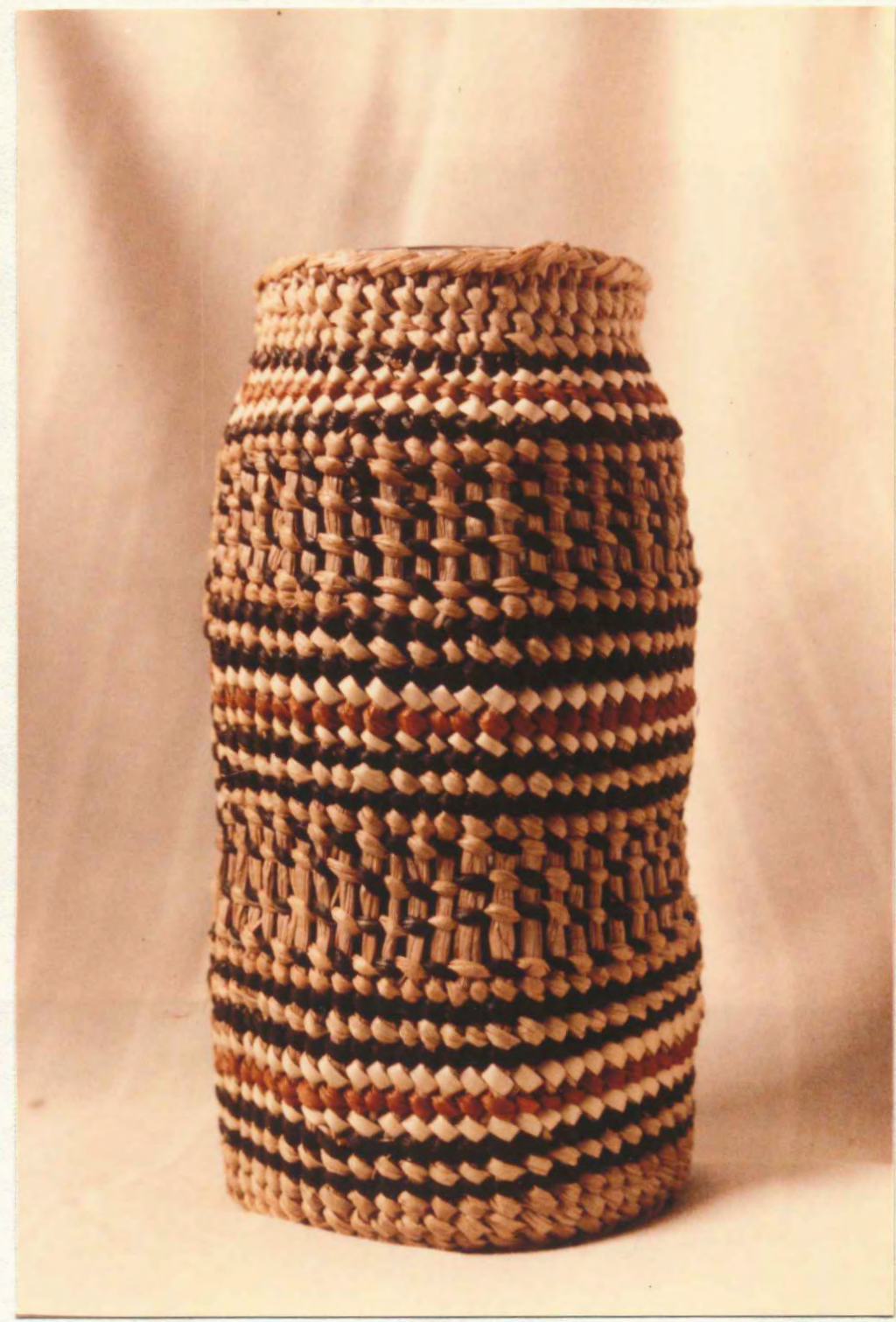

Figure 11. TCPM 1301 


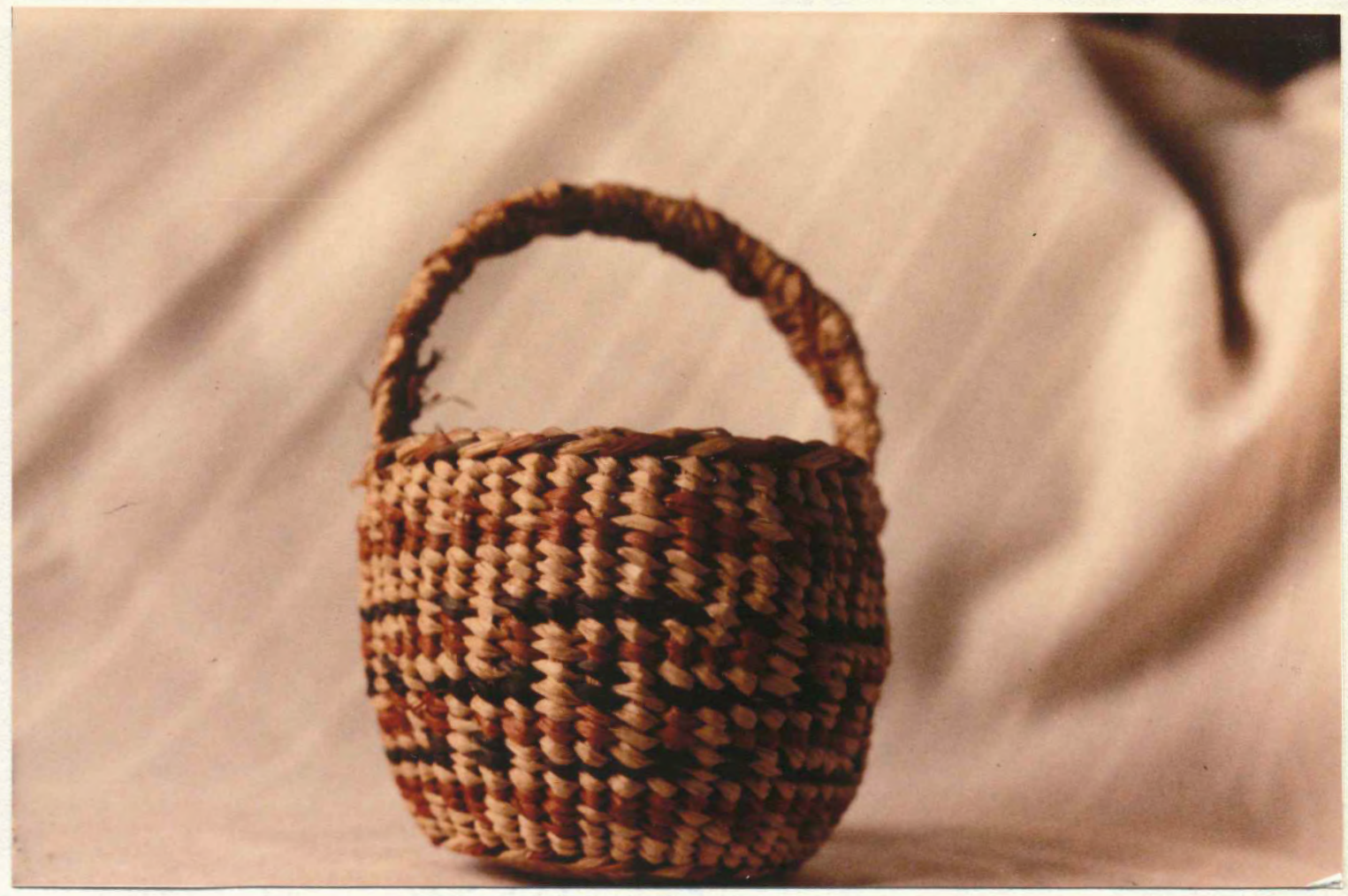

Figure 12. TCPM 1304 


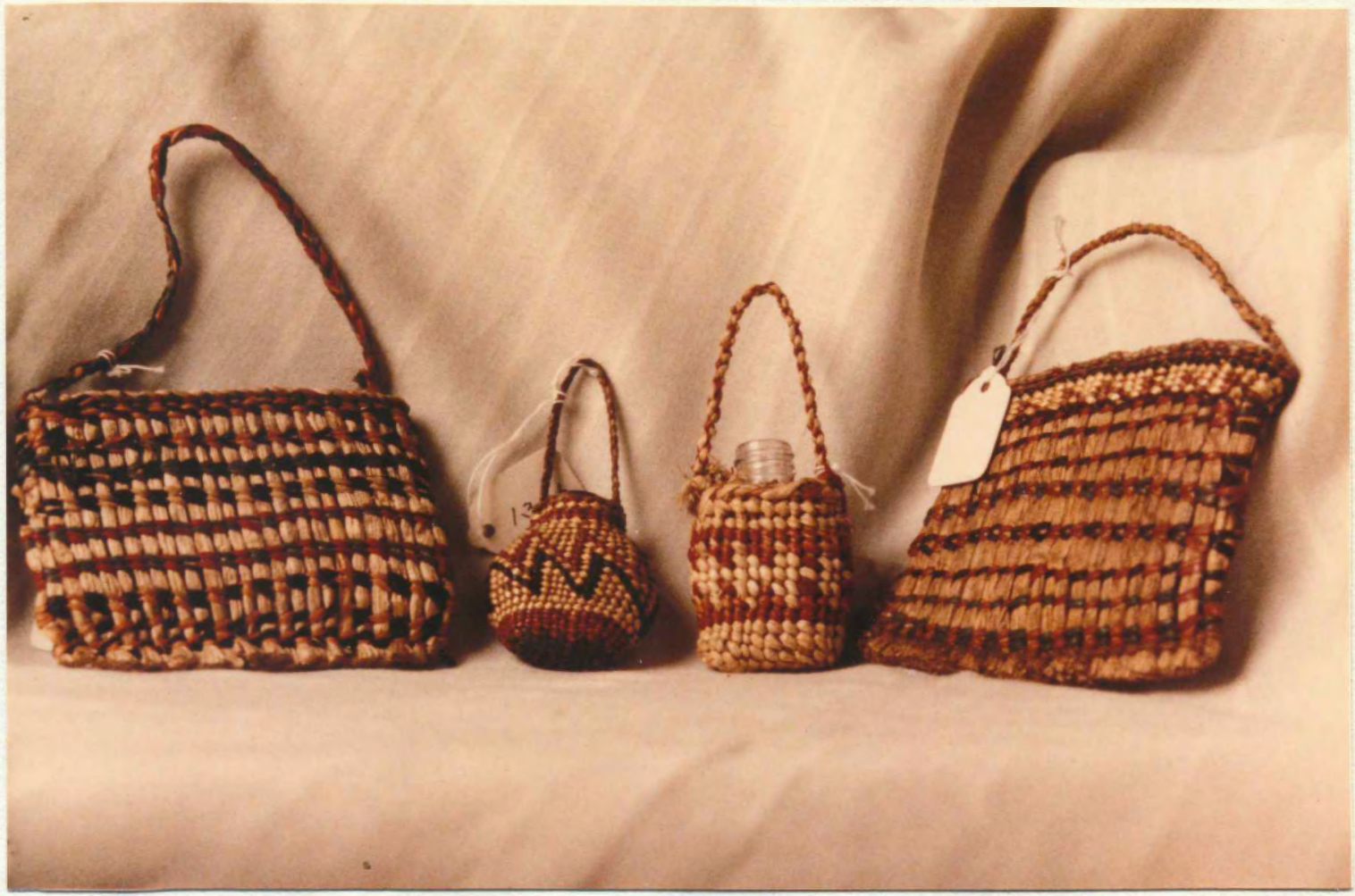

Figure 13. TCPM (left to right) 1309, 1306, 1321, 1308 


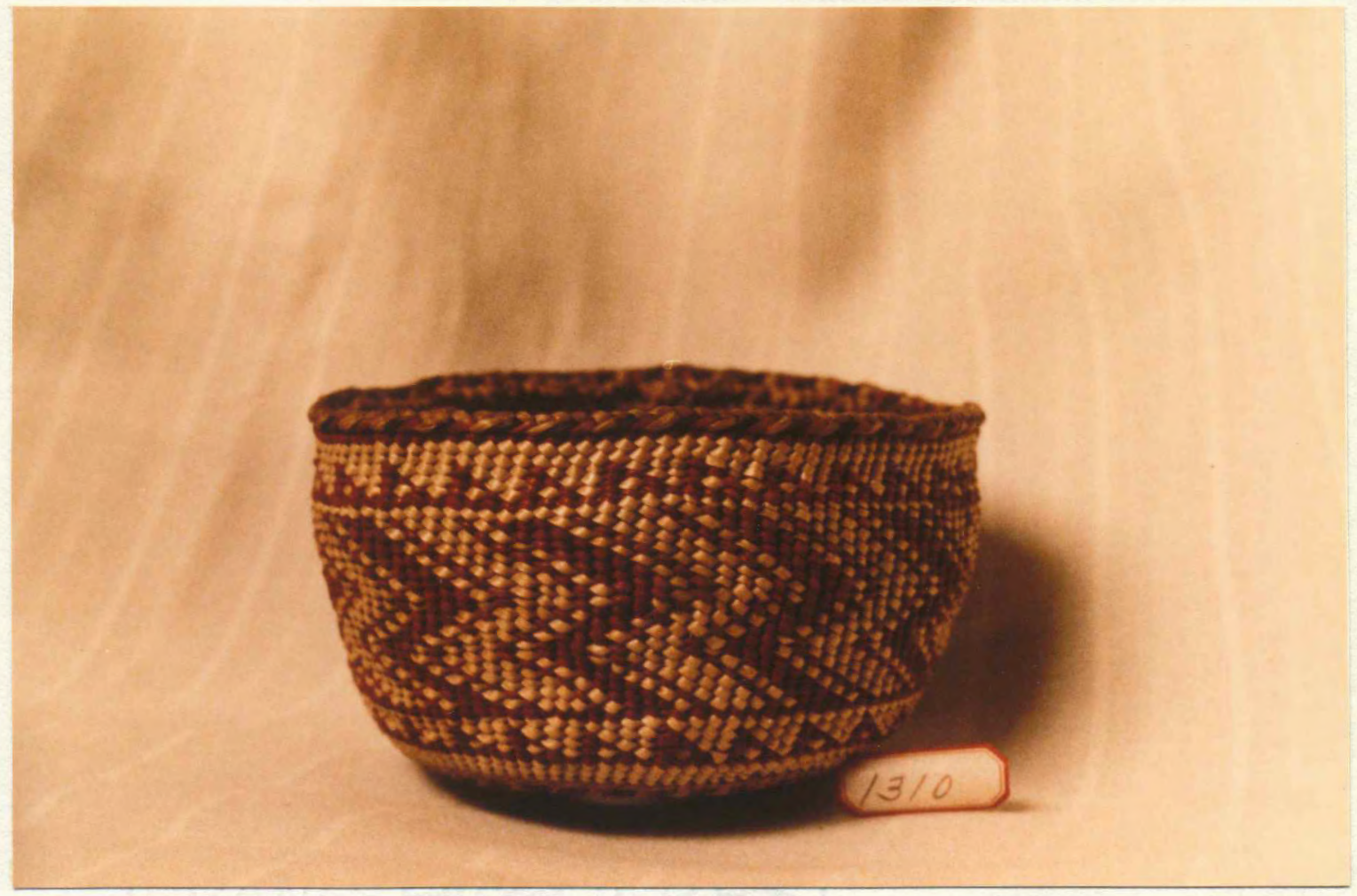

Figure 14. TCPM 1310 


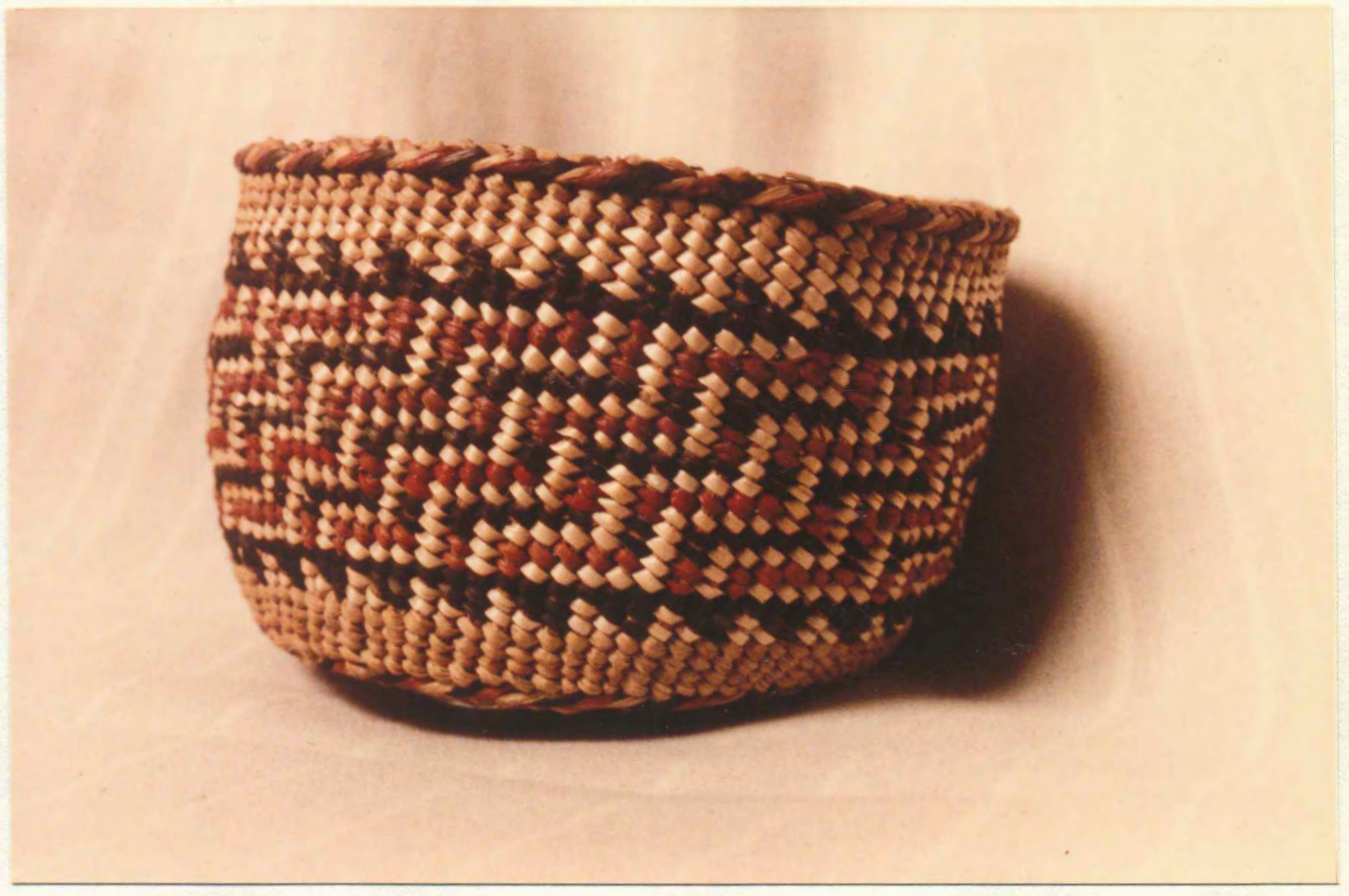

Figure 15. TCPM 1314 (side) 


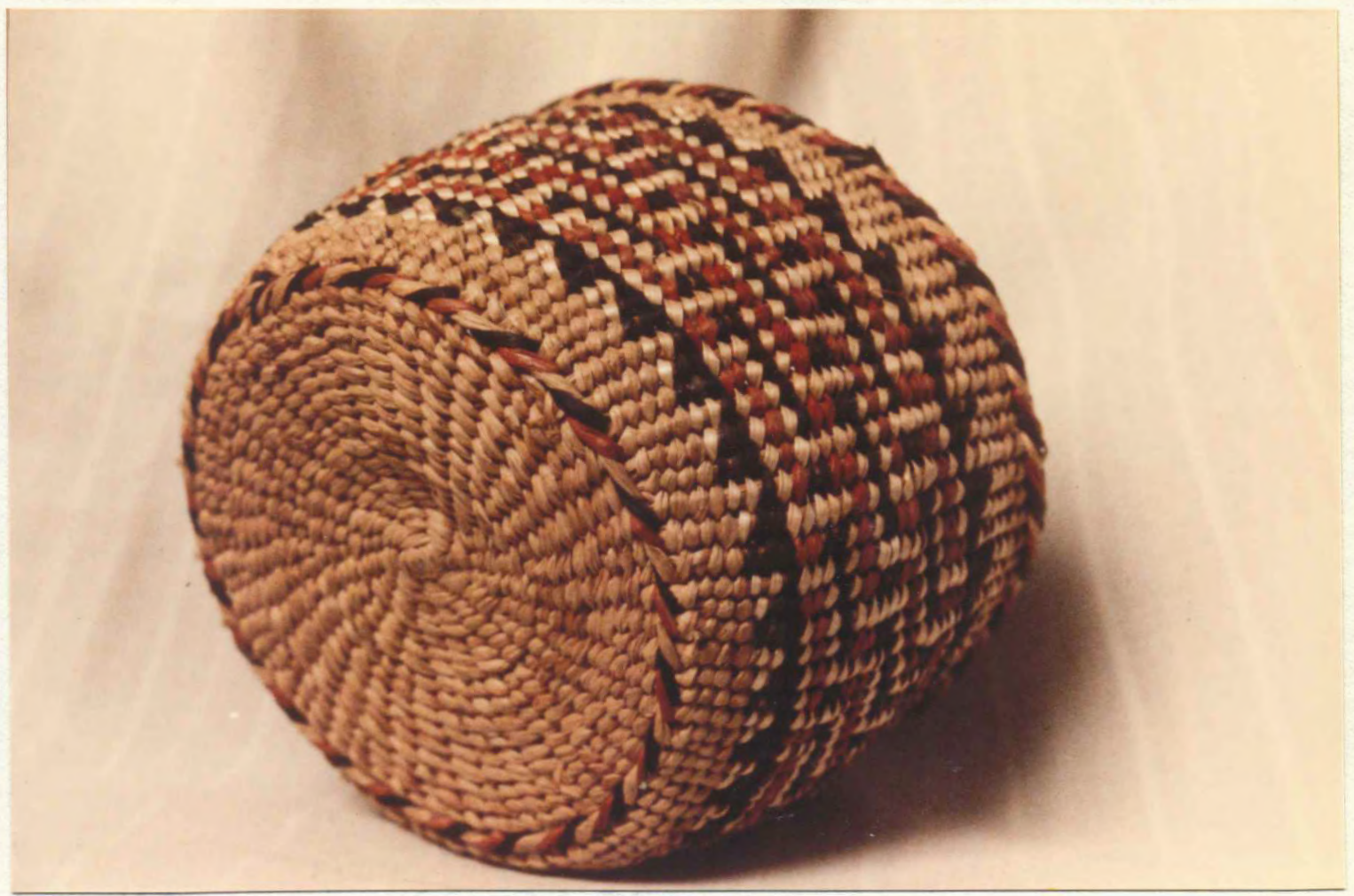

Figure 16. TCPM 1314 (base) 


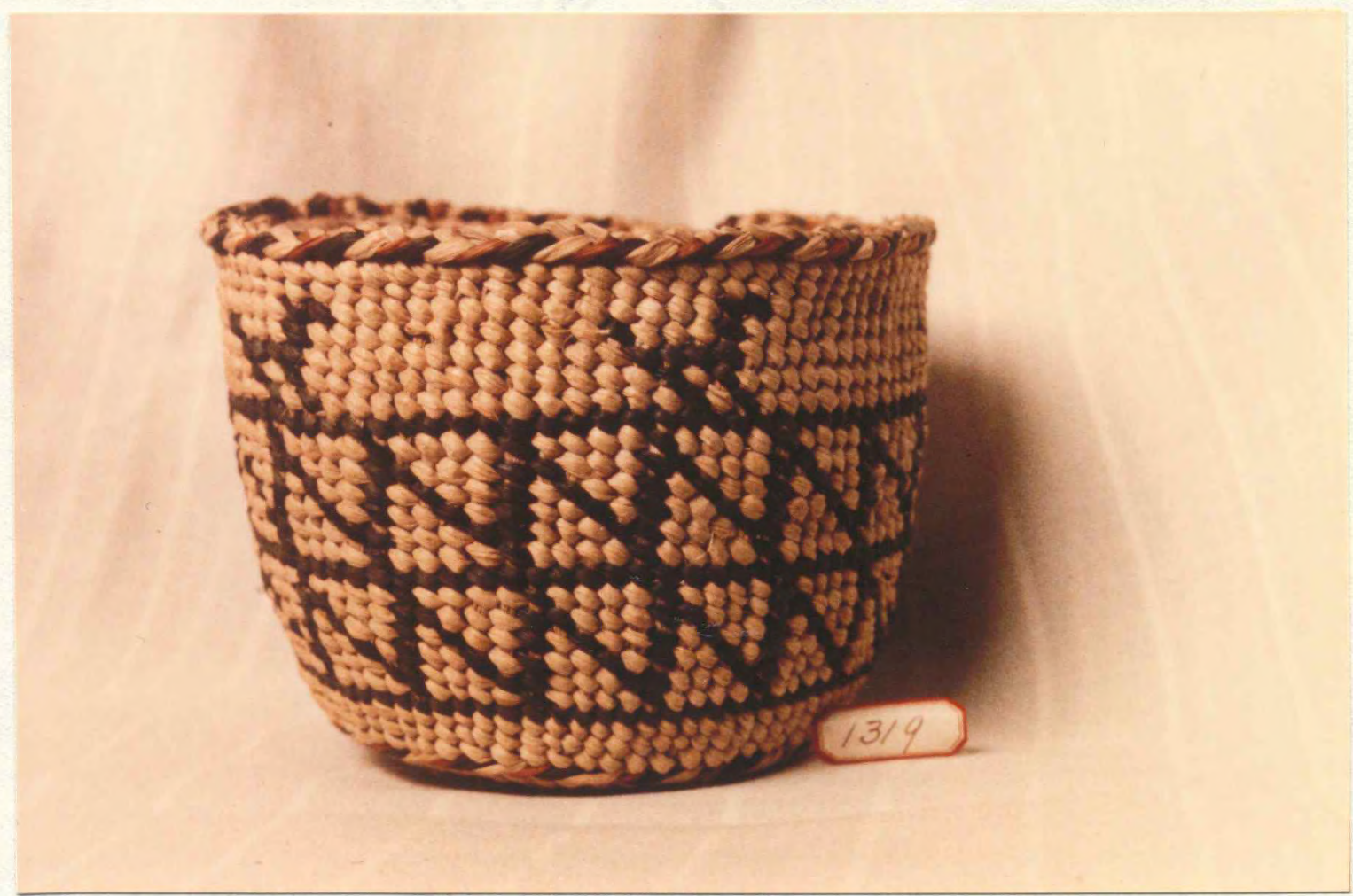

Figure 17. TCPM 1319 
attest to the skills of the makers of these baskets, whether from the Adams family or not.

\section{THE OTHER TILLAMOOK GROUP}

This group includes all of the baskets in my sample, aside from those in the Adams Collection. Photographs of four of the baskets are at the end of this section and more detailed descriptions of individual baskets are in Appendix B.

The baskets in this group exhibit a great variety of shape. Within the 39 baskets, 13 different shapes are represented, of the 19 shapes that I recorded. The greatest number of baskets are flat trapezoids and of these, 12 are clam-baskets. Many of the other shapes are represented by only one piece.

Most of the baskets are made of split root, bear-grass, or maidenhair-fern stem weft on warp of tule, cat-tail, or sedge. In contrast to the great amount of raffia in the baskets of the Adams Collection, only two baskets in this group have predominantly raffia weft. Several baskets from the Horner Museum are of unfamiliar and unidentified materials.

Wrapped twining; ful1-turn twining; and closed and open, plain twining occur most often and are in both $\mathrm{S}$ and $\mathrm{Z}-\mathrm{slant}$.

The circular bases are usually begun on a warp-cluster and the rectangular ones are begun on parallel warps, but there are instances of twill and of warp-cross starts. The bases are often finished with a row of three-strand twining. Three-strand twining also occurs on the body of some of the baskets, between the base and the rim. 
The rims of the baskets are usually finished in a braid, the clambaskets in the open double-braid; and there are several baskets with wrapped rims. Two pieces have loops worked into and around the rim.

Most of these baskets do not have handles, but those that do of ten have a soft, thin braided one.

Nearly all of the baskets are decorated in bands of repeated motifs or of solid colors using simple color-change or weft and warpoverlay, and crossed-warp structural variations.

In contrast to the smaller baskets in the Adams Collection, most of these baskets are over five inches high and range up to 20 inches high, with the clam baskets accounting for the largest dimensions. The stitch gauge in this group is usually finer than that of the Adams Collection baskets; half of these pieces are in the Fine range and over a fourth of them are in the Very Fine range.

Eight of these baskets, most of them from the Patterson Collection, are of very fine wrapped twining in bear-grass with dark maidenhair-fern stem decoration. It is tempting to believe that these represent "traditional (or pre-1850) Tillamook basketry. The fineness of the twining, the intricacy of the ornamentation, and the muted, but clear, colors evoke a sense of "real" basketry in contrast to the raffia weft and bright blues and red and yellows found in the Adams Collection. And, indeed, they may be closer to basketry produced before White domination than the Adams Collection baskets are, or appear to be. However, the techniques used and the motifs and their arrangement are constant in both sets of baskets. The greatest difference is in the materials and the effect they have on other aspects of the baskets. It is quite possible that these 
baskets are older than many of the others, since Mrs. Patterson did note that she had obtained them from a woman who said that she had had them for 20 or 30 years, which would place them near the middle of the 19th century.

The two baskets in this other Tillamook group which most resemble the pieces in the Adams Collection are both of wrapped twining with raffia weft. OHS 73-127.50 is a deep rounded-base cylinder nearly entirely covered with steps in red and green raffia and white bear-grass. While the gauge is finer and the basket a bit smaller, this piece is very similar to TCPM 1314 in shape, motif, and S-slant twining. OHS 8783/ 68-366 is a "shopping bag" of red, green, and black raffia in wrapped twining. It has many of the same motifs that baskets in the Adams Collection have including "dogs" or "animals", elongated-Zs, opentriangles, and "capital-Is" appearing here as positive, rather than negative space.

The two "shouldered" rounded-base cylinders are particularly distinctive. They are of fine wrapped twining and are about four inches high. The warps have been turned inward and twined flat for about an inch, creating the "shoulders". A basket similar to this shape is identified as Clatsop (HM 2028); and there is another like it in the Tillamook County Pioneer Museum, which has no provenience. I have not seen this shape in other basketry in the Northwest, although superficially they resemble the Nootka-Makah trinket baskets. They are unlike those in motifs and in stitch slant, which is S-slant in the Tillamook pleces and more usually Z-slant in the Nootka-Makah basketry. 
Four of the baskets in the Horner Museum are quite different from the baskets in the rest of my sample. HM 15590-11, 15590-30, 15590-42, and 15590-50 are all made of the same light-colored, unidentified material and are twined in plain, closed z-slant twining, except for the base of one which is of wicker. These pieces are similar enough to look like the work of a single person. Since they are all from the Tartar Collection, it is possible that they are; and it is also possible that they are from Siletz and have been misidentified as Tillamook, since Mrs. Kennedy, who began the Tartar Collection, was a visitor to Siletz. Weft-overlay twining occurs infrequently in this collection as a usual decorative technique, although several of the Tartar Collection baskets have bands of weft-overlay on them. However, there are two baskets which are entirely done in this technique. Uo 1-15587 is of split root with bear-grass weft-overlay and is twined in Z-slant, except for a band of wrapped twining ornamented with "animals" on the margin, which is in S-slant. UO 1015588 is also in Z-slant weft-overlay and the "animals" on the margin are Z-slant as well. Both of these baskets are ornamented with light-colored weft on a darker ground, in contrast to the usual light colored ground and darker ornamentation of the Tillamook baskets. The weft-overlay technique, the Z-slant, and the color-reversal of the designs suggest that these baskets may be from outside the Tillamook area. Mason (1904:plate 162) illustrates some Quinault baskets, which these do resemble.

The baskets in this 0ther Tillamook group exhibit a range of features. Some of the baskets may not be Tillamook while others most certainly are. Only with study of individual collections and places will the attribution of some of them be resolved. 


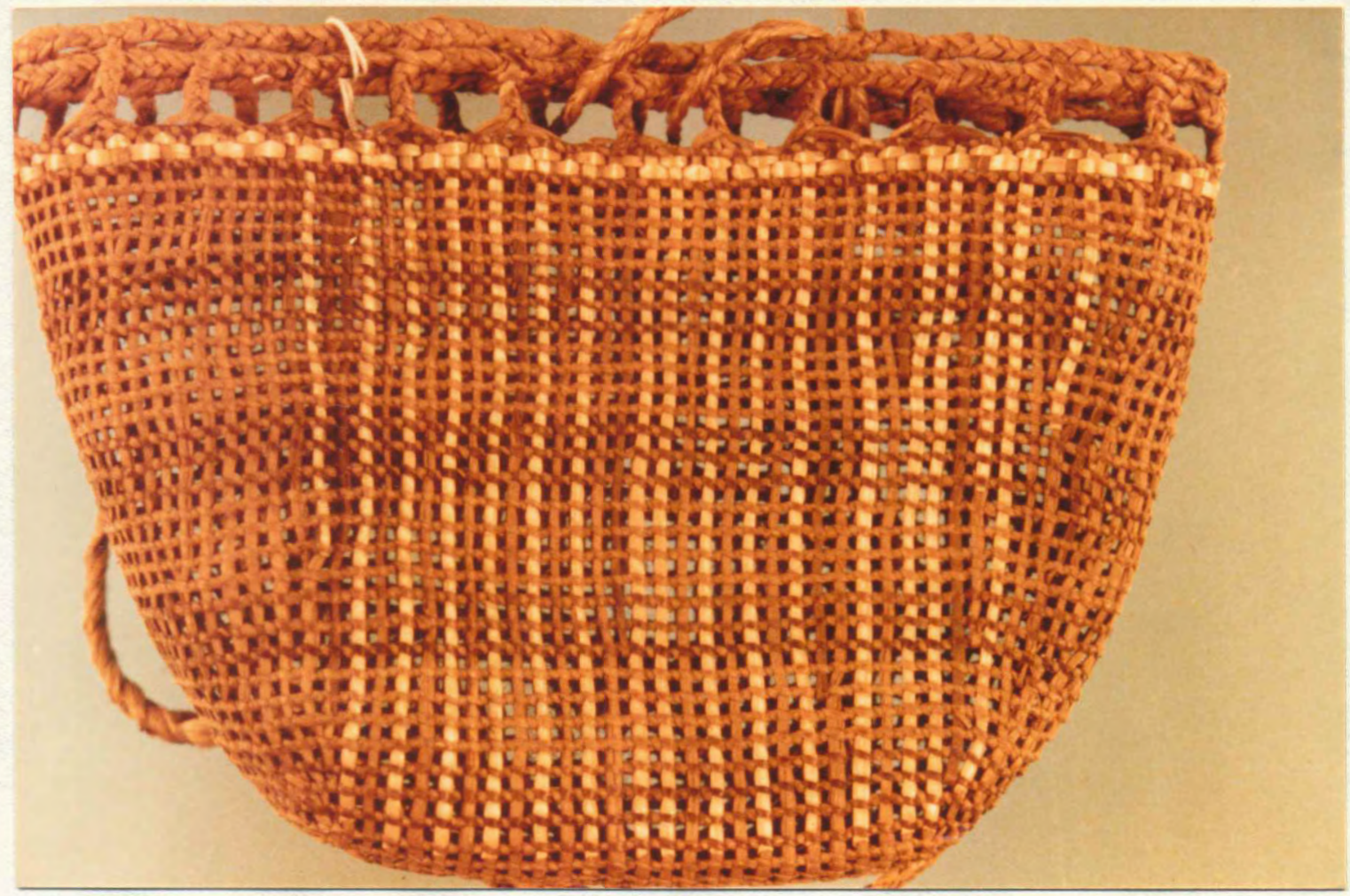

Figure 18. UO 1-894 


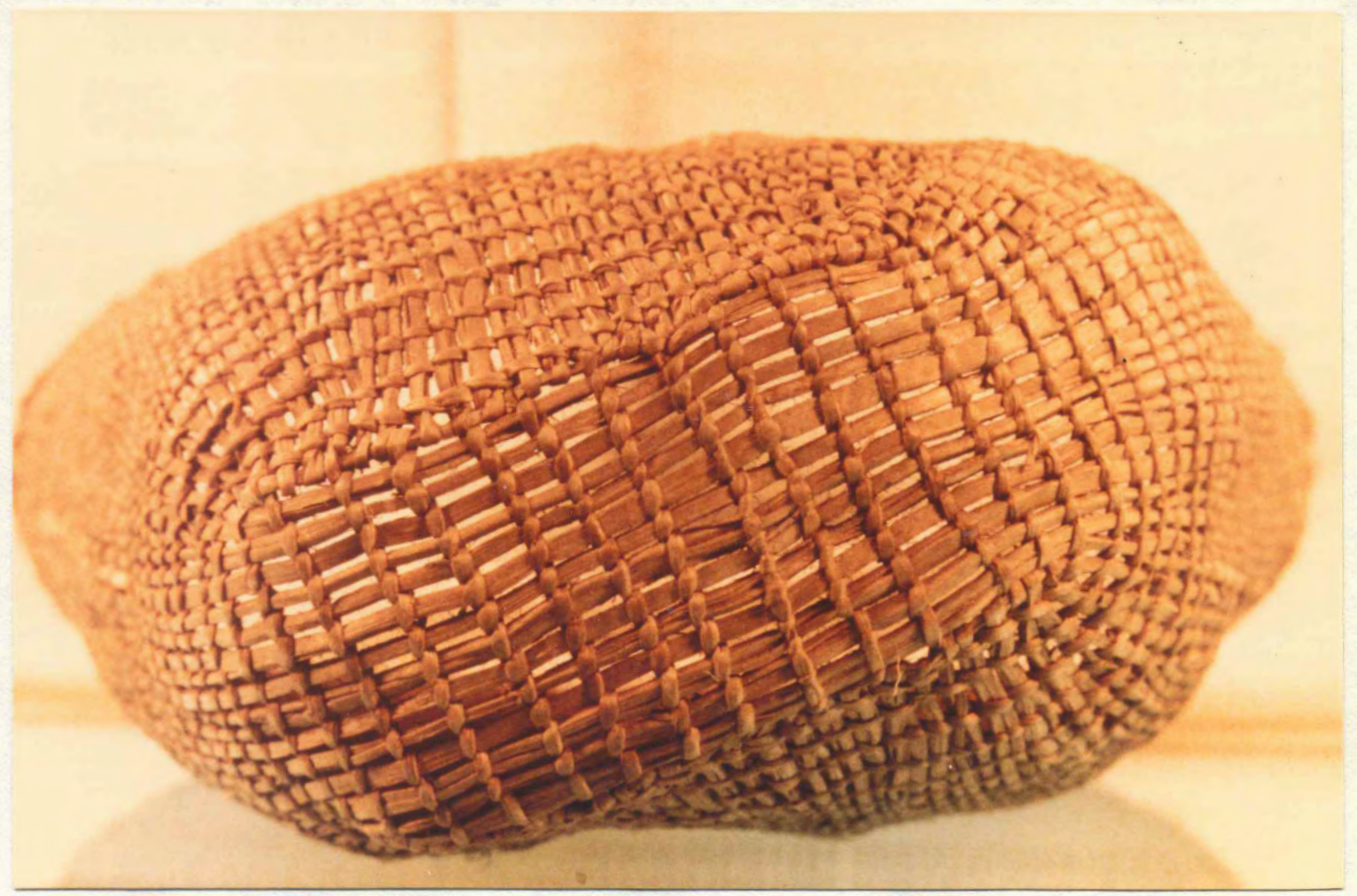

Figure 19. UO 1-897. 


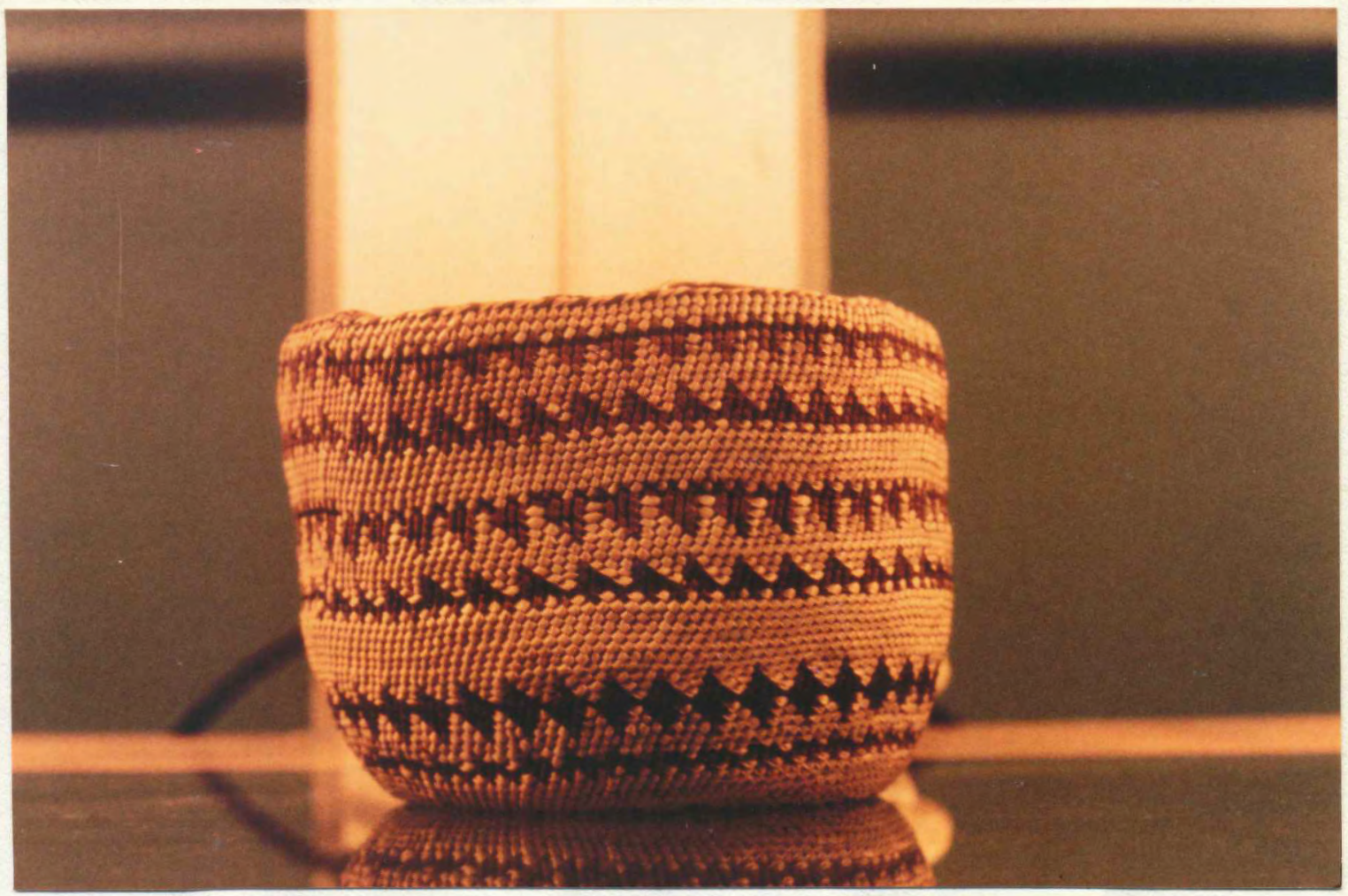

Figure 20. UO 1-15653 


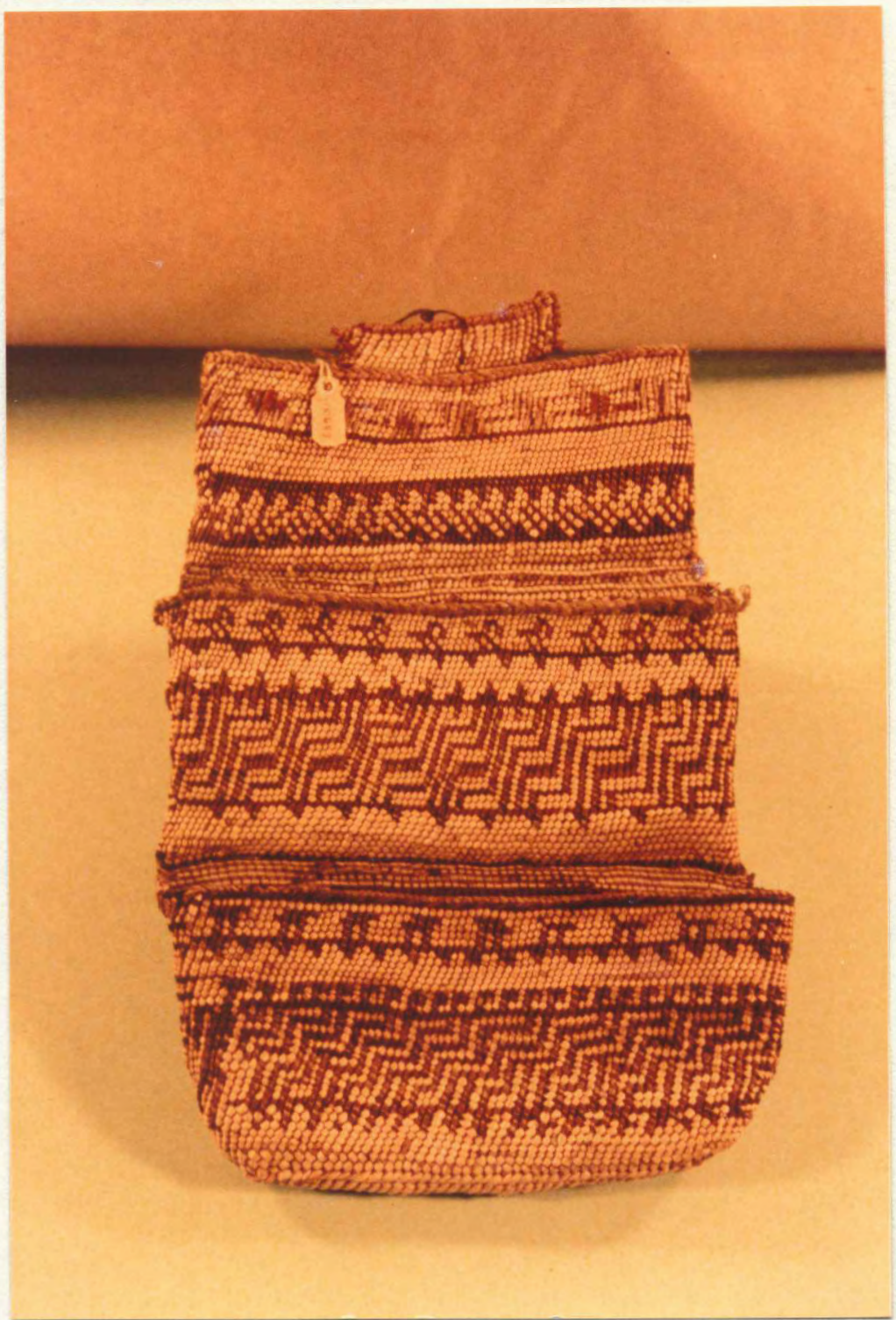

Figure 21. UO 1-15657 


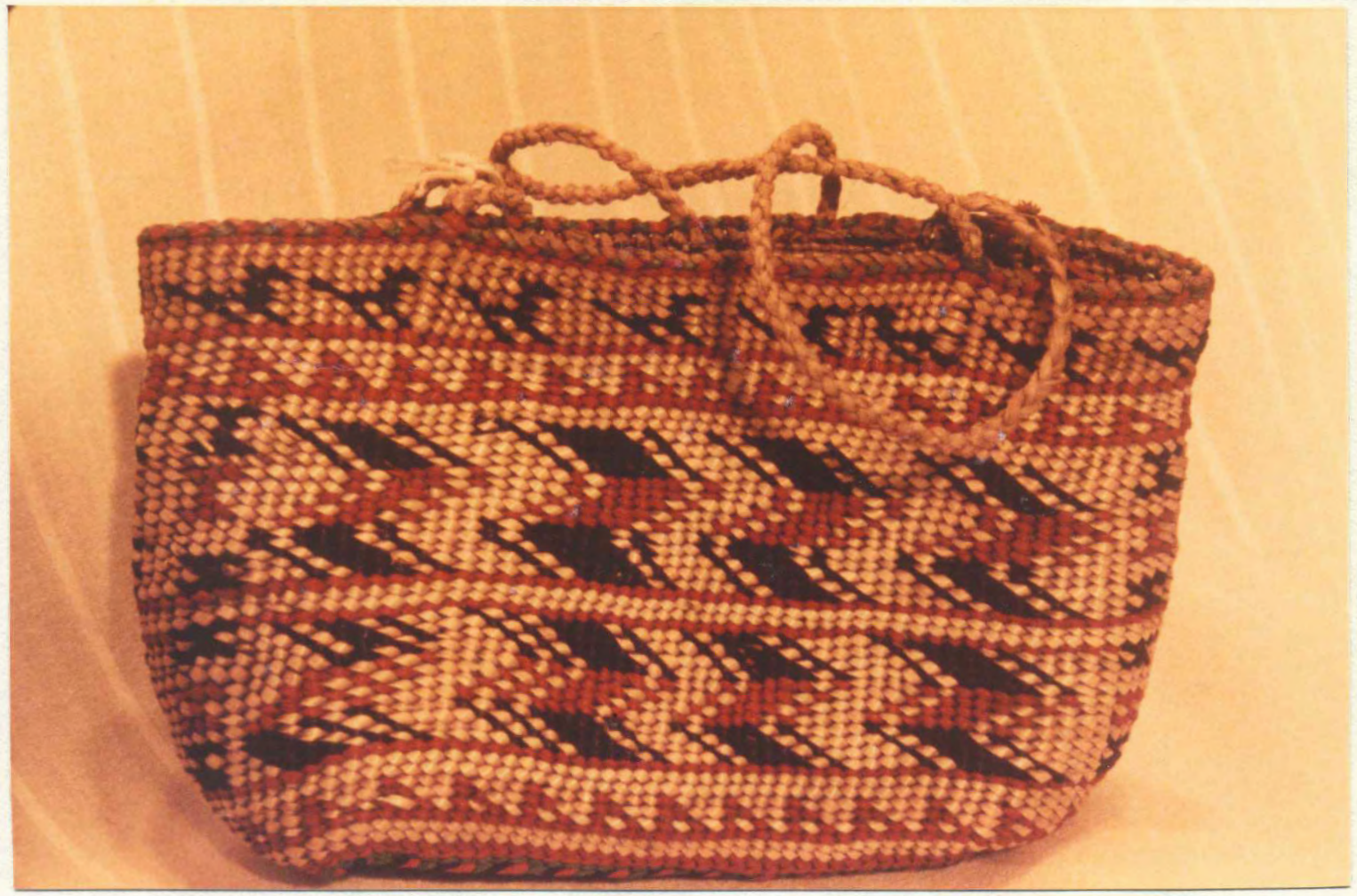

Figure 22. OHS $8783 / 68-366$ 
CHAPTER V

CONTINUITY AND CHANGE IN TILLAMOOK BASKETRY

After 1850, from a combination of decimation by epidemics, dislocation from land, and removal to reservations, the population of the Tillamook was greatly reduced. It is probable that within this smaller population there were fewer basket-makers. It is also probable that there was less need for the traditional, functional basketry, much of which had been supplanted by European goods earlier. Nontheless, baskets continued to be made.

How can we account for the continuing tradition of basket making by the Adamses and, by extension, the other Tillamook in the face of cultural disruption and domination by Whites?

Graburn (1976) has observed the continuing production of traditional arts, and arts based upon tradition, in contemporary Fourth World groups such as the Eskimos of eastern Canada, the Cuna of the San Blas Island, and the aborigines of Australia. These, and the other groups described in the papers which make up the Graburn anthology, are assigned Fourth World status on the basis of the domination of them and their traditional territory by colonists who were able to invade, settle, and take control over the native groups.

Although the groups that are described in the Graburn volume are contemporary ones, the circumstances in which they are does not appear to 
differ greatly from the situation in which the Tillamook found themselves from the 1850s through the first four decades of the 20 th century.

\section{SOURCES OF CONTINUITY IN TILLAMOOK BASKETRY}

The arts produced by Fourth World peoples can serve several different purposes, whether these arts are made for 1) the use of the Fourth World ethnic minority or 2) the use of members of the dominant society (Graburn 1976:4-5). On the basis of what Rena told me about the Adams family and from my observations of the basketry, it is possible to apply what Graburn has described for the arts of other Fourth World people to Tillamook basketry and the people who produced it.

1. Arts Made By and For the Use of the Fourth World People

The production of traditional arts, or arts based upon tradition, can serve to maintain ethnic identity and social structure, as well as to instill in group members the values important to them (Graburn 1976: 4-5)

For the Adams family, it seems likely that basket-making did contribute to their sense of ethnic identity. Whatever style the baskets assumed, however changed they might have become from baskets made in the previous century, the women of the Adams family were Tillamook and they produced Tillamook baskets. No doubt, this was a positive statement to the family members about themselves and their heritage.

It is easy to imagine that the basket-making of the old women in the Adams family gave them a productive role in the family, not only in the value that their baskets had for sale or trade but as a part of 
their heritage which they could pass on to the children and grandchildren. It is likely that much of the knowledge that they had of the family and the individual in society was restricted to their traditional Tillamook upbringing and that little of it was appropriate to the younger members of the family in early 20 th century in Garibaldi. These women may have used basketry as a means of passing on knowledge and giving themselves a traditional role in their own eyes, as well as a role of authority in the family.

At this point, there is no evidence, of which I am aware, of what sort of Tillamook values might have been carried in the basketmaking of the Adams family women; but certainly, it may well have been a means of communicating those values to others in the family.

\section{Arts Made by Fourth World People for the Dominant Society}

The arts produced by an ethnic group for the dominant society can have values beyond the economic reward that they may bring the producers of the arts. They are also "important in presenting to the outside world an ethnic image that must be maintained and projected as part of the allimportant boundary defining system" (Graburn 1976:5).

The Adamses may have found, in the manner that Graburn suggests, that the baskets they made did project an image to the dominant group in Garibaldi, the Whites, that was positive for the Indians. The acquisition of baskets and the recognition of them as having been made by "local Indians", as some tags on probable Tillamook baskets in the Tillamook County Pioneer Museum state, may be seen as an indication of a more positive attitude by some Whites toward the Indians. Often, 
where a less positive attitude exists, atrribution is given to a group other than the "local Indians", often to a group north of them. Graburn has observed, referring to colonial powers in Africa, in particular, that it was not until after the agents of these powers had overcome some of their revulsion toward the native people that they collected the native arts and crafts $(1976: 2)$. This is probably a justifiable observation about White settlers and collectors in North America, too.

The importance of defining amd maintaining ethnic boundaries may be more apparent, and more necessary, among groups with larger populations than was the case for the Tillamook in Garibaldi.

How the baskets in museum collections got from maker to collector has not been well documented, with the exception of baskets in the Adams Collection. There is not a great deal of evidence of the production of Tillamook baskets as "tourist art", for example; but it is likely that most of the baskets have come from non-Indian collectors.

Rena told me that the Adamses did give baskets to Whites in Garibaldi out of friendship and perhaps as payment for goods given them or favors done for them. Rena identified a basket in the Tillamook County Pioneer Museum as one her mother, Nora, had made and had given to Kate Farley, a local White woman (TCPM 10336, illustrated in S. Jones $1980: 58)$. Nora also sold baskets, charging up to $\$ 10$ for the largest ones, according to Rena. Clara Pearson said that Whites, who attended the winter dances, were given baskets as presents by the Indians (Jacobs Notebook 107:90). 


\section{SOURCES OF CHANGE IN TILLAMOOK BASKETRY}

The arts made for both of the groups described above appear to have undergone changes over time as a result of the interaction of the ethnic group with the dominant one. Graburn has outlined some of the sources of these changes and has described the directions in which these changes have taken the arts. By using his framework to investigate artistic change, it may be possible to account for the features exhibited by the Tillamook baskets in the Adams Collection.

Two major sets of forces have affected the arts of Fourth World peoples. These forces have arisen from the introduction of new materials and technology and from the cultural and formal influences resulting from contact of native peoples with non-native people (Graburn 1976:10).

\section{Materials and Technology}

Introduced materials are the most apparent feature of change in the Adams's baskets. Raffia, which they purchased dyed and undyed, is used for some or all of the weft on nearly all of the baskets, although I found raffia on only three of the baskets in the other Tillamook group. The absence of raffia in most of the rest of my sample may reflect choices made by collectors, who were in search of more "traditional" baskets. It might also reflect the time of collection; many of the Adams's baskets were probably made between 1900 and 1930. Although most of the baskets in the Other Tillamook group are without dates of collection, those that do exist are as early as the 1890s; and on the basis of some indications in the Patterson Collection documentation, the baskets themselves may have been made as much as 30 to 50 years earlier. 
The makers of these baskets may have had greater access to traditional materials, as well as having been less disrupted culturally than Tillamook people were to be in later years. The Adams women may have been the only Tillamook making baskets as late in the 20th century as they did, when basketry materials were probably increasingly difficult to find. The novelty of raffia, the ease with which it could be obtained and used in basketry, and the bright colors it could be dyed may have all contributed to the initial use of $i t$. This use may have continued because of the eventual obliteration of the old traditional basketrymaterial sites as the White population grew and its use of the land increased. Too, the women who made baskets and gathered the materials were growing older and may not have been physically able to travel far enough from the settled areas to locate new materials sites. The younger members of the family, who might have once helped to gather materials, were working or were in school and may not have had the time to assist the older women.

In the Other Tillamook group, there are very few obvious instances of introduced materials. The three baskets of raffia and two others which have small areas of red yarn are the only ones I noted. However, a shift in emphasis may have occurred in the use of some native materials for baskets. I found very little cedar bark in the basketry, for instance, although the literature describes it as a usual material (Barnett 1937).

No new techniques in the basketry in my sample were introduced by Whites, although the frequency of traditional techniques may have been altered. Full-turn twining, for example, is not evident in my sample except in the large clam baskets, and the Adams Collection has 
a larger proportion of closed, twined baskets than might have been seen in pre-1850 basketry. The changes in the frequencies of some techniques may be related to the gradual changes in the functions of the basketry. Another change related to techniques is the gauge of the stitches. The baskets in the Adams Collection are mostly in the Coarse and Fine range, while those in the Other Tillamook group are mostly Fine and Very Fine. I believe that this disparity can be accounted for, in part, by the use of raffia and, in part, by individual style. While it is possible to split raffia into very fine strands, it may have been more successfully used in larger, thicker strands. The use of raffia on the base and lower sides of a basket may have set the gauge for the decorative bands of bear-grass, which could also have been split into narrower widths, but was not, in these baskets. The individual style in the Adams Collection appears to have been that of Lizzie Adams. She was known for her basketmaking and many in the Adams Collection are attributed to her. Lizzie may have found that, because of her failing vision, the larger stitch gauge was more visible, allowing her to continue to make baskets and to teach the children and grandchildren of the household her knowledge and style of basketry.

Cultural and Formal Influences

Changes in traditional arts are not only the result of the loss of traditional materials or function but are frequently initiated by the makers as new materials, forms, and uses are introduced (Graburn 1976:12). The development of what are regarded as traditional arts has come about in this way, and these processes have continued under domination by 
outside groups, where arts have survived extinction. The changes made and initiated by makers are often seen by them as desirable as they can challenge their creative skill and knowledge.

Changes also come about as a positive reaction to the commercial markets developed through the circumstances of domination and the demands of the non-native buyers. In particular, new forms are often developed for the uses the buyers have for the arts.

Some of the features in Tillamook basketry may be due to these cultural and formal influences; but whether they were initiated by maker or non-native buyer is unknown, and perhaps at this late date, unknowable.

Nearly all of the baskets in my sample are decorated. This may not be representative of the frequency of decoration in the traditional, functional basketry. Since, with the advent of European containers, fewer baskets were needed, more time could be spent on those that were made. It seems likely that the decorative work on the basket was more time-consuming than the non-decorative areas would be. Not only are most of the baskets in my sample decorated, many have several bands of different designs, some of them quite complex and occupying most of a basket surface. The more elaborately decorated baskets may have had greater appeal to Whites who received baskets from the Adamses. This, in turn, may have encouraged the women to continue the more decorative styles. This may also be true of the baskets in the Other Tillamook group, many of which are even more elaborate than the Adams's baskets.

Size of the baskets is another feature which may have been altered by White contact, with the causes for change initiated by both the makers 
and recipients of the baskets. In the Adams Collection, nearly 80 percent of the baskets are no more than five inches high. In the Other Tillamook group, only 20 percent of the baskets are that size, with the others ranging up to 20 inches high. Again, the changes in basket function may account for this. The Adamses may have found that a basket five inches high was small enough to complete easily and conserved materials but was large enough to demonstrate designs and skill on. They may also have found that Whites had uses for baskets that size.

The largest baskets in the Other Tillamook group are the clambaskets. It seems likely that these are a traditional, functional type of basket on the basis of their size and technique of twining, found on no other baskets, and on the photographic evidence which shows them in use with a tumpline. Some of the clam-baskets in my sample have tumplines associated with them and even a small clam-basket in the Adams Collection has a tumpline.

Shape is very easily changed in basketry. Jones (1976:77) found that shape was the first attribute to exhibit the greatest amount of change in Tlingit basketry shortly after contact with Europeans. Such things as basketry goblets and teacups and basketry versions of 19 th century sailors' hats, as well as covered jars and bottles, demonstrate the flexibility of basketry, particularly in the twining technique, as well as the ingenuity of the basket-makers.

of the 19 categories of shape in my sample, only five are common to both the Adams Collection and the Other Tillamook group. Most of the other categories are represented by only one or two baskets, which leads me to believe that some may have been new shapes made to appeal to 
White buyers, although selection by the collectors must also be taken into account.

Kasner (1976) gives some evidence of the ways in which shape and function of the reservation basketry at Siletz were altered by the demands of the White market. She notes the use of open-work basketry sifters as calling-card holders by Whites and the development by basket-makers of flat bases on what were originally conical burden-baskets for use as waste-baskets by non-Indians. The basket-makers may have ultimately ceased to think of these products as variations of the traditional ones and may have simply made calling-card holders and waste-baskets. The social and economic forces molding the Siletz Reservation basketry may have had the same sorts of effects on the baskets made by the Adamses. The "shopping bags" in the Adams Collection may have grown out of the traditional trapezoidal shape of the clam-baskets; and the wall-pouches, possibly a traditional item of basketry hung on a house wall, may have been elaborated for the White market.

\section{DIRECTIONS OF CHANGE}

The process of the artistic development of traditional arts, as a result of the incorporation of introduced materials and values, has brought about greater or lesser change in the arts over time. Graburn has examined these changes in the arts of the Fourth World and has described the effect that they have had on the arts as "directions of change", (1976:5-7):

The directions of change that Graburn describes affect both the arts made by and for the ethnic group and the arts made for the dominant 
society, although not all of these changes occur in both categories of the arts. In some cases, the directions of change can be seen as sequential, each building on prior ones. This is most apparent in the arts from groups which have a long history of contact and domination without the loss of the greater part of their ethnic integrity. It is less apparent and is less likely to occur in groups such as the Tillamook which suffered ethnic and cultural disintegration soon after domination.

Graburn's Directions of Change

I have abbreviated and paraphrased Graburn's descriptions of the directions of change, which I believe may be described more closely as the consequences or the outcomes of the directions of these changes, although the sequence and identifying terms are his.

1. Extinction: the gradual disappearance of an art form.

2. Traditional or Functional Fine Arts: arts which persist in traditional form and use, or with some changes in features which do not result in a loss of cultural appropriateness.

3. Commercial Fine Arts: like those above but made with eventual sale in mind.

4. Souvenirs: arts made with sale in mind but, unlike the Commercial Fine Arts, with a greatly reduced ethnic cultural content which has been replaced by the prospective buyers' image of the group; the tourist or "airport" arts.

5. Reintegrated Arts: new art forms developed by an ethnic group with some element from the dominant society, such as technology or materials or function, but incorporated into the ethnic groups' esthetic. 
6. Assimilated Fine Arts: arts produced by ethnic artists which carry cultural content but are created in forms taken from the dominant society in competition with artists in the dominant group and on their terms.

7. Popular Arts: arts which have the form of the art of the conquerors with the content of the conquered used for cultural enhancement, particularly by those groups moving from Fourth World status to positions of greater power.

The Directions of Change in Tillamook Basketry

The directions of change which appear to fit the Tillamook

basketry include: 1) Extinction, 2) the perpetuation of Traditional or Functional Fine Arts, and 3) Commercial Fine Arts.

An important aspect of Graburn's description of the Traditional or Functional Fine Arts is the recognition that changes can be introduced into both of these without altering their traditional or functional status, as long as the changes are seen as culturally appropriate.

In the case of the Adamses, it seems likely that it was their family "culture" which judged their baskets as appropriate or not. I have no information which would reveal whether other Tillamook considered the Adams's baskets to be "Tillamook" ones. The population of the Tillamook in the early part of the 20th century was very small and, from what Rena told me, the Tillamook living in the Garibaldi area all appear to have been related to each other. These family relationships may well have overshadowed any doubts that the other Tillamook might have had as to the traditional and cultural approriateness of the Adams's baskets. Too, as 
non-Indians accepted the baskets as Tillamook, any Indian acceptance of variations from "traditional" style may have been reinforced.

It seems reasonable to suppose that during White settlement the Tillamook basket-makers continued to make traditional baskets, gradually eliminating forms no longer used and developing new ones. At this late date, it is probably not possible to know how much change was intentionally made in the baskets for sale or trade that would distinguish them from baskets made for home consumption. It is likely that as non-Indians expressed interest in the Tillamook baskets, changes were made which encouraged this interest, changes which may have eventually shown up in all of the basketry.

The ultimate outcome of these changes in Tillamook basketry was extinction. As far as I can tell, the death of the Adams women brought about the extinction of Tillamook basketry. No Tillamook are making baskets and no Indians are making baskets which they perceive to be Tillamook in origin. However, some aspects of Tillamook basketry may still be perpetuated. Many Tillamook went to the Siletz and Grand Ronde reservations where styles were developed that were a synthesis of basketry traditions brought by Indians from many areas of western Oregon and northern California. At Siletz, basketry is still being made, and it is possible that some distinctive features of Tillamook basketry are incorporated into these contemporary works.

Discussion

Graburn's framework for the study of change has been useful in examining Tillamook basketry made after the invasion of Whites. It has 
been particularly helpful in considering the possible motives of the basketmakers as they continued to produce basketry at a time of cultural disinitigration. The sources of change which Graburn describes are certainly applicable to the Tillamook. The direction in which the changes have shaped the arts of Fourth World people have opened some interesting new ways in which to view transitional, ethnic arts. Had the Tillamook population not been decimated so early in the history of White settlement, the basketry, and perhaps other sorts of arts, might have developed further along the lines and in the directions that Graburn suggests. Groups in the Northwest Coast which did not suffer population decimation to such an extent during the invasion of Whites are currently producing arts which can be seen to reflect the outcomes that Graburn has described. There are souvenirs: totem pole models made by carvers from non-totem pole groups such as the Coast Salish, reintegrated arts: button blankets made by people from the Kwakiutl north to the Tlingit, assimilated fine arts; the silk-screen prints of now-prominent Northwest Coast Indian artists, and popular arts: such as the Cowichan "opera" "Tzinquaw".

\section{TILLAMOOK BASKETRY STYLE}

\section{Problems of Identification}

Throughout this study, I have described the baskets in the Adams Collection and in the Other Tillamook group as Tillamook. In the Adams Collection, there is no doubt that the baskets attributed to basketmakers of the Adams family, as well as some of the unattributed ones are Tillamook. I have referred to the baskets in the Other Tillamook group 
as Tillamook solely on the basis of museum identification. In fact, except for the baskets made by the Adamses, there is no sure way of knowing whether all of the baskets in my sample were made by Tillamook women or not, in what part of the Tillamook territory they were collected, or on what basis they have been labelled as Tillamook. This last area is one of a great deal of confusion, particularly in regard to the term "Siletz".

The Siletz Problem. The use of the term "Siletz" for the multitribal reservation, the basketry from it, and the Siletz dialect of the Tillamook language has resulted in ambiguity which complicates the identification of baskets. While the reservation and basketry from it share the term, the basketry and the Siletz dialect of Tillamook have nothing necessarily in common. The original speakers of the Siletz dialect were decimated and the survivors were ultimately absorbed into the reservation established in their territory. It is unlikely that there are any baskets made by these Siletz dialect speakers in my sample. What is likely is that, in an effort to be "scientific" and with the awareness that some relationship existed between the terms "Siletz" and "Tillamook", collectors and ultimately museum personnel extended the identification of baskets from "Siletz" to "Tillamook". The baskets in the Tartar Collection of the Horner Museum are a case in point.

These seven baskets are all identified as Tillamook. They were collected by Rose Davis Kennedy and in the documents which accompany the collection is a picture of her at Siletz with Ella Ben, identified by Kasner (1976:99) as a Yuki basket-maker. Although the baskets do not 
have the names of the makers, it is not impossible that some were made by E1la Ben. If this is the case, these baskets can in no way be considered Tillamook. I included them in my sample only on the basis of the museum identification of them as Tillamook. In addition to their probable, non-Tillamook origins, they are all twined in Z-slant, not the dominant slant for the rest of my sample but typical for the Siletz reservation basketry that I have seen. Four of these baskets are very similar to one another in materials and general style. It occurred to me as I examined them that they might represent yet another source of basketry in collections. These four baskets could very well be a "sampler" of a basket-makers ingenuity made at the request of, and collected by someone who appreciated the creativity of the maker. In the Oregon Historical Society, I found baskets actually identified as Siletz and attributed to Ella Ben. These were given to the museum by a Mr. Kennedy, who, I presume, is of the same Kennedy family as the collector of the Tartar Collection.

Although I have no way of knowing to what degree baskets have been erroneously included or excluded from Tillamook identification, it is useful in assessing my sample to consider the possibilities. In addition to the Siletz-Tillamook problem, another possible one is the identification as Grand Ronde or Siletz of a basket which, in fact, adheres to a Tillamook tradition and was merely collected on the reservation. The identification of a basket with the tribal affiliation of the maker may also occur, though the basket may not necessarily be representative of the tribal style. The movement of goods between groups in the Northwest could also 
have resulted in the identification of baskets as "Tillamook" that were brought in and actually represent a very different tradition.

Is There a Tillamook Style?

I began this study under the impression that a Tillamook basketry style probably does exist and that it was only lacking a description which would place it as an equal with other, better known basketry from western Washington and Oregon. I have found that the situation is a far more complex one than can be satisfied by describing diagnostic features of the baskets which have Tillamook identification and assuming that this then describes the Tillamook style. Some of the complexities that I have encountered are the consequence of trying to subsume, under a single label, baskets which have a fairly wide distribution both geographically and temporally. It now appears that I should not have expected to find a Tillamook style co-extensive with the area occupied by Tillamook-speakers. Hymes (1968), cited by Fried (1975:27), notes that there are many instances where language and culture units fail to coincide; the relationship of Tillamook-speakers with the basketry that they produced may be one more instance of this.

Geographical distribution. The Tillamook language was spoken along 80 to 100 miles of the Oregon coast, north of the southwestern Oregon Athapaskan speakers. As I described it earlier, the language was spoken in what was probably an intergrading series of dialects by population groups settled along the many river mouths flowing into the ocean and into Tillamook Bay. While the rivers, beaches, and ocean made travel between these groups possible, it seems unlikely that the result 
of the relative ease of communication would have been a homogenized cultural tradition throughout the area. The same ease of communication which was afforded the Tillamook within their area also would have allowed them travel outside of it. Travel for the purposes of trade and marriage are evidence of this. Communication with neighboring groups and, in particular, the movement of women who were the basket-makers, as well as the local development of material culture styles must have brought about local styles in basketry.

The baskets in my sample may represent several local Tillamook traditions. However, even though they have Tillamook attribution, they lack provenience of maker or of collection, in most cases, so that there is no concrete evidence of how large an area they have been drawn from. In fact, the baskets in my sample may be representative of a northern, Nehalem-style tradition. The Adams Collection baskets are certainly an outgrowth of this tradition, based on the history of the family. Mrs. Patterson, whose Tillamook baskets at the University of Oregon make up about half of the Other Tillamook group, is known to have been in Seaside and probably collected many of her Tillamook baskets in the area south of Seaside, as well, apparently, as at Grand Ronde. One of the wall-pouches, collected by Mrs. McArthur, still has its "Nehalem" tag tied to it. It is possible that baskets which may be Tillamook but which were collected at Siletz or in the Siletz area, have been given Siletz attribution and, thus, have been eliminated from my sample, skewing the sample further.

Temporal distribution. The baskets in my sample have very few dates associated with them. Some of the Patterson baskets were collected 
as early as the 1890s and may be older than that, and the Adams Collection probably contains baskets made between 1880 and 1935. Otherwise, the only dates that can be established in a general way are from inferences made from the meagre documentation about the collectors and their sources. Were there better dates associated with the baskets, it might be possible to arrange them in chronological order and to determine, with greater accuracy, something about the changes in materials, shape, and design elements as we now see them in the Adams Collection and the rest of the sample.

Throughout time, the histories of groups within the Tillamookspeaking area and of their neighbors have undergone events which have affected the cultural traditions. With better dates for the baskets, it might be possible to correlate the events in groups' histories with changes in the basketry.

The Relationship of Tillamook Basketry With the Basketry of Neighboring Groups

Many of the features of Nehalem Tillamook basketry, which I have described as probably constituting the greater portion of my sample, can be found in the baskets of their linguistic relatives, the Chehalis, and their Chinookan neighbors, the Clatsop. My observation of the simflarities among Tillamook, Clatsop, and Chehalis basketry has been independently supported by Marr (1983 personal communication). While examining baskets in the U. S. National Museum, Smithsonian Institution, she came upon 11 unidentified baskets which were collected by wilkes in 1841 and which Marr suggested could be Clatsop or Chehalis or Tillamook on the basis of 
their similarity to known examples from all of these groups. Since Wilkes is known to have been in these areas, some or all of the baskets could be from any one of them.

The Wilkes Baskets in Relation to Tillamook, Clatsop, and Chehalis Baskets

Features of the Wilkes baskets which can also be seen in some Chehalis, Clatsop, and Nehalem Tillamook baskets include S-slant wrapped twining, horizontal bands of motifs, motifs of "dogs" or "animals", stair-steps, zig-zags, and open crosses which, when repeated vertically, become fretwork and concentric circles on the bases of some baskets. A deer motif occurs on the Wilkes pieces that is very similar to a deer motif on an unattributed, but probably Nehalem Tillamook envelope in the Tillamook County Pioneer Museum. Marr said that she had not found this motif on Chehalis baskets, nor have I found it on Clatsop ones, although it is a frequent one on Wasco "sally bags" from The Dalles area along the Columbia River. There is one instance of a figure which Marr suggests might be a human form with a truncated head found commonly in baskets from Puget Sound but not one $I$ have seen in northwestern Oregon baskets.

The shapes of the Wilkes baskets are particularly interesting. One is the "jar" shape I have described for one basket in my sample and that can also be seen in a Clatsop basket, illustrated in Gogol (1979:8). Another interesting form is a "pocketed" one similar to the Tillamook wall-pouches, with some variation. One basket with pockets like those in wall-pouches in my sample has Chinook provenience (TBW 250-147) and may be further evidence that some of these shapes were widely distributed. 
The early dates of collection for the Wilkes baskets make them very important as a basis for assessing changes in basketry styles among the three possible groups to which they could be attributed and in demonstrating the similarities in techniques, materials (bear-grass and cedar and cat-tail, according to Marr's description), motifs, and shape found in some of the basketry from these groups.

Some Other Examples from the Literature

In addition to the Wilkes baskets, there are several baskets described in the literature which could also be Tillamook or Chehalis or Clatsop.

Wardle (1912:facing page 297) describes a four inch high "grass cup, lower valley of Columbia River" collected by Thomas Nuttall, the botanist, when he was on a scientific expedition in the area in 1834 . The technique is wrapped twining in S-slant stitches worked in beargrass (?) and maidenhair-fern stem. The "cup" is a very straightsided cylinder with several horizontal bands of repeated motifs around it. At the margin, what Wardle calls "dogs" (identical to the Adams "dogs) are repeated in black, and below that are several bands of mirrored, clustered diagonals.

Another piece described by Wardle is an envelope apparently done in weft-overlay with bands of stair-steps across one side. On the other side, very un-Tillamook geometric human heads are repeated, similar to the ones on Wasco "sally bags"; and on both sides, in the margin, are animals resembling the Twana wolf, with four legs and downward-turned tail (Thompson et a1 , 1980:13), that I have not seen in Tillamook basketry. 
In Lobb (1978:39), there is another example of a basket which has features common to the basketry of all three groups. It is identified as, and may be, Chehalis. However, there is nothing in its appearance to exclude it from Clatsop or Tillamook attribution with its bear-grass and maidenhair-fern stem in S-slant wrapped twining, repeated dog-like animals at the margin, and bands of clustered diagonals.

\section{Discussion}

The features of the baskets described in Lobb and Wardle, when added to those found in the baskets from the Wilkes Expedition and in the basketry in my sample, begin to demonstrate the widespread use of similar techniques, materials, shapes, and motifs throughout the lower Columbia by linguistic relatives and by neighbors. Although many of the same features can be found outside the area of the Chehalis, Clatsop, and Nehalem Tillamook, and within these three groups there are also differences among their basket styles, I have limited my discussion to the basketry of these peoples as it relates to the Wilkes baskets and those in the literature that I cited.

Materials. Bear-grass, maidenhair-fern stem, cat-tail, tule, and sedges are common to all three groups. Cedar, described for the Wilkes baskets, may also be found in Clatsop and other Tillamook baskets, despite my failure to have identified it for the Nehalem Tillamook pieces.

Shapes. With greater research into museum collections, a larger inventory of shapes may be known. The envelopes and cylinders in the Wilkes Collection are similar to those in the Clatsop and Nehalem Tillamook 
basketry, although different from the Chehalis bowl-shaped pieces (Thompson, et a1, 1980) which are also found in the other two groups.

Techniques. Plain and wrapped twining are common to all three groups as the most frequent techniques used and are found in the Wilkes baskets, too. Weft-overlay, used on several baskets in my sample, but which I do not believe are Tillamook, is not usual for the Chehalis or the Nehalem Tillamook. I do not know how frequent its occurrence is in Clatsop basketry, but I do believe that it does occur to some extent on the basis of museum pieces that I have seen.

Motifs. Many of the motifs on the Wilkes baskets can be found in the Nehalem Tillamook pieces. The dog-like animals, solid-triangles, and clustered diagonals are common to Chehalis and Nehalem Tillamook pieces and to Clatsop ones. The occurrence of the steps with the Wascostyle head may demonstrate the widespread use of it up the Columbia River, as well as the possible spread of the motif between the Clatsop and Wasco, who were linguistic relatives. The occurrence of the more Oregon-style deer motif with the Puget Sound truncated human figure on a basket in the Wilkes Collection offers an interesting point for speculation about the changes in basketry motifs over time and geography.

\section{SUMMARY AND CONCLUSIONS}

I began this study by examining a body of baskets in the Adams Collection that are known to have been made by Tillamook women but which exhibit features of size, shape, and materials that may be described as untraditional, when compared to the features that I found in Tillamook baskets that are probably older than the Adams ones. I have been able to 
account for the differences between these two groups of baskets by using Graburn's analysis of the changes seen in the arts and crafts of Fourth World peoples. I found that the changed features in the Adams baskets are expectable ones in the arts of people undergoing cultural disruption and that they are not unique to the Adams baskets. A decrease in the size of items with a concommitant shift in the kinds of shapes and numbers of shapes made, and the use of non-native material in otherwise traditional, native arts, can all be found in the arts of other colonially-dominated groups.

The Adams baskets have, and many of those in the rest of my sample appear to have, developed from a Nehalem Tillamook tradition. In order to place these baskets in a wider context, I compared them with basketry from the Nehalem Tillamook's neighbors, the Chinookan Clatsop, and linguistic relatives, the Salishan Chehalis, and found that some of the baskets from all of these groups have many features in common. Given the history of trade among these people and the marriages which moved women among them, it is not suprising that these similarities exist. How similar the Nehalem Tillamook baskets were to baskets from the southern part of the Tillamook area is unknown. In my sample, I found features in several baskets which do not occur in those from the Nehalem Tillamook tradition. It is possible that these differences represent a different Tillamook tradition. The establishment, on Tillamook land, of reservations which brought together people from much of the Oregon Coast, and even from northern California, and the resulting population disruption and decimation appears to have obliterated any evidence of pre-White basketry in the 
southern area, although further research might reveal some indications of the pre-reservation styles.

It is unlikely that there was a Tillamook basketry style found throughout the Tillamook area that was distinct from the basketry styles of the neighboring groups. What seems more likely is that, within the Tillamook area, local variation developed from a basketry tradition that was widespread throughout southwestern Washington and northwestern Oregon, and that it was shaped by relations with neighboring groups. The Adams Collection appears to be the most recent manifestation of a Nehalem-Tillamook style developed from a local tradition and influenced by cultural disruption during White settlement. 
REFERENCES CITED

Adovasio, James M.

1977 Basketry technology: a guide to identification and analysis. Chicago: Aldine Publishing Company.

Barnett, Homer

1937 Culture element distributions: VII Oregon Coast. University of California Anthropological Records 1(5): 155-204. Berkeley.

Beckham, Stephen Dow

1977 The Indians of western Oregon. Coos Bay, Oregon: Arago Press.

Bedwe11, S. F., and L. S. Cressman

1970 Fort Rock report: prehistory and environment of the Pluvial

Fort Rock Lake area of south central Oregon. University of Oregon Anthropological Papers 1:1-25.

Berreman, Joel

1937 Tribal distribution in Oregon. Memoirs of the American Anthropological Association 47.

Birrell, Verla

1959 The textile arts: a handbook of weaving, braiding, printing, and other textile techniques. New York: Schocken Books.

Boas, Franz

1888 The Indians of British Columbia. The Popular Science Month1y 17: 628-636.

1894 Chinook texts. Bureau of American Ethnology Bulletin 20. Washington

1898 Traditions of the Tillamook Indians. Journal of American Folklore $11: 23-38$ and 133-150.

1923 Notes on the Tillamook. University of California Publications in American Archaeology and Ethnology 20:3-16. Berkeley.

Boge, Lila, editor

1972 Tillamook memories. Tillamook, Oregon: Tillamook County Pioneer Association.

1975 Tillamook history. Tillamook, Oregon: Tillamook County Pioneer Association 
Boge, Lila (Continued)

1979 Tillamook: lest we forget. Tillamook, Oregon: Tillamook County Pioneer Association.

Borden, Charles E.

1976 A water-saturated site on the southern mainland coast of British Columbia. Pp. 230-260 in The Excavation of Water Saturated Archaeological Sites (Wet Sites) on the Northwest Coast of North America, edited by Dale R. Croes. Archaeological Survey of Canada Paper 50 (Mercury Series). Ottawa: National Museum of Man.

Boyd, Robert

1975 Another look at the "fever and ague" of western Oregon. Ethnohistory $22(2): 135-154$.

Brasser, Ted J.

1975 A basketful of Indian culture change. Canadian Ethnology Service Paper 22 (Mercury Series). Ottawa: National Museum of Man.

Commisioner of Indian Affairs

1885 Annual report of the Commisioner for Indian Affairs. Washington

1887 Annual report of the Commisioner for Indian Affairs. Washington.

Copeland, Margaret Ayr

1956 An analysis of Modoc basketry. M.A. thesis. University of Washington.

Coues, Elliott

1893 History of the expedition under the command of Lewis and Clark. New York: Francis Harper; reprint edition New York: Dover Publications, Inc., 1964.

Crawford, Ailsa

1977 Tillamook basketry field notes. (Manuscript in the University Archives, Suzzallo Library, Seattle.)

Croes, Dale R.

1976 An early "wet" site at the mouth of the Hoko River, the Hoko River site (45CA213). Pp. 201-232 in The Excavation of Water Saturated Archaeological Sites (Wet Sites) on the Northwest Coast of North America, edited by Dale R. Croes. Archaeological Survey of Canada Paper 50 (Mercury Series). Ottawa: National Museum of Man.

- 1977 Basketry from the Ozette Village archaeological site: a technological, functional, and comparative study. Ph.D. dissertation. Washington State University. 
Croes, Dale R. and Eric Blinman, editors

1980 Hoko River: a 2500 year old fishing camp on the northwest coast of North America. Pullman: Washington State University.

Douglas, Frederic

1934 Symbolism in Indian art and the difficulties of its interpretation. Indian Leaflet Series 61. Denver Art Museum

1935 Basketry construction techniques. Indian Leaflet Series 67. Denver Art Museum.

Douglas, Mary

1947 Oregon Indian basketry: types and distribution. M.A. thesis. University of Oregon.

Driver, Harold E. and William C. Massey

1957 Comparative studies of North American Indians. Transactions of the American Philosophical Society 47(2):165-456. Philadelphia.

Drucker, Philip

1963 Indians of the Northwest Coast. Garden City, New York: Natural History Press.

1965 Cultures of the North Pacific coast. San Francisco: Chandler.

Ede1, May M.

1931 May M. Edel Papers. Box 4. University of Washington Library, Seattle.

1939 The Tillamook language. International Journal of American Linguistics 10:1-57.

1944 Stability in Tillamook folklore. Journal of American Folklore $57: 116-127$.

Emery, Irene

1966 The primary structure of fabrics. Washington, D.C.: The Textile Museum.

Farrand, Livingston

1900 Basketry designs of the Salish Indians. American Museum of Natural History Memoirs 1 (Anthropology 1):391-399.

Frachtenberg, Leo J.

1917 A Siletz vocabulary. International Journal of American Linguistics $1: 45-46$.

Fried, Morton H.

1975 The notion of tribe. Menlo Park, California: Cummings. 
Gatschet, Albert S.

1877 Texts, sentences, and vocables of the Atfa'lati dialect of the Kalapuya language of Willa'met Valley, northwestern Oregon.

(Manuscript field notes, catalogue no. 472-a, National Anthropological Archives, Smithsonian Institution. Washington.

Gogol, John M.

1979 Columbia River Indian basketry. American Indian Basketry Magazine $1(1): 4-9$.

Graburn, Nelson H. H.

1976 Ethnic and tourist arts: cultural expression from the Fourth World. Berkeley: University of California Press.

Gunther, Erna

1945 Ethnobotany of western Washington. University of Washington Publications in Anthropology 10(1):1-61.

1968 Art in the life of primitive peoples. Pp. 77-114 in Introduction to Cultural Anthropology edited by James A. Clifton. Boston: Houghton Mifflin Company.

Haeberlin, H. K., James A. Teit, and Helen H. Roberts

1928 Coiled basketry in British Columbia and surrounding regions. 41st Annual Report of the Bureau of American Ethnology for the Years 1919-1924. Washington.

Harcourt, Raoul d'

1974 Textiles of ancient Peru and their techniques. Seattle: University of Washington Press.

Harrington, John Peabody

1942 The Tillamook. John P. Harrington Papers, Reel 20. National Anthropological Archives. Smithsonian Institution. Washington.

Hodge, Frederick W., editor

1907 Handbook of American Indians north of Mexico. 2 vols. Bureau of

1910 American Ethnology Bulletin 30. Washington.

Holmes, W. H.

1888 A study of textile art: in its relation to the development of form and ornament. 6 th Annual Report of the Bureau of American Ethnology for the Years 1884-1885. Washington.

Howay, Frederick W., editor

1969 Voyages of the "Columbia": to the Northwest Coast 1787, 1790, and 1790-1792. Amsterdam: N. Israel. (Published under the same title by the Massachusetts Historical Society, Boston, 1941.) 
Jacobs, Elizabeth

1934 Notebooks 非106 and 非107. Melville Jacobs Collection. University

1935 of Washington Archives, Seattle.

Jones, Joan Megan

1976 Northwest Coast Indian basketry: a stylistic analysis. Ph.D. dissertation. University of Washington.

1977 Basketry of the Quinault. Taholah, Washington.

Jones, Suzi

1980 Webfoots and bunchgrassers: folk art of the Oregon country. Oregon Arts Commission.

Kasner, Leone Letson

1976 Siletz: survival for an artifact. Dallas, Oregon.

Kent, William Eguene

1973 The Siletz Indian Reservation: 1855-1900. M.A. thesis. Portland State University.

Kroeber, Alfred L.

1905 Basket designs of the Indians of northwestern California. University of California Publications in American Archaeology and Ethnology 2(4):105-164. Berkeley.

1939 Cultural and natural areas of native North America. University of California Publications in American Archaeology and Ethnology 38: 1-242. Berkeley.

Lewis, Albert Buell

1906 Tribes of the Columbia Valley and Oregon coast. American Anthropological Association Memoirs 1(2).

Lobb, Allan

1978 Indian baskets of the Northwest Coast. Portland: Graphic Arts Center Publishing Co.

Mason, Otis Tufton

1904 Aboriginal American basketry: studies in a textile art without machinery. Pp. 171-548 in Report of the U. S. National Museum for the Year 1902. Smithsonian Institution. Washington.

McChesney, Charles E.

1906 The rolls of certain Indian tribes in Washington and Oregon. Fairfield, Washington: Ye Galleon Press, 1969.

Miles, Charles and Pierre Bovis

1969 American Indian and Eskimo basketry: a key to identification. New York: Bonanza Books. 
Murdock, George Peter and Timothy J. O'Leary

1975 Ethnographic bibliography of North America. 4th ed. Vol. 3: Far West and Pacific States. New Haven, Conn.: Human Relations Area Files Press.

Newman, Sandra Corrie

1974 Indian basket weaving: how to weave Pomo, Yurok, Pima, and Navajo baskets. Flagstaff: Northland Press.

Newman, Thomas M.

1959 Tillamook prehistory and its relation to the Northwest Coast culture area. Ph.D. dissertation, University of Oregon.

Rozaire, Charles

1977 Indian basketry of western North America. Los Angeles: Brooke House.

Sauter, John and Bruce Johnson

1974 Tillamook Indians of the Oregon coast. Portland: Binfords and Mort.

Smith, Marian

1949 Salish coiled basketry. Pp. 111-132 in Indians of the Urban Northwest, edited by Marian Smith. New York: Columbia University.

Smith, Silas

1901 Primitive customs and religious beliefs of the Indians of the Pacific Northwest coast. Oregon Historical Quarterly 2:255-265.

Spier, Leslie and Edward Sapir

1930 Wishram ethnography. University of Washington Publications in Anthropology $3: 151-300$.

Sprague, Roderick

1971 Field notes and correspondence of the 1901 Field Columbia Museum Expedition by Merton L. Miller to the Columbia Plateau. Northwest Anthropological Research Notes 5(2):201-232.

Suttles, Wayne

1975 The recent emergence of the Coast Salish: the function of an anthropologocial myth. Paper read at the 28th Annual Northwest Coast Anthropological Conference. Seattle.

1977 Productivity and its constraints: a Coast Salish case. Paper read at the Northwest coast Studies Conference, Simon Fraser University, Burnaby, B. C.

1978 (map) Native languages of the North Pacific coast of North America. Portland: Cameron Suttles.

Thompson, Laurence and M. Terry Thompson

1966 A Fresh look at Tillamook phonology. International Journal of American Linguistics 32:313-319. 
Thompson, Nile, Caroly Marr and Janda Volkmer

1980 Twined basketry of the Twana, Chehalis, and Quinault. American

Indian Basketry Magazine 1(3):12-19.

Thwaites, Reuben Gold, editor

1905 Original journals of the Lewis and Clark expedition 1804-1806. New York: Dodd, Mead, \& Co.; reprint edition, New York: Antiquarian Press, 1959.

Turner, Nancy J.

1979 Plants in British Columbia Indian technology. British Columbia Provincial Museum Handbook 38. Victoria.

Wardle, H. Newell

1912 Certain rare west-coast baskets. American Anthropologist 14(2): 287-313.

Weber, Ronald L.

1982 Tsimshian twined basketry: stylistic and cultural relationships. American Indian Basketry Magazine 6:26-32.

Weltfish, Gene

1930 Prehistoric North American basketry: techniques and modern distributions. American Anthropologist 32(3): 454-495.

Whiteford, Andrew Hunter

1970 North American Indian arts. New York: Golden Press.

Zenk, Henry

1976 Contributions to Tualatin ethnography: subsistence and ethnobiology. M.A. thesis. Portland State University. 
APPENDIX A

\section{TILLAMOOK BASKETRY TERMS}

I have extracted the following basketry-related terms from the field notes of Boas, Edel, Jacobs, and Harrington, and a publication by Edel and have recorded them as they appear in the sources. The Boas (B) and Ede1 (E) terms are from Box 4, folders 1-9 of the May M. Edel Papers at the University of Washington Library in Seattle. The Elizabeth Jacobs (J) terms are in Notebook \#106 in the Melville Jacobs Collection at the University of Washington Archives. The Harrington (H) material is from Reel \#20: The Tillamook, of his microfilmed papers at the University of Washington Library. Edel's publication on the Tillamook language (1939) is the source for the terms preceded by E-T.

I have organized the terms into categories of materials, anatomy and process, designs, and products.

The terms in brackets identifying designs are my terms for the drawings that accompanied each Tillamook word and are the terms that I have used in identifying these designs in the section on Tillamook Basketry Motifs (p. 56 )

\section{Materials}

$\begin{array}{lll}\text { B tlast e'naha } & \text { 'bullrushes } \\ \text { B } \quad \text { ta let se } & \text { 'hazel bush' } \\ \text { E } \quad \text { d ale'ts'e } & \text { 'hazel' } \\ \text { E } & \text { stawai'n } & \text { 'reed woven with' }\end{array}$




\begin{tabular}{|c|c|}
\hline E & salutctc \\
\hline$E$ & netcst'e \\
\hline E & netct'e \\
\hline$E$ & hot stc, $12 x^{w}$ \\
\hline $\mathrm{H}$ & dafnatft'e $x \times N$ \\
\hline $\mathrm{H}$ & $n z^{\prime} \cdot n f t^{\prime}$ Iy $\partial$ \\
\hline $\mathrm{H}$ & $n v \cdot n g t^{\prime} I$ \\
\hline $\mathrm{J}$ & $\varepsilon^{\prime} \varepsilon s t^{\prime} t c$ \\
\hline $\mathrm{J}$ & daka.' $\mathrm{ga}^{\prime \prime}$ as \\
\hline$E-T$ & fa nitcti \\
\hline
\end{tabular}

'3-corner grass'

'white grass'

'mountain straw'

'cat-tail'

'basketry grass'

'basketry grass'

'basketry grass'

'spruce'

'spruce root' (used for baskets)

'mountain grass'

Anatomy and Process
E it yalogwahso
'a braid'
E tsià logó tzin
'braided edge'
E wek'qis
'braiding at'
E qátc
'handle'
E nicóots'
'handle weaving'
E-T nc-hudz-.aha-wins
'ridge at bottom of basket'
E-T -uh or - ah
'bottom'
E shála
'bottom'
E nchudz'o howens
'ridge'
E fadzug' cn
'warp'
E tsgàts
'weaving around'
E-T ha.1-il
'to decorate'
E-T ha.'1
'to weave' 
ET ts ha' $1 i \cdot^{\prime} 1 u$

E-T sax

E-T Ұa ni. $t$ sosAx-A $n-i$

E-T qax

E-T yil or $\mathrm{yA}^{*} \mathrm{I}$

Designs

E nzckawaqi'dzin

E d1tctc'axagsni

E dagegeyayəq

E dagikaxis

E dzcgøgodzin

Products

B slagyin

B ta shói at 1

J daq'éfi

E-T da s-natc ${ }^{\prime}$-áktc

E-T da s-tsá -witc

E-T da s-tcan $A^{\prime} k-t c$

E-t da s-wi s-a'.1tc

E shalél 'it is decorated or woven'

'to stripe'

'I made many stripes'

'to wrap'

'to twist'

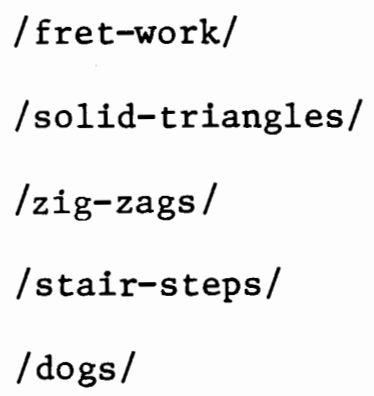

'mat two fathoms long'

'grass blanket'

'packstrap (woven) or belt'

'one basket'

'two baskets'

'three baskets'

'four baskets'

'trap-long basket used in deep water' 


\section{APPENDIX B}

\section{THE BASKETRY}

In the following descriptions of the individual baskets, I have grouped them by shape (page 35) or by kind of basket (page 37 ). Preceding each description are the letters identifying the holding institution (see Museums: page 24) and the catalog number used by the institution. Following the description of each basket, in parentheses, are the height (H) and base (B) and mouth (M) measurements of diameter or length and width and the gauge of the twining: Coarse (C), Fine (F), or Very Fine (VF).

\section{THE ADAMS COLLECTION BASKETS}

\section{Rounded-base Cylinders}

All of these baskets have a warp cluster start and a closed, plain twined base. The sides, with the exception of TCPM 1307 and TCPM 1327, are S-slant wrapped twining in raffia and/or bear-grass. The rim finish on all of them is a braid.

TCPM 1290 (Figure 9) has a large, dark blue raffia center on the base, surrounded by natural tan raffia. Horizontal, alternating bands of natural and dark blue bear-grass cover most of the sides. The handle is the wrapped, figure-elght style with black raffia chevrons on it. On either side of the decorative band are several rows of natural tan raffia. (H. $3 \frac{1}{2}$, B. $4 \frac{1}{2}$, M. $6 \frac{1}{2} ;$ C). 
TCPM 1303 is of raffia on the lower sides, but the rest of the basket is bear-grass. At the margin, there is a band of repeated, solidtriangles, and below them are several alternating blue and white bands

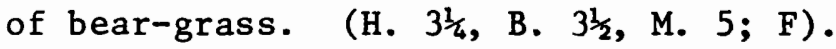

TCPM 1304 (Figure 12) is of raffia only. A band of the step motif ornaments it; but because of the small size of this basket and the large gauge of the twining, the design is fairly difficult to see. The handle is the wrapped, figure-eight style and has red chevrons on it. (H. 3, B. 3, M. $4 ; \mathrm{C}$ )

$\underline{\text { TCPM } 1307}$ has sides of alternating bands of fairly open, plain twining in blue raffia and has bright yellow bear-grass beading in paired rows. The bear-grass appears to have been dyed on only one side; the interior is white. A small, braided handle was added to the basket. (H. 3, B. 3, M. 4; C).

TCPM 1310 (Figure 14) is decorated with red raffia on a white beargrass ground. The broad, central band is done in repeated, elongatedZs bordered on either side with repeated, open-triangles. The base on this basket is Z-slant, although the sides are S-slant. (H. 3, B $3 \frac{1}{4}$, M. 5; F).

TCPM 1314 (Figure 15 side, figure 16 base) is nearly covered with the step motif in red and black raffia and white bear-grass and is bordered with black, solid triangles.

TCPM 1315 is entirely of raffia. Just below the margin is a band of repeated, red open triangles with no base-line. Below that is a band of free, red, diagonal 1ines: The handle is a wrapped, figureeight one with red chevrons on it. (H. 3, B. $3 \frac{1}{4}$, M. 5: F). 
$\underline{\text { TCPM } 1319}$ (Figure 17) is of tan and black raffia. At the margin, a band of black "dogs" occurs, each "dog" resting on the uppermost edge of the central band, which is composed of two bound bands of zig-zags

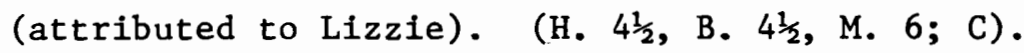

TCPM 1327 is of natural, tan raffia with a band of several rows of pink raffia on either side of a row of white and a row of orange bear-

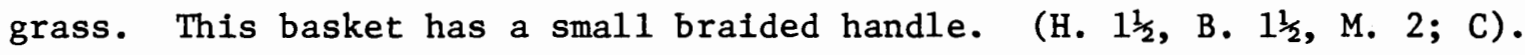
$\underline{\text { TCPM } 1329}$ is twined in a brown, unidentified material and has a band of orange bear-grass zig-zags on white bear-grass ground. It has

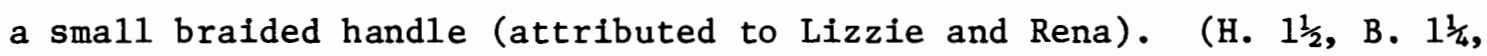
M. $\left.2 \frac{1}{4} ; C\right)$.

\section{Covered Bottles}

The only covered bottles in my sample are from the Adams Collection. Each of these baskets assumes the shape of the bottle that it was twined over and is contained in it.

TCPM 1301 (Figure 11) covers what appears to be a small, milk bottle. It is twined in alternating bands of wrapped twining and open, plain

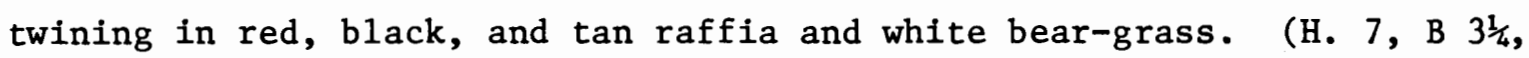
M. $\left.2 \frac{1}{2} ; F\right)$.

TCPM 1320 is much the same as TCPM 1301 but is done in red, black, and purple raffia and white bear-grass. (H. approx. 9, other dimensions not available; F).

TCPM 1306 (Figure 13, second from the left) covers a very small bottle, perhaps for perfume. Of wrapped twining in white bear-grass, it has two rows of free zig-zags, one is red and the other is dark green, 
purple, or possibly black around it. The small, braided handle was worked into the twining on one side but either was broken or never incorporated into the twining on the other side. This basket has no three-strand twining. (H. $2 \frac{1}{4}$, B. $\left.\frac{1}{2}, M .1 ; V F\right)$.

TCPM 1321 (Figure 13, second from the right) is another very small bottle covered with wrapped twining of tan raffia with two bands of red solid-triangles around it. The braided handle has simply been tied to it, and there is no three-strand twining. (H. 2, B. 2, M. 2.F). TCPM 1325 covers a small, opaque, white jar. The sides are nearly entirely covered with a band of step motif in red and black raffia and white bear-grass. (H. $2 \frac{1}{4}$, B. $2 \frac{1}{2}$, M. $2 \frac{1}{2} ;$ F).

\section{Envelopes}

These baskets have in common long, narrow, rectangular bases with high, slightly outward-flaring sides. The envelopes are quite flat. In shape, one is a flat trapezoid and one is a flat rectangle. TCPM 7981 is a small envelope of open twining on tule or sedge warp. The weft is of alternating stitches in red and black raffia. Four rows of bear-grass are beaded in below the rim and a thin, braided handle is attached (attributed to Minnie Adams). (H. 4, B. 4, M. 6; F). Pinned to this envelope is a small twined item which appears to be a wide-brimmed doll's hat. It is about three inches in diameter and has a very shallow crown. The top of the hat is of red raffia, and the sides and brim are of wrapped twining in white bear-grass. Although it is of basketry, it is not a basket so I did not include it in my sample. 
ICPM 10336 is an envelope of wrapped twining. Black "dogs" facing to the right are repeated at the margin. Below them are two bands of the step motif. The ornamentation is of red and black raffia and white bear-grass on the ground of white bear-grass. This envelope was exhibited in a touring show and is illustrated in Jones (1980:58) (attributed to Nora). (H. $6 \frac{1}{2}$, B. 11, M. $12 ; \mathrm{VF}$ )

"Shopping Bags"

These "shopping bags" are deeper from front to back than are the envelope, and two of them have paired handles.

TCPM 1291 (Figure 10) is one in alternating bands of wrapped twining and open, plain twining in red, blue, and tan raffia. A band of blue solid-triangles are repeated around the margin. The twisted raffia handles have been incorporated into the warp of the last band of wrapped twining (attributed to Lizzie). (H. 9, B. 9, M. 12; C) $\underline{\text { TCPM } 1292}$ is of tan raffia in wrapped twining. Three bands of fretwork in dark brown and red raffia are worked across it. The base is unusual because it extends out from the sides in, what appears to be, a row of braid before the sides are worked inward slightly and then vertically. The rim has a braid finish and two loops attached to each side of it which may have once held handles. (H. 4, B. 4, M. 6: F) TCPM 1300 is nearly identical to TCPM 1292 but is worked in red, black and tan raffia and white bear-grass. (H. 9, B. 10, M. 14; C) 
Clam-Baskets

Neither of the clam-baskets in this collection are as large as those in the Other Tillamook group, but they do have many of the same features despite their smaller size.

$\underline{T C P M} 1302$ is of cat-tail weft and warp in S-slant, full-turn twining. It is ornamented with a row of green and a row of purple beargrass beading just below the rim. The rim is finished in an open, single braid and has a small, braided handle attached to it (attributed to Lizzie). (H. 4, B. 1, M. 2; F)

$\underline{\text { TCPM } 2182}$ is twined in S-slant, crossed-warp, not usual for clambaskets in my sample, of split root, probably spruce. The base is round but is begun on parallel warp, rather than the more usual, rectangular shape. Two rows of bear-grass are beaded in just below the open, doublebraid rim finish. A single row of three-strand twining occurs at the base perimeter. This basket is less flexible than the larger clambaskets which may be due to its spherical shape as well as to its rela-

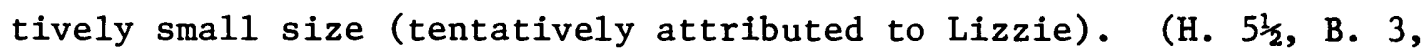
M. $5 \frac{1}{2} ; \mathrm{F}$ )

Ovate, Inverted, Truncated Cone

TCPM 1328 has an oval base of parallel warps in open, plain twining with a single row of three-strand twining at the perimeter of it. The sides are done in tule or cat-tail checkerwork and twining. The rim is covered with a once white, now grey, satin ribbon and a braided handle

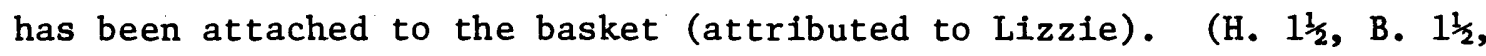
M. $\left.2 \frac{1}{2} ; C\right)$. 
Inverted, Truncated Pyramid

TCPM 1305 is begun on a rectangular base with square corners which gradually give way to rounding near the mouth of the basket. It is done in both checkerwork and twining. The base and sides have alternating rows of cat-tail checkerwork and plain twining of orange raffia. The base has a row of three-strand twining around the perimeter and the rim is finished in a braid. The handle, which has been added to the basket after it was completed, is a wrapped, figure-eight one with red raffia chevrons worked along it. (H. $4 \frac{1}{2}$, B. $8 \frac{1}{2} \times 4 \frac{1}{2}$, M. $11 \times 5 \frac{1}{2} ;$ C)

Square-based Cylinder

TCPM 1326 is of cat-tail with a square base in checkerwork surrounded by a row of three-strand twining. The cylindrical checkerwork sides are interrupted half way up by a row of crossed-warp, which is twined on either side of the crosses. The rim is finished in a braid, and a braided cat-tail handle has been added (attributed to Lizzie). (H. 2,

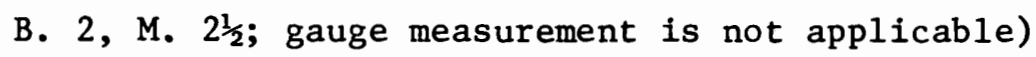

Wall-Pouch

TCPM 1323 is the first basket I saw that was described as a wal1pouch. It is a single pouch of wrapped twining in tan raffia with single, spaced rows of red, orange, and blue raffia. The pouch itself occupies only half the height of the piece with an extension of twining on the warps of one side making up the rest of the height. The top of the extension is finished in a braid and has a loop attached to it for hanging. Rena said that this was a "comb-case" wall-pouch (attributed to Lizzie). (H. $4 \frac{1}{4}$, B. 3, M. $4 \frac{1}{2} ;$ C) 
Layered-Warp, or "Seamed", Pockets

These bags, or pockets, are composed of two layers of multiple, parallel warps placed on top of each other. They have no real base but are "seamed" with a row or two of twining across them at one end before the layers are separated and twined spirally upward around both sides. These pockets are twined in plain, open twining and much of the warp is visible.

TCPM 1308 (Figure 13, right) is twined on cat-tail warp with red and black raffia. At the margin there are four rows of wrapped twining in bear-grass with repeated open-traingles in red raffia. The rim finish is

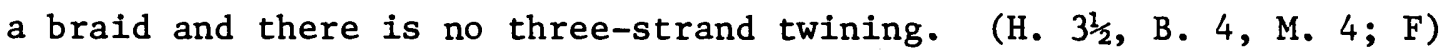
TCPM 1309 (Figure 13, left) is similar to TCPM 1308 but has no wrapped twining band. The open twining is in orange, black, red, green,

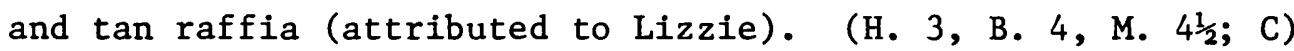

TCPM 1324 is twined on tule warps in blue and tan raffia. The second row of twining, nearest the base, has been drawn in tightly and creates a "waist". Two loops have been worked into the braided rim and a small, braided handle has been tied to them. (H. 3, B. 3, M. $4 ;$ C)

THE OTHER TILLAMOOK GROUP BASKETS

Rounded-base Cylinders

Like those in the Adams Collection, these baskets are begun on a warp-cluster start on a circular base. The basket sides curve outward slightly at the base and extend upward in a fairly vertical manner. Most of the baskets have a braided rim finish. 
UO 1-893 is done in S-slant, open, plain twining with diagonal warp overlay. The margin has several rows of closed, weft-overlay twining in S and 2-slant of red and white bear-grass. (H. $33 / 4$, B. $3 \frac{1}{4}, \mathrm{M} .5 ; \mathrm{F}$ ). UO 1-15585 has tall, vertical sides in S-slant closed, plain twining. It is ornamented with five bands of geometric designs, such as alternating squares and diagonally layered rectangles. The design material is a dark brown/black on a natural, 1ight-tan ground. The designs are worked in wrapped twining with two flexible wefts, one dark and one light. The unused one acts as the passive weft as the design colors are changed. There is a tumpline associated with this large, deep basket. (H. 10, B. 9, M. 9; F).

HM 15590-128 is done in Z-slant closed, plain twining. It is undecorated but has a strip of green cloth covering the rim and a small handle is attached to it. There is no three-strand twining. (H. 3, B. $23 / 4$, M. $3 \frac{1}{2} ;$ F).

OHS 73-127.50 is of S-slant wrapped twining. Red raffia solidtriangles are repeated around the margin on a white bear-grass ground. Below the rim, the body is entirely covered with the step motif in red and green raffia and white bear-grass. There is a row of three-strand

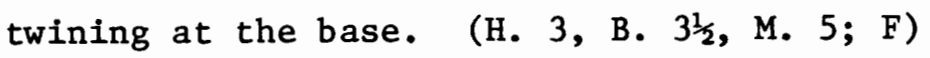

OHS 73-127.51 is of z-slant closed, plain twining on the base and sides. The base start is a variation of the warp-cluster, but the warps are divided into thirds and twined across the center of them for several rows before radiating outward. There is a single row of three-strand twining at the base, and the rim is finished in a braid with a braided handle attached to it. The basket is ornamented with short stripes, or 
"columns", and a row of crossed-warp occurs just below the rim. The tag on the basket identifies it as "Tillamuk-Salish Made by 90 year old Mrs. David Leno." The other side of the tag reads, "Mason says Grand

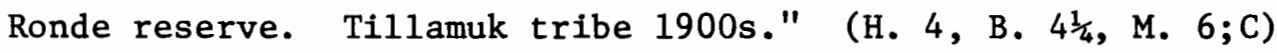

\section{Clam-Baskets}

These clam-baskets show some variation in construction techniques and ornamentation, but they are generally all the same. They are usually flexible baskets constructed of split roots in open, full-turn twining and are trapezoidal, or wedge-shaped. They have a rectangular base, fairly straight sides flaring outward, and a wide mouth.

Both the rim finish and the base start are distinctive. The rim is composed of groups of warp-ends braided together and worked into a horizontal, double-braid around the rim circumference. The base is begun across the center of long, parallel warps, the ends of which are turned upward to form the opposing narrow sides. The foundation warps for the two broad sides are attached to the edges of the rectangular base. Figure 19 illustrates the arrangement of the base warps and the attachment of the side warps, although this basket is done in plain twining, rather than ful1-turn twining (UO 1-897). Mason (1904:436) describes this base as "rather ingenious", a comment which may reflect the infrequency of $i t$, at least in the basketry that he examined. While many baskets have the warp ends turned upward to form the sides, what may be most distinctive about these baskets is the continuity of the warp ends, so visible because of the open twining, from the rim of one narrow side, down the side to form a base and up the other side to the 
rim. Also, there is no three-strand twining or other means of distinguishing the base from the side of the basket.

UO 1-15583 is different from most of the clam-baskets. It has a twilled base with a row of twining securing the twilling and rounding the base out to a more circular shape. The entire basket is worked in open, plain twining with weft-overlay of bear-grass on one of the elements, which creates alternating dark and light stitches. Warp-overlay of beargrass covers some of the warps and may have been arranged in a pattern, no longer discernible. The basket is done in Z-slant twining and the rim has only one round of open braid. (H. 7, B. 4 x 2, M. 12; C)

The decoration on clam-baskets is usually fairly simple, but some of it appears to be more complex because of the use of several decorative techniques on a single basket. Uo 1-894 (Figure 18) has alternating bands of dark and light weft, warp-overlay, and two rows of beading below the rim.

UO $1-838,1-839,1-894,1-896,1-897,1-15583,1-15586,1-15589$, 1-15590, 1-15659, 1-15661, and TBW 197 constitute this group which contains the largest baskets in my sample. Of these 12 baskets, eight of them are between 12 and 20 inches high. (Individual measurements were not obtained)

\section{Envelopes}

These are fairly flat, rectangular baskets. Some of them might be considered to be "shopping bags", but I have restricted Rena's term to the Adams Collection. 
UO 1-15656 is an envelope of S-slant wrapped twining decorated in horizontal bands with a repeat of "animals" on the margin and two bands of fretwork on the body. The designs are worked in maidenhair-fern stem and red yarn on a bear-grass ground. The rim is finished in a braid, and

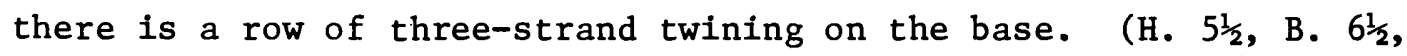
M. 10; VF).

HM 15590-100 is in Z-slant, closed, plain twining. The piece is made of split root with three bands of light-colored weft-overlay. There is a single row of three-strand twining at the base perimeter and the rim is finished in wrapping. A small piece of shaped wood is secured to the base interior. (H. 8, B. $10 \frac{1}{2} \times 3 \frac{1}{2}, \mathrm{M}, 13 ; \mathrm{F}$ )

HM 15590-101 is in Z-slant, closed, plain twining with two bands of open, crossed-warp and several narrow bands of dark and light weftoverlay. The basket is made of split root and the rim is finished with wrapping. Both this basket and HM 15590-100, above, have paired handles wrapped with hide strips. This basket has a piece of wood secured to the base interior like the one above. (H. $9 \frac{1}{2}$, B. $10 \frac{1}{2} \times 3 \frac{1}{2}, \mathrm{M} .14 ; \mathrm{F}$ ) OHS 8783/68-366 (Figure 22) is done in S-slant wrapped twining of split root, bear-grass, and raffia. At the margin "animals" are repeated and below them are two, broad bands of elongated-Zs in black and red raffia on bear-grass ground. Red raffia, open-triangles edge the elongated-Zs on both sides. Some green raffia is worked into the base, the three-strand twining around the base, and the rim. The base of the basket is done in both $\mathrm{S}$ and $\mathrm{Z}$-slant. (H. 4, B. 5, M. 7; F) 
Flat Rectangle

UO 1-15660 is much larger than the envelopes and much more squarecornered than the "shopping bags" in the Adams Collection. It is a deep and wide, but shallow from front to back, rectangular box with a cover flap. This basket is done in S-slant wrapped twining of bear-grass with maidenhair-fern stem motifs. The base is of wrapped twining across parallel warps and has a row of three-strand twining at the perimeter. The front of the basket has four bands of repeated motifs across it, but they do not continue clear around the basket. The upper-most band is of diagonal lines in clusters of threes and is bound. Below that is a band of repeated steps. The next band toward the base is like the upper-most one of clustered diagonal lines but has been mirrored so that the larger design in this band appears to be chevrons, with the opening to the right. The band nearest the base is a repeat of the second one of steps. Across the back and base of the basket are alternating dark and light rows in clusters. The cover flap has been made by twining an extension from the back, long enough to extend across the opening and over the front rim edge. A loop has been worked into the edge of the flap and probably could have been fastened to a button-like device, although there is

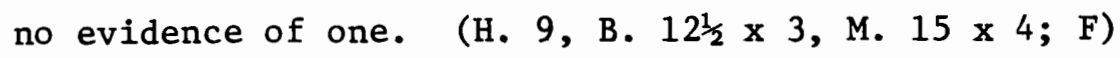

Inverted, Truncated Cones

These inverted, truncated cones all have a round base and straight, flaring sides which rise directly from the base, without the outward curve into the sides found in the rounded-base cylinders. UO 1-15582 is done in Z-slant open, plain twining with alternating dark and light stitches. There are nine stripes of warp-overlay, dark and 
light, widely spaced around the sides. The base is begun on a warpcluster, and the rim is finished with a braid that appears to have been stitched on rather than being the product of the warp ends. Twisted cordage loops, many of which are now missing, have been worked onto the basket rim. Just below the rim is a row of three-strand twining. (H. 10, B. $9 \frac{1}{2}$, M. $\left.13 ; \mathrm{C}\right)$

UO $1-15584$ is made of dark, split root and is done in S-slant twining. The base is of open, plain twining worked over parallel warps, and the sides are of crossed-warp twining. Two rows of wrapped twining occur around a very heavy, rigid, interior weft element. One of these is at the base, where the warps are turned upward to form the sides. The other is about half-way up the basket. There is no three-strand twining. The sides flare outward from the base to the mid-point row of wrapped twining and from there are vertical to the rim. The rim is wrapped and has two handles projecting above it. The handles are long-legged shapes of carved wood which have been whip-stitched to the interior of the basket sides. Flanges are carved into the ends of them, probably to prevent them from pulling out of the stitching. (H. 10, B. 12, M. 15; C) While this basket is identified as, and may be, Tillamook, it has a curious, although perhaps only slight and coincidental, resemblance to an Iroquois basket in Brasser (1975: plate 17). The Iroquois basket is done in hexagonal plaiting rather than twining, but the interstices look very much like those in the Tillamook basket, which has closely set, twined rows, giving the openings a similarly hexagonal appearance. The Iroquois basket also has a wrapped rim and is in the shape of an inverted, truncated cone, although without the cylindrical upper portion. The 
similarity that I perceive between the two is intriguing because there were Iroquois living at Grand Ronde Reservation with Tillamook in 1887. Research into Mrs. Patterson's records might clarify the origin of Uo $1-15584 .^{1}$

UO 1-15587 is made of dark, split root in Z-slant, closed, plain twining with a bear-grass weft-overlay design. At the margin "animals" are repeated in S-slant twining, and below them a step motif covers the basket sides. The base of this basket was once probably flat, or slightly

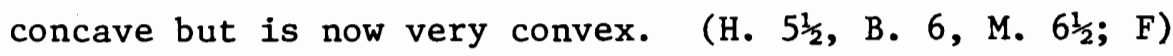

UO 1-15588 is made of dark, split root with bear-grass weftoverlay in Z-slant, plain twining. At the margin "animals" are repeated, facing to the left, which coincides with the z-slant twining. The body of the basket is completely covered with the weft-overlay, which occurs on only one of the dark elements. This creates the alternating dark and light stitches. There are four bands of columns alternating with five bands of over-all dots. The base is begun on warp-cluster and finished in closed, plain twining with a row of three-strand twining

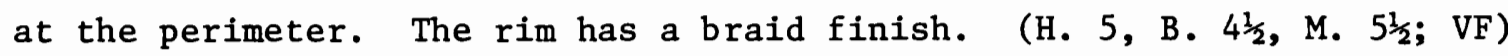
HM 15590-30 is of unidentified material in Z-slant, closed, plain twining with three bands of alternating dark and light weft-overlay. The

$1_{\text {Were the Tillamook basket found to be the product of Iroquois }}$ influence, it would not be the first instance of such influence in the Northwest Coast. A Kwakiutl, Mungo Martin, sang a Chinook Jargon song composed by an Iroquois who had settled among the Kwakiut1 (Wayne Suttles, personal communication). 
rim is braided and has a loop on it for hanging, apparently. The base is begun on a warp-cross and is finished in wicker to the perimeter row of three-strand twining. (H. 6, B. 4, M. 5; C)

HM 15590-42 is similar in color and material to HM 15590-30 above. It is done in Z-slant closed, plain twining with a broad band of dullbrown, possible cedar bark, on the upper half, on either side of which are several rows of three-strand twining. The rim is unusual; the warp ends have been trimmed in scallops and wrapped with brown raffia. (H. 6, B. $6 \frac{1}{4}$, M. $10 \frac{1}{2} ;$ F)

"Shouldered", Rounded-base Cylinders

These S-slant wrapped twined baskets have circular bases, begun on a warp-cluster, slightly rounding into vertical sides. The "shoulders" are made by bending the side warps inward at a 90 degree angle. They are then twined horizontally for an inch or so and finished with a braided rim, leaving a hole in the center of a flat surface. There is one row of three-strand twining around the base and another occurs at the "shoulder" bend.

UO 1-15653 (Figure 20) is made of bear-grass with maidenhair-fern stem ornamentation. The sides of the basket have bands of repeated solidtriangles on them. Single rows of maidenhair-fern stem appear as concentric circles on the top surface of the basket, around the mouth. (H. 4, B. $5 \frac{1}{2}, \mathrm{M} .5 \frac{1}{2} ; \mathrm{VF}$ )

Uo 1-15654 is similar in materials and technique to vo 1-15653 but varies in motifs. Four bands of repeated solid-triangles edge two broader bands of bound zig-zags around the sides. This basket has 
concentric circles on the base as well as on the top surfaces around the

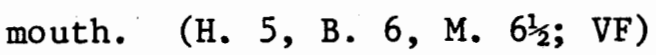

Wa11-Pouches

UO 1-12723, of S-slant, wrapped twining in bear-grass, is composed of two tiers and at the top is a twined extension of the back warp to which a loop may once have been attached for hanging. Each envelope is ornamented with a band of maidenhair-fern stem solid-triangles at the margin and two bands of alternating maidenhair-fern stem and bear-grass squares. The back of the wall-pouch has spaced rows of maidenhair-fern stem wrapped twining across it. The upper envelope, or pouch, is slightly narrower than the lower one. The base of the wall pouch is done in alternating $\mathrm{S}$ and $\mathrm{Z}$-slant twining. There is no three-strand twining on

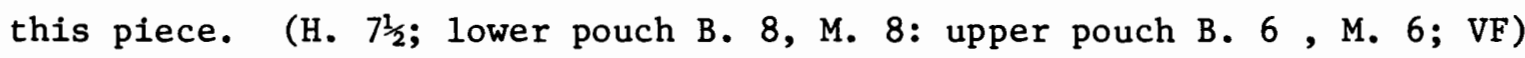
UO 1-15647 (Figure 21) is composed of three envelopes, or pouches, each about the same size. The S-slant, wrapped twining is of bear-grass, ornamented with maidenhair-fern stem. The lower pouch has a band of "animals", probably facing to the right, although they are peculiarly portrayed; and what sort of "animals" they might be is not possible to detect. A band of steps covers most of the rest of this pouch. The central pouch has a band of bird-like "animals" on it. They have long, bent necks on horizontal bodies and two legs. Below them is a broad band of a variation of the step motif. The top pouch was at one time ornamented across the margin. The remaining weft indicates that red yarn was probably used. Below the margin are two bands of solid-triangles facing each other point-to-point with diagonal lines between them. The 
back of the piece is decorated with single, spaced rows of maidenhair-

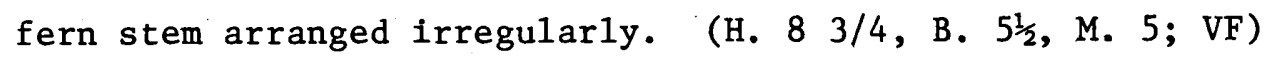

\section{Truncated Spheres}

UO 1-15580 is labelled as Tillamook, is from the Patterson Collection, and has a small tag which reads, "L-1895 Tillamook berry cup." However, it does not resemble, in shape or design motif, any other Tillamook basket that I have seen. This basket is quite spherical and is done in what may be a "full-twist overlay" twining technique (Whiteford 1970:47), since the pattern is visible on the inside, as well as on the outside, of the basket. The warp of this piece appears to be fairly large, commercial cord and the weft is of a shiny, yellowish-tan material that may be bear-grass. The design weft is shiny and black, quite probably maidenhair-fern stem. The design field is arranged in large V-shapes which extend from the base to the rim. These V-shapes are very similar to designs in Whiteford (1970:47) and Copeland (1956: plate 5, figure 31) for pieces from northeastern California, which may be the provenience of this one.

This basket provides another instance of the value in future research into Mrs. Patterson's notes and collection.

UO 1-15658 is a broad-mouthed, truncated sphere of Z-slant, closed, plain twining of, what may be, hazel shoots. There are faint traces of darker bands around the basket that may be mud-dyed. The sides have a very pronounced outward curve from the base to about two inches below the rim, where they become more vertical. The base is begun on a warp-cross and has a row of three-strand twining at the perimeter. The rim is 
finished with a flat, horizontal braid, only a portion of which still exists. The braid finish is much like the Siletz Reservation-style rim braids. (H. $8 \frac{1}{2}$, B. $6 \frac{1}{2}$, M. $16 ;$ C)

Round-based, Truncated Ovoid

HM 15590-11 is done in Z-slant, closed, plain twining of an unidentified material. The base start is a warp-cross and the base itself is round. The sides flare outward from the base quite acutely and recurve at midpoint in the height of the basket. This midpoint diameter is greater than the base or rim diameters. In the lower half of the basket there are several rows of weft overlay in alternating bear-grass and cedar bark. Below them is a single row of three-strand twining and another occurs at the base perimeter. Three rows of three-strand twining occur

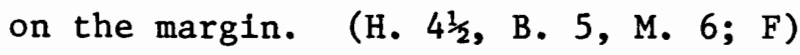

\section{Inverted, Truncated Pyramid}

UO 1-12676 is done in S-slant wrapped twining of bear-grass with maidenhair-fern stem designs. The basket is begun on a broad rectangular base of both $S$ and Z-slant wrapped twining from which the sides rise with a slight, outward curve, before becoming straight and outwardly flared. The rim edge is much rounder than the base and is finished in a braid. Three different designs are repeated around the basket. At the margin is a band of solid-triangles, the band below that and the one at the base of the basket are of interrupted columns bound on either side by a solid 1ine. Between these bands are two more, edge-to-edge, of crosshatching. This large piece is particularly well made, and the designs

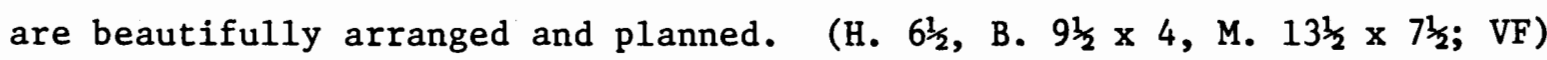


Round-based, Truncated Cone

HM 15590-50 is similar in material, unidentified, technique, Zslant twining, and decoration to HM 15590-11. The base is begun on a warp-cross and is inverted to nearly half the height of the basket. This is the only instance of such a base that I have seen. From the circumference of the base, which has one row of three-strand twining, the sides curve outward slightly before rising upward and slanting inward to the mouth, which is finished at the rim with a braid. Three bands of dullbrown weft overlay, perhaps cedar bark, are spaced up the basket sides; and there is a single row of three-strand twining just below the rim. (H. 3, B. 4, M. $3 \frac{1}{2} ;$ F)

$\underline{\text { Jar }}$

UO 1-15655 is made entirely of S-slant, wrapped twining on the sides, in bear-grass and maidenhair-fern stem, and $S$ and Z-slant wrapped twining in bear-grass on the base. The base is started on a warp cluster and twined in plain, closed twining for nearly an inch with the dark warp and a dark weft, before wrapped twining with bear-grass continues the base to the three-strand twining. The result of the plain twining in dark material is a dark circle in the center of the base. The rim has a braid finish. The sides of the basket curve outward gently as they rise and then recurve just below the margin, which flares outward brief1y. This creates a slight constriction, or neck, just below the rim. A band of "animals" is repeated around the margin. Two bands of paired zig-zags and five bands of repeated, solid-triangles cover the basket sides. (H. $5 \frac{1}{4}$, B. 4, M. $43 / 4$; VF) 
"Footed", Bulbous Rectangle

HM 881-3-56 is of Z-slant, closed, plain twining on the sides and $\mathrm{S}$ and Z-slant on the base. The base is started on parallel warps and is rectangular. The sides rise vertically from a row of three-strand twining around the base for about two inches and then curve outward and recurve to the wrapped rim. The surface of the curved, bulbous portion of the basket is quite rippled, indicating that perhaps more warps were added than could be smoothly accomodated in the space allowed. This basket is decorated with three bands of widely spaced, large, black lozenges. This same design appears on a flat, inverted, conical "cow's nose" basket from the Copeland Collection (LCH 67-465) collected before 1890. It also occurs on another Siletz Reservation-style basket in the Horner Museum (catalog number not recorded) but is done in white on a darker ground. (H. 10, B. $12 \frac{1}{4} \times 3 \frac{1}{2}$, M. $12 \times 7 \frac{1}{4} ;$ F) 